\title{
Habilitação e reabilitação visual de escolares com baixa visão : aspectos médico-sociais
}

Tese apresentada à Faculdade de Medicina da Universidade de São Paulo para obtenção do título de Doutor em Ciências

Área de concentração: Oftalmologia

Orientador: Prof. Dr. Newton Kara-José

SÃO PAULO

2006 
Dados Internacionais de Catalogação na Publicação (CIP)

Preparada pela Biblioteca da

Faculdade de Medicina da Universidade de São Paulo

Creprodução autorizada pelo autor

Haddad, Maria Aparecida Onuki

Habilitação e reabilitação visual de escolares com baixa visão : aspectos médico-sociais / Maria Aparecida Onuki Haddad. -- São Paulo, 2006.

Tese(doutorado)--Faculdade de Medicina da Universidade de São Paulo. Departamento de Oftalmologia e Otorrinolaringologia.

Área de concentração: Oftalmologia.

Orientador: Newton Kara-José.

Descritores: 1.Baixa visão 2.Cegueira/reabilitação 3.Crianças portadoras de deficiência 4.Saúde escolar 5.Saúde ocular 6.Cegueira/etiologia

7.Cegueira/prevenção \& controle 8.Cegueira/congênito 9.Toxoplasmose ocular

USP/FM/SBD-244/06 
Aos meus pais, Nobuco e Hideo, pela condução da minha vida e pelo amor incondicional.

Ao meu marido, Maurício, que sempre esteve ao meu lado com palavras de afeto.

Aos meus tios, Olga e Takeci, sempre presentes e prontos a ajudar. 


\section{AGRADECIMENTOS}

Ao Prof. Dr. Newton Kara-José, pela preciosa orientação, estímulo e apoio integralmente concedidos, não só para o desenvolvimento deste trabalho, mas também ao longo de minha vida profissional.

A Profa. Dra. Edméa Rita Temporini-Nastari, por partilhar sua experiência e por estar sempre pronta a ensinar e a colaborar com seus alunos .

Ao Prof. Dr. Marcos Wilson Sampaio, pelas palavras de otimismo, pela orientação e incentivo constantes e pela amizade.

Aos Professores Dr. Milton Ruiz Alves, Dr. Mario Luiz Monteiro e Dr. Fernando Cresta pelas orientações e sugestões no exame de qualificação.

A Profa. Mara O. de Campos Siaulys e ao Sr. Victor Siaulys, pela confiança e pelo incentivo constante nos meus projetos profissionais.

Ao Dr. Jurandir Duarte, pelo auxílio na formatação de dados e pela análise estatística.

Às amigas Dra. Mayumi Sei, Raquel Aleixo, Keli Roberta Mariano Mateus, Sônia Mítico Fucasse Gondo e Hsu Yun Min, por compartilhar experiências positivas e pelas palavras de otimismo nos momentos difíceis.

A Regina Ferreira de Almeida, pelo apoio e competência em todos os momentos.

A Regina S. Carvalho, pelo compartilhamento de conhecimentos e pelo carinho.

Aos residentes, estagiários e colaboradores do Serviço de Visão Subnormal do Hospital das Clínicas, pelo auxílio e carinho.

Aos escolares e suas famílias, que participaram dessa pesquisa e que confiaram.

A todos os pacientes da Laramara e do Serviço de Visão Subnormal do Hospital das Clínicas, que muito me ensinaram.

A Lourdes, Rosana, Junia e Márcia, que organizaram minha agenda para que eu pudesse estudar.

A todos que direta ou indiretamente contribuíram para a realização deste trabalho, 


\section{SUMÁRIO}

Lista de Abreviaturas e Siglas

Lista de Tabelas

Resumo

Summary

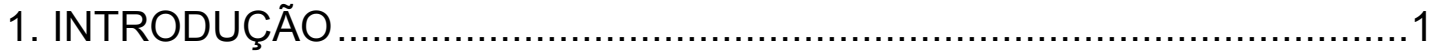

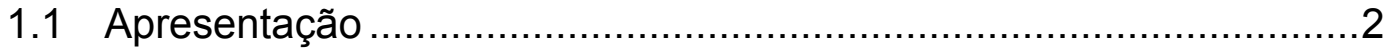

1.2 A deficiência visual na infância ...................................................

1.3 Ações para habilitação e reabilitação visual na infância .................11

1.4 A detecção de escolares com problemas visuais..........................14

1.5 O escolar com baixa visão ....................................................... 17

1.6 A atenção oftalmológica ao escolar com baixa visão ......................20

1.6.1 O papel do oftalmologista na reabilitação da baixa visão .....20

1.6.2 Histórico da reabilitação da pessoa com baixa visão e da atuação do oftalmologista.

1.6.3 A avaliação oftalmológica da criança com baixa visão ..........31

1.7 Acesso a serviços de habilitação e reabilitação visual ....................55

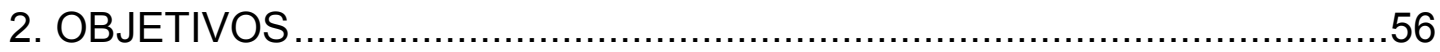

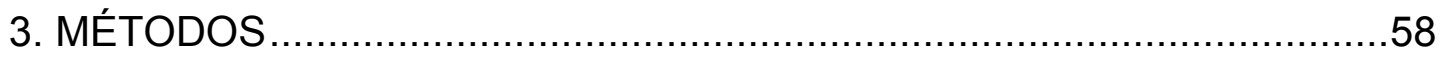

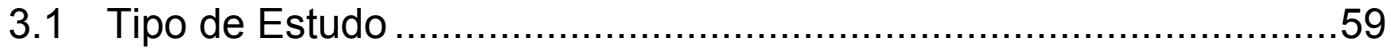

3.2 Populações ..........................................................................59

3.2.1 População de escolares com baixa visão ...........................59

3.2.2 População de mães ou responsáveis desses escolares .......60

3.2.3 Critérios de inclusão ......................................................60

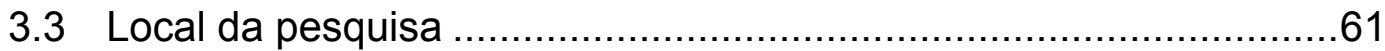

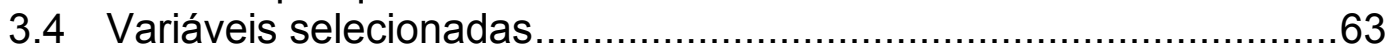

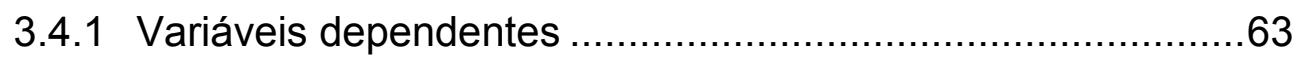

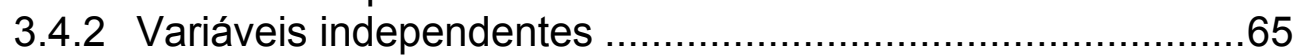

3.5 Instrumentos da pesquisa ................................................65

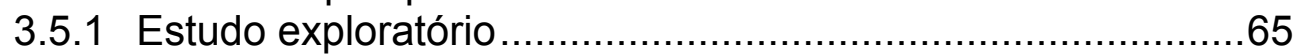

3.5.2 Teste prévio ..........................................................66

3.5.3 Avaliação oftalmológica da população de escolares com baixa visão....................................................................66

3.5.4 Registro de dados da avaliação oftalmológica ...................68

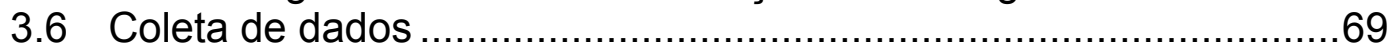

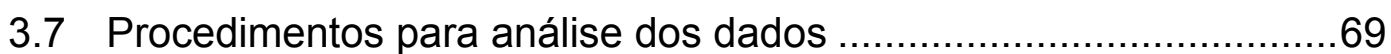

3.7.1 Banco de dados..........................................................69

3.7.2 Análise estatística descritiva e analítica ............................ 70 


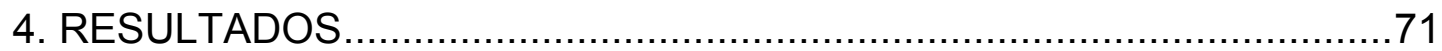

4.1 Características das populações .............................................. 72

4.2 Aspectos clínicos referentes aos escolares com baixa visão ...........77

4.2.1 Características do quadro visual......................................77

4.2.2 Necessidades ópticas ............................................ 83

4.2.3 Necessidades reabilitacionais .................................... 89

4.3 Percepção de mães/responsáveis. ......................................90

4.3.1 Percepção de mães/responsáveis quanto à detecção da deficiência visual..........................................................90

4.3.2 Percepção de mães/responsáveis quanto ao atendimento médico para diagnóstico ....................................................91

4.3.3 Percepção de mães/responsáveis quanto ao atendimento em serviço especializado...................................................93

4.3.4 Percepção de mães/responsáveis quanto ao uso de auxílios ópticos para baixa visão .......................................94

4.3.5 Percepção de mães/responsáveis quanto à dificuldade na escolar .......................................................................96

4.3.6 Percepção de mães/responsáveis quanto a benefícios concedidos pelos órgãos governamentais pela deficiência....97

4.4 Resultados analíticos ..........................................................99

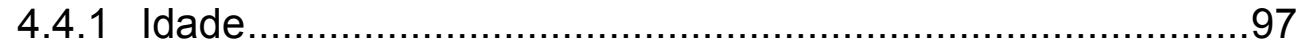

4.4.2 Classe de deficiência visual ..........................................98

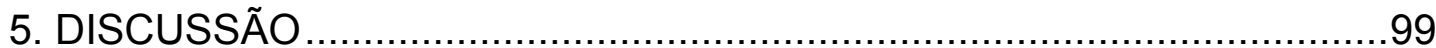

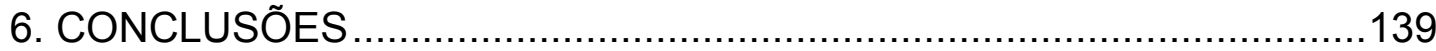

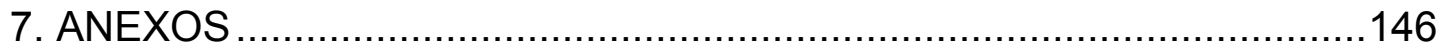

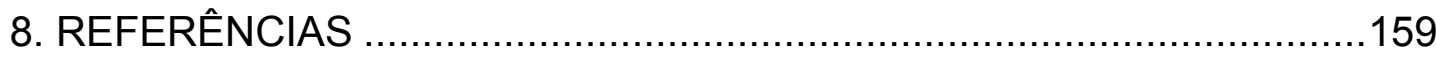




\section{LISTA DE SIGLAS E ABREVIATURAS}

\begin{tabular}{|c|c|c|}
\hline AV & - & Acuidade visual \\
\hline CIF & - & $\begin{array}{l}\text { Classificação Internacional de Funcionalidade, } \\
\text { Incapacidade e Saúde }\end{array}$ \\
\hline CETREVIS & - & Centro de Treinamento de Visão Subnormal \\
\hline CORDE & - & $\begin{array}{l}\text { Coordenadoria Nacional para a Integração da } \\
\text { Pessoa Portadora de Deficiência }\end{array}$ \\
\hline DE & - & Dioptrias esféricas \\
\hline FDN & - & Fundação Dorina Nowill para Cegos \\
\hline IAPB & - & International Agency for Prevention of Blindness \\
\hline IBC & - & Instituto Benjamin Constant \\
\hline IBGE & - & Instituto Brasileiro de Geografia e Estatística \\
\hline ICO & - & International Council of Ophthalmology \\
\hline ISLRR & - & $\begin{array}{l}\text { International Society for Low Vision Research and } \\
\text { Rehabilitation }\end{array}$ \\
\hline OMS & - & Organização Mundial da Saúde \\
\hline SICORDE & - & Sistema Nacional de Informações sobre Deficiência \\
\hline SVSN HCFMUSP & - & $\begin{array}{l}\text { Serviço de Visão Subnormal da Clínica } \\
\text { Oftalmológica do Hospital das Clínicas da Faculdade } \\
\text { de Medicina da Universidade de São Paulo }\end{array}$ \\
\hline WHO & - & World Health Organization \\
\hline$\Delta$ & - & Diopitrias prismáticas \\
\hline
\end{tabular}




\section{LISTA DE TABELAS}

Tabela 1 - Faixa etária e escolaridade de crianças com baixa visão.

Tabela 2 - Pessoa entrevistada e sua relação com o escolar com baixa visão

Tabela 3 - Escolaridade do pai. Percepção de mães/responsáveis .75

Tabela 4 - Escolaridade da mãe. Percepção de mães/responsáveis. .75

Tabela 5 - Atividade remunerada ou não remunerada do pai.

Percepção de mães/ responsáveis

Tabela 6 - Atividade remunerada ou não remunerada da mãe.

Percepção de mães/ responsáveis

Tabela 7 - Pessoas com quem o escolar mora. Percepção de mães/responsáveis

Tabela 8 - Responsável(is) pelo sustento da casa. Percepção de mães/ responsáveis

Tabela 9 - Causas da deficiência visual de escolares com baixa visão

Tabela 10 - Causas da deficiência visual de escolares com baixa visão segundo a localização da afecção

Tabela 11 - Principal etiologia da deficiência visual de escolares com baixa visão

Tabela 12 - Valores de acuidade visual de escolares com baixa visão

Tabela 13 - Valores de sensibilidade ao contraste de escolares com baixa visão

Tabela 14 - Visão de cores de escolares com baixa visão.

Tabela 15 - Amplitude do campo visual de escolares com baixa visão.

Tabela 16 - Auxílios ópticos para longe em uso por escolares com baixa visão.

Tabela 17 - Auxílios ópticos para perto em uso por escolares com baixa visão

Tabela 18 - Indicação/não indicação e tipos de auxílios ópticos nos escolares com baixa visão 
Tabela 19 - Auxílios ópticos para longe para escolares com baixa visão (indicação e tipos)

Tabela 20 - Auxílios ópticos para perto para escolares com baixa visão (indicação e tipos).

Tabela 21 - Correção óptica para ametropias de escolares com baixa visão

Tabela 22 - Pessoa que observou primeiro a dificuldade visual do escolar. Percepção de mães/responsáveis

Tabela 23 - Idade do escolar em que foi observado o problema visual.

Percepção de mães/responsáveis

Tabela 24 - Conduta do oftalmologista como primeiro profissional da área da saúde consultado após a identificação do problema visual. Percepção de mães/ responsáveis

Tabela 25 - Orientações do pediatra como primeiro profissional da área da saúde consultado após a identificação do problema visual.

Percepção de mães/ responsáveis

Tabela 26 - Local do primeiro atendimento oftalmológico. Percepção de mães/ responsáveis

Tabela 27 - Intervalo de tempo entre a identificação do problema visual e a primeira consulta oftalmológica. Percepção de mães/responsáveis

Tabela 28 - Razões do retardo da avaliação oftalmológica do escolar com baixa visão. Percepção de mães/responsáveis

Tabela 29 - Grau de dificuldade para conseguir a primeira consulta oftalmológica para o escolar com baixa visão. Percepção de mães/responsáveis

Tabela 30 - Idade em que foi realizado o diagnóstico de baixa visão.

Percepção de mães/responsáveis

Tabela 31 - Idade do escolar ao encaminhamento a serviço de baixa visão. Percepção de mães/responsáveis.

Tabela 32 - Responsável pelo encaminhamento do escolar com baixa visão ao serviço de visão subnormal ou à instituição. Percepção de mães/responsáveis

Tabela 33 - Atendimento anterior dos escolares com baixa visão em outro serviço de reabilitação visual. Percepção de mães/responsáveis 
Tabela 34 - Conhecimento da existência de outros serviços de baixa visão. Percepção de mães/responsáveis

Tabela 35 - Tipo de auxílio óptico em uso por escolar com baixa visão.

Percepção de mães/responsáveis

Tabela 36 - Dificuldade de escolares com baixa visão para uso do auxílio óptico para longe. Percepção de mães/responsáveis

Tabela 37 - Uso de auxílio óptico para perto por escolares com baixa visão. Percepção de mães/responsáveis

Tabela 38 - Dificuldade de aquisição do auxílio óptico prescrito ao escolar. Percepção de de mãesresponsáveis

Tabela 39 - Presença e tipo de dificuldade na escola de crianças com baixa visão. Percepção de mães/responsáveis

Tabela 40 - Recebimento de benefício doado por entidade governamental ao escolar de baixa visão. Percepção de mães/responsáveis

Tabela 41 - Quem percebeu a dificuldade para enxergar segundo a idade no diagnóstico. Percepção de mães/responsáveis

Tabela 42 - Indicação/não indicação de auxílios ópticos para longe segundo a classe da deficiência visual de escolares com baixa visão

Tabela 43 - Indicação/ não indicação de auxílios ópticos para perto segundo a classe da deficiência visual de escolares com baixa visão 


\section{RESUMO}

Haddad MAO. Habilitação e reabilitação de escolares com baixa visão: aspectos médicos-sociais [tese]. São Paulo: Faculdade de Medicina, Universidade de São Paulo; 2006. 169p.

INTRODUÇÃO: A baixa visão na infância pode limitar as experiências de vida, a velocidade de realização de tarefas, o desenvolvimento motor, as habilidades, a educação e o desenvolvimento emocional e social, com comprometimento da qualidade de vida. O conhecimento de aspectos médico-sociais colaboram para a elaboração de ações efetivas para a reabilitação visual e a inclusão educacional. OBJETIVOS: 1)Identificar aspectos clínicos referentes a população com baixa visão em idade escolar atendida no Serviço de Visão Subnormal da Clínica Oftalmológica do Hospital das Clínicas da Faculdade de Medicina da Universidade de São Paulo e da Associação Brasileira de Assistência ao Deficiente Visual, com relação a causa da baixa visão, localização da anormalidade, classes de comprometimento visual, função visual atual, prescrição óptica para correção de ametropias e para auxílios para baixa visão; necessidades reabilitacionais; 2) Verificar percepção de mães ou responsáveis quanto a detecção da deficiência visual, encaminhamentos e condutas realizados por profissionais da área médica, acesso a serviços de atenção oftalmológica especializada à baixa visão, acesso a auxílios ópticos prescritos para baixa visão; 3) fornecer subsídios para desenvolvimento de ações para habilitação/reabilitação da baixa visão na infância. MÉTODOS: Realizou-se estudo transversal analítico, tendo sido estudadas a população de 115 escolares com baixa visão, sem outras deficiências associadas e a população de mães ou responsáveis pelos escolares, detectados no período de fevereiro a novembro de 2005. Realizou-se a avaliação oftalmológica dos escolares e aplicou-se questionário semi-estruturado às mães ou responsáveis. RESULTADOS: As principais causas da deficiência visual foram a retinocoroidite macular bilateral por toxoplasmose congênita $(27,8 \%)$, a catarata congênita(11,3\%), o albinismo oculocutâneo $(7,8 \%)$ e o glaucoma congênito $(6,1 \%)$; a retina foi a principal localização da afecção ocular causadora da deficiência visual $(54,8 \%)$; as principais etiologias foram hereditárias(36,5\%) e pré-natais infecciosas(32,1\%); as classes de deficiência visual moderada $(67,8 \%)$ e grave $(27,0 \%)$ foram mais freqüentes;a correção óptica da ametropia foi prescrita para todos os casos de retinocoroidite macular bilateral, de amaurose congênita de Leber e de albinismo oculocutâneo; os auxílios ópticos para longe $(87,8 \%)$ foram mais prescritos que os auxílios ópticos para perto $(34,7 \%)$; a mãe foi a pessoa que percebeu primeiro a dificuldade visual em 53,0\%; a escola foi importante na detecção de problemas visuais nos escolares com baixa visão(6,1\%); o pediatra mostrou-se despreparado para a detecção de problemas visuais, tratamentos, orientação à família e encaminhamentos; diagnosticou-se a baixa visão no primeiro ano de vida em $83,0 \%$ dos casos; o 
encaminhamento a serviços de reabilitação visual foi realizado tardiamente ao diagnóstico e ocorreu principalmente na idade escolar $(53,9 \%)$; o principal responsável pelo encaminhamento a serviços de reabilitação foi 0 oftalmologista(60\%); a menor parte dos escolares havia sido atendida por outro serviço de reabilitação $(23,0 \%)$; apesar da existência de outros serviços terciários de reabilitação visual na cidade de São Paulo, 67,0\% dos responsáveis não tinha conhecimento dos mesmos. CONCLUSÕES Verificase necessidade de: programas de detecção precoce de problemas visuais na infância, por meio de capacitação de pediatras em saúde ocular; programas de detecção de problemas oculares na idade escolar, em parceria com serviços de saúde e educação, como a Campanha Olho no Olho; capacitação de professores do sistema regular de ensino, quanto à saúde ocular e aspectos da baixa visão; maior acesso a auxílios ópticos prescritos à pessoa com baixa visão;educação continuada de oftalmologistas para atuação na área da baixa visão e maior divulgação das implicações da baixa visão na infância e na vida adulta e dos serviços disponíveis na comunidade.

Descritores: baixa visão, cegueira/reabilitação, crianças portadoras de deficiência, saúde escolar, saúde ocular, cegueira/etiologia, cegueira/prevenção e controle, cegueira/congênito, toxoplasmose ocular. 


\section{SUMMARY}

Haddad MAO. Habilitação e reabilitação de escolares com baixa visão: aspectos médicos-sociais [tese]. São Paulo: Faculdade de Medicina, Universidade de São Paulo; 2006. 169p.

INTRODUCTION: Low vision in childhood can limit experiences, speed in performing daily activities, sensory and motor development, educational, social and emotional improvement and compromise quality of life. Knowledge of medical and social features can cooperate to the development of effective actions to educational inclusion and visual rehabilitation. OBJECTIVES: 1 . to identify clinical features of a population of school age children with low vision evaluated at the low vision service of the University of São Paulo Ophthalmology Department and the Brazilian Association for the Visually Impaired. (Laramara) concerning causes of low vision, anatomical site of the abnormality, classes of visual impairment, visual functions, use of optical correction, low vision devices and rehabiliattion needs. 2. to evaluate perceptions of mothers or the persons responsible concerning detection of the visual impairment, procedures of the professionals involved, access to low vision services and to the prescribed low vision aids. 3. to contribute to improve actions of habilitation or rehabilitation of visually impaired school children. METHODS: a population of 115 school children with visual impairment was submitted to ophthalmologic low vision evaluation and a semistructured questionnaire was applied to the mother or person responsible. RESULTS: main causes of visual impairment were presumed toxoplasmic retinochoroiditis $(27,8 \%)$, congenital cataracts $(11,3 \%)$, albinism $(7,8 \%)$ and congenital glaucoma $(6,1 \%)$. Retina $(54,8 \%)$ was the main affected area and the main causes involved heredity $(36,5 \%)$ or pre-natal infections $(32,1 \%)$. Moderated $(67,8 \%)$ and Severe $(27,0 \%)$ low vision were more frequent. Glasses for refractive errors were prescribed to all with bilateral macular retinochoroiditis, Leber congenital amaurosis and albinism. Mothers were the first to notice visual impairment in the majority of cases $(53,0 \%)$ and the school was also important $(6,1 \%)$. Pediatricians were not very efficient in the detection of visual impaiment in these children. Low vision was detected in the first year of life in $83 \%$ and referral to visual rehabilitation unit ocurred chiefly at school age $(53,9 \%)$, being the ophthalmologist the professional responsible for the majority of referrals $(60 \%)$. These children, in general, never had a prior low vision examination $(73 \%)$ and the mothers or responsibles had little knowledge of other available rehabilitation units in the area $(67,0 \%)$. CONCLUSIONS: early detection programs for visual impairment in children and capacitation of pediatricians is important as well as the screening for refractive errors of children at school age. Regular school teachers should receive information on basic eye health and low vision. Improved access to low vision aids and increased awareness on the subject among 
ophthalmologists is a necessity as well as more information on community services and visual impairment should be available to the population.

Keywords: low vision, blindness/rehabilitation, disabled children, school health, eye health, blindness/etiology, blindness/prevention and control, blindness/congenital, ocular toxoplamosis. 


\subsection{Apresentação}

A oportunidade de atuar profissionalmente na área da reabilitação visual em duas das mais conceituadas instituições de nosso país, a Associação Brasileira de Assistência ao Deficiente Visual (Laramara) e o Serviço de Visão Subnormal da Clínica Oftalmológica do Hospital das Clínicas da Faculdade de Medicina da Universidade de São Paulo (SVSN HC FMUSP), possibilitou-me vivenciar o universo do escolar com baixa visão e de sua família. A partir deste contato, pude aprender e perceber como a atuação do oftalmologista, com condutas mais resolutivas, pode ser decisiva para o futuro daquela criança ou adolescente. Foi o que motivou o presente estudo.

A Organização Mundial da Saúde (OMS) define saúde como um estado de completo bem-estar físico, mental e social e, não apenas a ausência de doenças ou enfermidades. Esta perspectiva sugere que iniciativas de promoção da saúde ocular não tenham embasamento somente nos dados clínicos de um indivíduo com deficiência visual, pois não possibilitam uma caracterização fidedigna das dificuldades por ele enfrentadas nas suas atividades diárias. Recomenda-se, então, que sejam empregados métodos qualitativos para a avaliação da condição funcional 
visual e de sua qualidade de vida. (WHO, 2003) O oftalmologista deve tomar conhecimento da condição visual e funcional do indivíduo, além de compreendê-lo em seu contexto social.

\subsection{A deficiência visual na infância}

Os elementos anatômicos essenciais para o processamento visual estão presentes desde o nascimento; porém, pouco desenvolvidos. O diâmetro do globo ocular normal aumenta de $16,5 \mathrm{~mm}$ ao nascimento para $24,5 \mathrm{~mm}$ na vida adulta. Mais da metade deste crescimento sagital ocorre no primeiro ano de vida. O aumento do desempenho visual é concomitante ao desenvolvimento e crescimento anatômico do globo e ao desenvolvimento do sistema visual central. O crescimento dos dendritos dos neurônios corticais e a mielinização das vias ópticas, que se iniciam na $25^{\mathrm{a}}$ semana de gestação e prolongam-se até os 2 anos de idade, justificam o desenvolvimento visual gradual ao longo desse período. (Catalano e Nelson, 1994) O desenvolvimento das capacidades visuais ao longo dos primeiros meses de vida é uma ação coordenada que envolve aspectos sensoriais e motores. (Daw, 1995)

A acuidade visual de um recém -nascido é 0,03 , na escala decimal, e melhora rapidamente durante as primeiras semanas de vida, quando a retina, as vias ópticas e o córtex visual desenvolvem seus contatos 
celulares. A acuidade visual atinge valores de 0,1, 0,2 e 1,0 em torno dos 6 meses, 1 ano de vida e 4 anos de vida, respectivamente. (Teplin, 1995)

Segundo Hyvarinen (1988), ao nascimento, a sensibilidade aos contrastes (habilidade para discernir pequenas diferenças na luminosidade de superfícies adjacentes) é pobre e aprimora-se rapidamente durante $01^{\circ}$ ano de vida; a visão de cores será semelhante ao do adulto ao redor dos 2 meses de vida; o campo visual passará de uma amplitude de 60 graus aos 3 meses para uma amplitude de 180 graus aos 6 meses de idade; a visão estereoscópica poderá ser medida aos 2 meses de vida e a acomodação será próxima ao do adulto em torno dos 2-3 meses de vida.

Segundo Catalano e Nelson (1994), o principal erro refrativo nos recém-nascidos a termo é a hipermetropia (em torno de 2 dioptrias), que obedece uma distribuição normal na população, e tende a diminuir ao longo da infância. O astigmatismo é mais comum em recém-nascidos do que em crianças maiores e adultos e tende a decair a partir dos 6 meses de vida. A miopia geralmente começa a estar presente a partir dos 8 anos de vida, a não ser nas formas congênitas caracterizadas por alto grau.

O sistema visual humano é vulnerável a modificações desencadeadas por agentes externos durante o período de desenvolvimento pré-natal e pósnatal e pode ser considerado como período crítico da vida, no qual experiências visuais são importantes para o desenvolvimento integral da visão. A visão requer de 5 a 6 anos para o seu desenvolvimento e apresenta uma vulnerabilidade até os 9 anos de vida.(Catalano e Nelson. 1994) 
A visão é o sentido que fornece mais dados do meio ambiente e é o único capaz de organizar outras informações sensoriais. (Scholl, 1986; Teplin, 1995) A deficiência visual na infância, ao limitar o de número experiências e informações, interfere no desenvolvimento motor, cognitivo e emocional.(Scholl, 1995) Fatores etiológicos, idade de acometimento, presença de outras deficiências, aspectos ambientais e suas interações determinam dificuldades e defasagens na criança .(Teplin, 1995) Os resultados da detecção de doenças oculares e intervenções precoces são melhores do que quando realizados tardiamente, após o período de desenvolvimento visual. (Catalano e Nelson, 1994; Gilbert e Foster, 2001a)

Quanto aos aspectos etiológicos, podemos considerar os seguintes fatores que podem levar a distúrios visuais na infância: fatores genéticos, fatores pré-natais (infecções e exposição a agentes tóxicos); fatores neonatais e perinatais (hipóxia, infecções, prematuridade) e fatores pósnatais (nutricionais, infecciosos ou traumas, por exemplo).

De acordo com a $10^{\text {a }}$ revisão da Classificação Estatística Internacional das Doenças e Problemas relacionados à Saúde (CID-10), considera-se visão subnormal, ou baixa visão, quando o valor da acuidade visual corrigida no melhor olho é menor do que 0,3 e maior ou igual a 0,05 ou seu campo visual é menor do que 20 graus no melhor olho com a melhor correção óptica (categorias 1 e 2 de graus de comprometimento visual) e considera-se cegueira quando esses valores encontram-se abaixo de 0,05 ou o campo visual menor do que 10 graus (categorias 3, 4 e 5 ). (OMS, 1993) A presente categorização baseia-se nas recomendações realizadas no ano de 
1972 pelo Grupo de Estudo para a Prevenção da Cegueira da OMS e foram incluídas na $9^{a}$ revisão da Classificação Estatística das Doenças e Problemas Relacionados à Saúde de 1975.(WHO,2003)

Os serviços de atenção à baixa visão utilizam a seguinte definição: "A pessoa com baixa visão é aquela que apresenta, após tratamentos e/ou correção óptica, diminuição de sua função visual e tem valores de acuidade visual menor do que 0,3 a percepção de luz ou um campo visual menor do que 10 graus de seu ponto de fixação; porém usa ou é potencialmente capaz de usar a visão para o planejamento e/ou execução de uma tarefa". (WHO, 1992; WHO, 1999) Justifica-se o uso dessa definição pelo fato de que a maior parte da população considerada cega (por alguma definição legal) tem, na verdade, baixa visão e é, a princípio, capazes de usar sua visão para realização de tarefas .(ISLVRR, 2005)

A OMS, de acordo com dados baseados na população mundial do ano de 2002, estima que mais de 161 milhões de pessoas sejam portadoras de deficiência visual, das quais 124 milhões teriam baixa visão e 37 milhões seriam cegas. De maneira geral, para cada pessoa cega há uma média de 3,7 pessoas com baixa visão, com variações regionais de 2,4 a 5,8 . As principais causas de cegueira, na população adulta, no mundo são: a catarata, o glaucoma e a degeneração macular relacionada à idade . (WHO, 2004; Resnikoff et al, 2004)

Estima-se que $90 \%$ dos casos de deficiência visual estejam nos países em desenvolvimento e a maior parte poderia ser evitada por prevenção ou tratamentos existentes. (West e Sommer, 2001) Na ausência de ações 
globais de prevenção à deficiência visual, a cegueira poderá atingir 76 milhões de pessoas no mundo no ano de 2020, em conseqüência ao crescimento e envelhecimento da população mundial. (Pizzarello et al., 2004)

Segundo Gilbert \& Foster (2001a), a deficiência visual na infância tem repercussões sociais e econômicas para a sociedade tanto quanto a deficiência visual na população idosa. Muitas das causas de cegueira são passíveis de prevenção ou tratamento e diversas condições associadas à deficiência visual na infância estão também relacionadas às causas de mortalidade infantil. Estima-se mundialmente a incidência de 500.000 casos de cegueira na infância/ano e $60 \%$ vão à óbito por causas evitáveis nas regiões mais pobres. (Gilbert e Awam, 2003)

A prevalência e causas da deficiência visual na infância são parcialmente conhecidas e variáveis nas diversas regiões do mundo, de acordo com fatores sócio-econômicos e culturais. (West e Sommer, 2001; Foster e Gilbert, 2001a) A prevalência da baixa visão na infância é subestimada por falta de registros e pesquisas e pela ausência de abrangência nos estudos (geralmente em instituições de atendimento à população cega) e sua associação com a mortalidade infantil, além da inexistência do diagnóstico ocular na população com outras deficiências associadas. (WHO, 1992)

Estimativas da prevalência de cegueira na infância mostram valores entre $0,3 / 1000$ a 1,0/1000, de acordo com taxas de mortalidade infantil abaixo de 5 anos de idade, o que leva a valores entre 80-100 crianças cegas a 400 crianças cegas por milhão, respectivamente nos países economicamente desenvolvidos e nas regiões mais pobres do mundo. 
(Gilbert e Foster, 2001a; Gilbert e Foster, 2001b; Foster e Gilbert, 1992) Dessa forma, estima-se, no mundo, cerca de 1.500 .000 crianças cegas, 3/4 dessa população na Ásia e África. (Gilbert e Foster, 2001b)

O conhecimento da magnitude e das causas da deficiência visual é fundamental para o planejamento, provisão e avaliação de programas de prevenção, de serviços de saúde e educacionais. A prevalência da cegueira é maior nos países em desenvolvimento em decorrência de fatores nutricionais, infecciosos e falta de tecnologia apropriada. Nos países com renda per capita intermediária as causas são variadas e observa-se a retinopatia da prematuridade (como causa emergente de cegueira nos países da América Latina e leste europeu). Causas não evitáveis como distrofias retinianas, doenças do sistema nervoso central e anomalias congênitas são observadas nos países desenvolvidos. (Gilbert e Awan, 2003)

A deficiência múltipla, presença de duas ou mais deficiências no mesmo indivíduo, tem importância crescente na população infantil cega ou com baixa visão e é mais prevalente nos países em desenvolvimento. (WHO, 1992) As afecções associadas podem ser: motoras, sensoriais, cognitivas ou doenças crônicas que afetam o desenvolvimento, a educação e a vida independente. Crianças com deficiência múltipla geralmente requerem atendimento oftalmológico, mas também acompanhamento multidisciplinar de longa duração. (Keeffe, 2004)

Cerca de 30 a $70 \%$ da população infantil com deficiência visual grave apresenta outras deficiências associadas (deficiência física, mental, auditiva e distúrbios do comportamento) e que podem não ser detectadas. (Teplin, 
1995) No Reino Unido, $78 \%$ das crianças diagnosticadas com perda visual irreversível tinham, após 1 ano de observação, outras deficiências associadas à visual. (Keeffe, 2004)

$\mathrm{Na}$ América Latina, aspectos referentes à deficiência visual na infância são pouco conhecidos, uma vez que dependem de estudos populacionais ou de registros de casos, inexistentes nesta região. (Gilbert et al., 1994) Estudos de Kara-José et al (1988), Moreira et al (1991), Leal et al (1995), Carvalho et al (1996), Haddad et al (2000a), Gilbert et al (1994), Muñoz et al (2002) têm contribuído para a reconhecimento do perfil da deficiência visual no nosso meio.

Haddad et al (2006a) observaram a retinocoroidite macular por toxoplasmose, as distrofias retinianas, a retinopatia da prematuridade, as malformações oculares, o glaucoma congênito, a atrofia óptica e a catarata congênita .como principais causas de deficiência visual numa população infantil atendida na cidade de São Paulo.

A deficiência visual leva a restrições na vida da criança e de sua família quanto a aspectos educacionais, pessoais, sociais e laborativos. (Rahi e Dezateus, 1998; Rahi, 1999) O controle da cegueira infantil é uma ação prioritária da OMS: as causas são, na sua maioria, passíveis de prevenção ou tratamento e estão relacionadas às taxas de mortalidade infantil; o impacto da doença ocular no sistema visual durante a infância, uma vez que o desenvolvimento visual ocorre nos primeiros anos de vida, é maior do que na vida adulta e, portanto, o tratamento deve ser precoce; além do alto custo social da cegueira infantil se a vida média do indivíduo for 
considerada. (Gilbert e Foster, 2001a) A estimativa de 1,5 milhão de crianças cegas no mundo pode implicar em 75 milhões de anos cegos, equivalente à cegueira mundial por catarata, que corresponde a $40 \%$ das causas de cegueira na vida adulta. (Eckestein et al., 1995)

De acordo com Gilbert e Awan (2003), o controle da deficiência visual na infância é complexo e requer desde atividades comunitárias até atendimento em serviços terciários sofisticados. A colaboração multidisciplinar requer ações para a promoção da saúde, medidas de prevenção, recursos ópticos, recursos médicos e cirúrgicos, serviços de baixa visão, serviços de educação especial e reabilitação. Objetiva-se o compromisso político no combate à pobreza e no desenvolvimento de modelos que sejam efetivos, replicáveis, sustentáveis e com poder de mobilização de recursos necessários.

A OMS, no ano de 1999, em resposta à demanda global de crescimento da população cega mundial, lançou, em parceria com a Agência Internacional de Prevenção à Cegueira (IAPB), uma ação global denominada de "Vision 2020: The right to Sight" . A ação "Vision 2020" tem como meta a eliminação da cegueira evitável até o ano de 2020 e prioriza ações no combate à catarata, tracoma, oncocercose, cegueira na infância, erros refrativos e baixa visão. Na América do Sul, são considerados os seguintes objetivos: capacitação de oftalmologistas para programas de prevenção à cegueira, desenvolvimento de planos nacionais de prevenção à cegueira, aumento de cirurgias de catarata e desenvolvimento de programas de prevenção à cegueira na infância. (Pizzarello et al., 2004) 


\subsection{Ações para habilitação e reabilitação visual na infância}

A baixa visão na infância é entre 3 a 10 vezes mais prevalente do que a cegueira. (Foster e Gilbert, 1992; Thylefors et al., 1995) A maior parte da população mundial classificada como cega tem, na verdade, baixa visão e é capaz de usar a sua visão para a realização de tarefas. (ISLVRR, 2005)

A criança com baixa visão tem necessidades especiais para desenvolver o uso funcional da visão. A baixa visão pode limitar as experiências de vida, a velocidade na realização de tarefas, o desenvolvimento motor, as habilidades, a educação e o desenvolvimento emocional e social, com comprometimento de sua qualidade de vida (WHO, 1992; Gieser, 2004) Crianças com perda irreversível da visão são beneficiadas com o atendimento em serviços de baixa visão que promoverão sua inclusão educacional. (Gilbert e Awan, 2003)

As crianças com baixa visão devem ser encorajadas a fazer uso eficiente da sua resposta visual por meio de um programa com abordagem interdisciplinar. Os serviços de habilitação/ reabilitação visual têm a finalidade de prevenir seqüelas da deficiência visual no indivíduo; evitando a incapacidade e promovendo o desenvolvimento global (WHO, 1992)

O reconhecimento das necessidades específicas da criança com deficiência visual grave ocorreu nos últimos 30 anos nos países desenvolvidos. A prática prévia era da "economia da visão" e do uso do braille e de materiais táteis para o aprendizado de alunos que ainda apresentavam alguma visão.(WHO, 1992) 
Barraga, na década de 60, demonstrou, a partir de estudos experimentais, que muitas crianças classificadas como legalmente cegas poderiam perceber e organizar seu ambiente e também aprender por meio do uso de sua visão. (WHO, 1992) Os postulados de Barraga foram concomitantes ao desenvolvimento nas áreas médica e tecnológica da atenção à baixa visão (em especial os avanços na área de recursos para baixa visão).

Willian Feinbloom, em 1961, fundou a companhia Designs for Vision para desenvolvimento e fornecimento de recursos de magnificação para pessoas com baixa visão. (Studebaker e Pankow, 2004) Estudos desenvolvidos por oftalmologistas como Gerald Fonda, Richard Hoover, Eleanor Faye e August Colenbrander e por educadores como Sam Ascroft, Katie Sibert, Eric Searle e Bengt Linquist colaboraram para o reconhecimento, aceitação e uso do conceito de baixa visão. (Barraga, 1996)

Os objetivos da atenção à baixa visão são: minimizar as restrições na participação em atividades; realizar, por meio de testes compatíveis com o desenvolvimento da criança e aspectos culturais, a avaliação da função visual; avaliar o impacto da deficiência visual nas atividades diárias da criança; disponibilizar auxílios ópticos de alta qualidade e custo acessível e que atendam às necessidades diferenciadas da população infantil e assegurar que toda criança com baixa visão seja encaminhada a serviços de intervenção precoce e receba orientação educacional adequada dentro de um programa integrado. (WHO, 1999) 
De acordo com Brohier (1990), a visão não se desenvolve isoladamente; a criança necessita habilidades motoras e táteis para alcançar e examinar o que vê, habilidades cognitivas para organizar e interpretar os vários tipos de informações sensoriais recebidas e da linguagem para fortalecer associações cognitivas, portanto, a ênfase isolada na função visual em detrimento do desenvolvimento global da criança deve ser evitada. Desta forma, o desenvolvimento de um trabalho interdisciplinar, com envolvimento das áreas clínica e educacional, permite a compreensão das necessidades individuais de cada criança. (WHO, 1992)

Os serviços de baixa visão devem desenvolver parcerias com outras áreas de atenção à deficiência visual na comunidade. $\mathrm{O}$ atendimento oftalmológico deve ser coordenado com ações educacionais e de reabilitação. (ISLVRR, 2005)

Os modelos de serviços de baixa visão podem ser: 1) de atenção primária, baseados na comunidade, com o objetivo de disseminar informações sobre a área de baixa visão, de triar, de detectar, de encaminhar e de fornecer orientações básicas na área de reabilitação; 2) de atenção secundária, baseados em consultórios oftalmológicos e hospitais regionais (objetivam o diagnóstico, tratamento, refração, avaliação da baixa visão, prescrição de auxílios para baixa visão e instrução para uso funcional dos mesmos) e também no sistema educacional (educação especial e centros de recursos para promover a inclusão do estudante na classe comum, por meio de recursos e orientações); 3) de atenção terciária, baseados em centros multidisciplinares providos por hospitais de grande 
porte ou instituições especializadas (oferecem gama maior de serviços: educação especial, programas de orientação e mobilidade, apoio psicológico e social, preparo para a empregabilidade e pesquisa). (ISLVRR, 2005)

A implantação de serviços de baixa visão deve ser coordenada com educação pública extensa, com atividades de sensibilização, para seu maior alcance, visibilidade e aceitação social dessa condição visual. (ISLVRR, 2005)

\subsection{A detecção de escolares com problemas visuais}

Alguns dos aspectos mais críticos no estudo dos serviços de saúde para a população infantil, referem-se a à observação da época, da necessidade e da adequação dos encaminhamentos para a possibilidade de intervenções precoces. Esses estudos devem considerar o papel do atendimento infantil na área pediátrica, oftalmológica e educacional. (Keeffe, 2004)

$\mathrm{Na}$ realidade brasileira, alguns autores indicam barreiras, para a detecção de problemas de saúde ocular, na atuação de profissionais da área da infância: pediatras e professores do ensino regular.

Manica (2003) afirma que os pediatras não apresentam conhecimento suficiente para diagnosticar e tratar doenças oculares prevalentes na infância, bem como orientar os pais e familiares. Assim, aponta a necessidade de capacitação de pediatras quanto a conhecimentos necessários para a orientação básica e o encaminhamento ao oftalmologista. 
Da mesma forma, Armond e Temporini (2000) apontam que o desconhecimento por parte do professor do ensino regular sobre aspectos básicos de saúde ocular e a presença de crenças equivocadas indicam a necessidade de desenvolvimento de ações de oftalmologia sanitária nas escolas de primeiro grau.

Segundo Kara-José e Alves (1994), aproximadamente 15\% das crianças em idade escolar necessitam de correção óptica, 4\% são amblíopes, $25 \%$ necessitam de algum atendimento oftalmológico, sendo os erros de refração não corrigidos uma das principais causas de deficiência visual nas crianças no Brasil .

Até a idade escolar, pode passar despercebida da família a maior parte das dificuldades visuais da criança por desconhecimento e/ou ausência de sinais ou queixas. Ao ingresso na escola, contudo, manifestamse distúrbios oculares, pré-existentes ou não, evidenciados em razão do esforço visual necessário à realização do processo de aprendizagem .

Os problemas visuais interferem no rendimento escolar e na sociabilização da criança, requerendo ações precoces de identificação e tratamento. (Temporini, 1990) A convivência diária e prolongada do professor com o aluno propicia vantagem incomum para a observação de mudanças na aparência ou na conduta, que podem ser prenúncio de enfermidades. A escola, instituição que consegue aglutinar grande número de crianças, permite uma ação programada de cunho preventivo, no que se refere à promoção da saúde ocular ou no diagnóstico precoce e pronto tratamento dos casos identificados. (Temporini, 1988) Assim, Nobre (2001) 
observou numa população de escolares com baixa visão, que $58,3 \%$ da percepção do problema visual foi realizada pelo professor do ensino regular.

Saúde escolar, de acordo com o Grupo Informal de Estudos e Discussão sobre Saúde Escolar de São Paulo (GIEDISE), refere-se a um conjunto de atividades desenvolvidas por uma equipe multiprofissional, envolvendo inclusive o professor, que visa promover, proteger e recuperar a saúde do ser humano em idade escolar, esteja dentro ou fora da escola, quer por meio de ações educativas e assistenciais, que levam em conta suas origens e realidade de vida, quer interagindo com recursos institucionais disponíveis na comunidade, assim como a família, buscando influir de maneira decisiva no ambiente físico e emocional da escola, no processo de ensino da saúde e na assistência integral à saúde pessoal da criança .(Conceição, 1994)

Dentro desse contexto, o Conselho Brasileiro de Oftalmologia elaborou, em parceria com o Ministério da Educação, a "Campanha Nacional de Prevenção e Reabilitação Visual Olho no Olho", que visava identificar, prevenir e proporcionar assistência à saúde visual da criança, contribuindo para a redução do índice de repetência e de evasão escolar, além de conscientizar pais e profissionais da educação sobre a necessidade de reconhecer sinais e sintomas de alterações visuais e a importância do tratamento precoce (Kara-José et al., 2006)

Gasparetto (2004) aponta, ainda, que os professores apresentam conhecimento insuficiente quanto à saúde ocular e sugere a implantação de um programa de saúde ocular em todo o sistema público de ensino, com 
abrangência sobre todas as séries escolares do ensino fundamental, visando desenvolver ações de prevenção da incapacidade visual, de promoção e recuperação da saúde ocular. É imperativo que a escola participe de ações de promoção de saúde ocular, bem como de identificação e encaminhamento de alunos a especialistas para diagnóstico e tratamento dos problemas visuais detectados.

Segundo Temporini e Kara-José (2004) o planejamento de programas de saúde ocular deve ser realizado com base no conhecimento da realidade à qual se destinam as ações. É necessário analisar os seguintes aspectos: 1) Informações sobre a situação epidemiológica do problema focalizado; 2) formação de recursos humanos adequados às demandas; 3) infra-estrutura; 4) fatores psicossocioculturais.

\section{5 escolar com baixa visão}

Lowenfeld (1973) afirma que a cegueira causa limitações nas funções do conhecimento, no que se refere à percepção e a cognição em cinco áreas específicas: no alcance e variedade de experiências, na formação de conceitos, na capacidade de locomoção, no controle e relacionamento com o ambiente e no acesso às informações escritas. $\mathrm{Na}$ baixa visão, conforme o grau de comprometimento do sistema visual, podemos observar essas limitações em intensidades variadas. 
O escolar com baixa visão necessita, uma vez detectado o problema, de atendimento oftalmológico para avaliação de suas funções visuais e prescrição de recursos ópticos; do emprego de auxílios não ópticos para adaptação do ambiente e de materiais; do apoio de serviços especializados que busquem sua inclusão; das ações do professor do ensino regular para efetivação e concretização das medidas necessárias para melhora de sua resolução visual e desempenho; da educação da comunidade escolar, de sua família e da sociedade quanto ao seu quadro de baixa visão.

De acordo com Lora (2000), vários aspectos interferem de maneira significativa na educação formal dos alunos com limitação visual e para que possam atingir os objetivos almejados pela educação quanto a independência pessoal, qualificação para o trabalho e exercício da cidadania. Fica implícito que o professor especializado não poderá trabalhar apenas com o aluno, ele precisa envolver a família e o pessoal da escola no seu processo educacional .

Para que isto ocorra, o professor deverá planejar e desenvolver seu trabalho de tal forma que consiga efetivamente realizar todas as tarefas exigidas pela deficiência; prestando serviços diretos e indiretos ao aluno. Os serviços diretos são os procedimentos exercidos diretamente com o educando, quando está ensinando, orientando ou desenvolvendo certas habilidades; os indiretos, quando prepara materiais ou procura criar condições que favoreçam o desenvolvimento ou atuação do mesmo em diferentes situações que poderá enfrentar, quer seja na escola, na família ou na sociedade. (Lora, 2000) 
A Declaração Universal de Salamanca, de 1994, preconiza a educação inclusiva, cujo princípio fundamental é o de que todas as crianças devam aprender juntas, independentemente de suas dificuldades e diferenças. As escolas inclusivas devem reconhecer e responder às diversas necessidades de seus alunos, acomodando tanto estilos quanto ritmos diferentes de aprendizagem e assegurando um educação de qualidade a todos, por meio de currículo apropriado, modificações organizacionais, estratégias de ensino, uso de recursos e parcerias com a comunidade. (Corde, 1994; Bolonhini Junior, 2004)

Para a viabilização da inclusão educacional do aluno, portador de visão subnormal, são necessários a ação conjunta e o envolvimento de profissionais da área da saúde e da educação, para garantir que todos os aspectos sejam abordados. (WHO, 1992)

De acordo com Bishop (1986), a inclusão de alunos com deficiência visual no sistema regular de ensino, sem preparo, raramente funciona. Destacam-se, portanto, a necessidade do preparo dos professores e do provimento de recursos materiais específicos.

Gasparetto (2001a) sugere que seja realizada a capacitação de professores do sistema regular de ensino e dos diferentes profissionais que integram as áreas da saúde e educação, visando o seu preparo para atuar junto ao aluno com baixa visão e que pode ser realizada por meio de parcerias entre universidade, serviços especializados e escolas. 


\subsection{A atenção oftalmológica ao escolar com baixa visão}

\subsubsection{O papel do oftalmologista na reabilitação da baixa visão}

O oftalmologista, na sua prática médica diária, lida com uma grande variedade de situações de saúde que afetam a vida de seus pacientes. $O$ foco de sua atuação é a intervenção imediata para cura dessas afecções. No entanto, apesar do pronto atendimento e dos recursos terapêuticos existentes, condições crônicas e deficiências permanentes podem existir e lidar com as suas conseqüências constitui-se numa parte da atuação médica denominada de medicina da reabilitação, na qual está incluída a oftalmologia. (Colenbrander e Fletcher, 2003)

A atuação do oftalmologista na área da baixa visão não é uma ação isolada; é parte de um trabalho conjunto de profissionais de diferentes áreas, com o objetivo da inclusão social do indivíduo com a deficiência visual. (Haddad et al., 2001)

Segundo Fonda (1965) a prática do oftalmologista na área da baixa visão constitui-se numa simples extensão de sua rotina e é dificultada , muitas vezes, por falta de conhecimento e por informações equivocadas.

O oftalmologista é o agente catalisador do processo de reabilitação visual. A atenção oftalmológica à baixa visão permite o direcionamento de ações, desde o esclarecimento à família, tratamentos pertinentes, adaptação de auxílios para baixa visão até a referência a profissionais de outras áreas para subsídio no trabalho de habilitação ou reabilitação visual. A partir do 
conhecimento das características da resposta visual as ações tornam-se eficientes, sendo a promoção do desenvolvimento da criança com baixa visão o objetivo. (Haddad et al., 2001; Sampaio et al., 2001)

As estratégias de ações para habilitação e reabilitação visual são estabelecidas a partir das necessidades individuais da criança, de acordo com o impacto da deficiência visual sobre sua funcionalidade. A função visual é frequentemente estudada por meio de medidas de acuidade visual, campo visual, sensibilidade ao contraste, visão de cores e binocularidade . (Massof, 2002)

Até a década de 80 , a acuidade visual era o principal dado de interesse na avaliação oftalmológica para uso em escalas psicométricas (para efeitos legais). (Rahi, 1998; Massof, 2002; Boer et al., 2004) Ao longo dos últimos 20 anos, profissionais da área clínica observaram que dados de medida da função visual isoladamente não refletiam, quanto à perspectiva do indivíduo com a deficiência visual, aspectos importantes de sua condição. Atualmente maior ênfase tem sido dada a aspectos da qualidade de vida relacionada à resposta visual . (Boer et al., 2004)

O atual conceito de prevenção enfatiza a preservação da visão e relaciona-se estreitamente à qualidade de vida do ser humano, na qual desempenha importante função a sua capacidade visual. (Temporini e KaraJosé, 2004)

A OMS define qualidade de vida, dentre as diversas definições com perspectiva multidimensional (física, funcional e psicossocial), como uma percepção do indivíduo em seu contexto cultural e de valores e em relação a 
suas metas, expectativas, padrões e interesses, sendo saúde um estado de bem-estar físico, mental e social.(Boer et al., 2004; Massof e Fletcher, 2001; Parrish, 1996)

A Classificação Internacional de Funcionalidade, Incapacidade e Saúde (CIF) proporciona base científica para a compreensão e o estudo da saúde e das condições de bem-estar relacionadas à saúde em qualquer indivíduo. A funcionalidade indica os aspectos positivos da interação entre o indívíduo e seus fatores contextuais, enquanto que a incapacidade indica os aspectos negativos. A CIF integra conceitos do modelo médico e social de funcionalidade e incapacidade; sua abordagem é biopsicossocial.(OMS, 2001) O significado da condição visual para o indivíduo depende da sua interação com fatores sociais, ambientais, psíquicos, familiares, laborativos. (Green et al., 2002)

Instrumentos para mensurar qualidade de vida têm sido empregados para determinação de condutas e tratamentos, assim como para estudo do seu impacto na vida do indivíduo. (Hinds et al., 2003; Massof, 2002; Bôer et al., 2004; Massof e Fletcher, 2001; Ellwein et al., 1995; Stemack, 2001; Haynes et al., 2002; Hassell e Keeffe, 2000; Keeffe et al., 1998 ) Na infância, instrumentos para estudo da qualidade de vida têm sido pouco empregados.

A medida da incapacidade resultante da deficiência visual na infância, dentre outros aspectos, faz-se necessária para o desenvolvimento de ferramentas para avaliar a qualidade de vida nas diversas faixas etárias e os achados dessa pesquisa influenciarão a prática de trabalho. (Soori, 2004) 
O oftalmologista deve apresentar atuação bem mais abrangente do que diagnosticar e tratar doenças ou proteger a saúde ocular do paciente. Destaca-se a necessidade de sua liderança e participação em programas e em grupos interessados no controle e na erradicação de afecções oculares, bem como na prevenção da perda visual. Essas ações visam à preservação e/ou melhoria da visão, contribuindo para o alcance de melhor qualidade de vida e baseiam-se na necessidade de identificar e tratar pessoas, ainda em tempo de manter a própria independência. (Nizetic, 1973; Resnikoff, 2000)

\subsubsection{Histórico da reabilitação da pessoa com baixa visão e da atuação do oftalmologista.}

Historicamente, podemos ressaltar alguns fatos relacionados à reabilitação visual, ao uso de recursos ópticos e à atuação do oftalmologista na área da baixa visão:

- lentes rudimentares foram encontradas em escavações na ilha de Creta e datam de 2000 a.C.;

- óculos com lentes convexas para ampliação já eram utilizados desde 1270 num relato de uma visita de Marco Polo a China;

- Hans Lippershey (1570-1619) desenvolveu o primeiro sistema telescópico em 1608 na Holanda;

- Galileu Galilei (1569-1642) construi um sistema telescópico de três vezes de aumento em 1610; 
- Johannes Kepler (1571-1630) apresentou seu modelo de telescópio em 1611;

- o primeiro instrumento para ampliação da imagem empregado nos casos de dificuldade visual (cone de vidro plano-convexo) é atribuído a René Descarte em 1637;

- Issac Newton (1643-1727) desenvolveu um telescópio refletor com uso de espelhos em 1668;

- Herman Snellen (1834-1908) publicou "Optotypes", o primeiro cartão de medida da acuidade visual em 1862;

- Benjamin Franklin inventou as lentes bifocais em 1784;

- Charles Prentice descreveu o tiposcópio em 1897;

- a Escola de Míopes é implantada, em Londres, como a primeira escola no mundo para crianças com baixa visão em 1908;

- primeira classe para alunos com baixa visão é implantada no Instituto Perkins nos Estados Unidos em 1913;

- a American Foundation for the Blind disponibiliza lentes telescópicas e se torna referência a profissionais da área de saúde ocular;

- em 1924 há relato de uma apresentação no Congresso da Academia Americana de Medicina sobre a utilização de sistemas telescópicos por pacientes;

- em 1930, oftalmologistas declaram que o uso da visão não leva a prejuízo nos pacientes com visão parcial; 
- em 1935, Dr. Feinbloom publica o artigo "Introdução aos princípios e à prática da correção em visão subnormal" e em 1938 relata o uso de auxílios ópticos em 500 indivíduos;

- na década de 40, Dr. Kestenbaum desenvolveu seus trabalhos sobre o uso da ampliação para pacientes com visão subnormal na Áustria e nos Estados Unidos ;

- a American Printing House for the Blind inicia a impressão de livros com letras ampliadas;

- a Clínica de baixa visão da New York Lighthouse é implantada sob a direção do Dr. Gerald Fonda no ano de 1953;

- Gerald Fonda e Eleanor Faye sugerem o termo baixa visão em 1954

- na década de 50 , há aexibição de auxílios para baixa visão no Congresso Internacional de Oftalmologia;

- Berthold Lowenfeld, educador, publica artigos sobre aspectos psicológicos de crianças com visão parcial em 1955;

- Louise Sloan, oftalmologista, publica método para quantificar e prescrever auxílios para baixa visão em 1956;

- Richard Hoover, oftalmologista, apresenta definições funcionais de cegueira em 1957;

- vários outros profissionais contribuíram para a área no século XX: von Rohr, Policoff, Ellerbrock, Bechtold, Lederer, Hoff, Keeler, Bier, Hellinger, Sloan, Genensky; 
- em 1962, emprega-se, pela primeira vez,a técnica de olhar preferencial para avaliação da acuidade visual na infância por Fantz, Ordy e Udelf ;

- Natalie Barraga publica estudo sobre resposta visual em crianças no ano de 1964;

- Gerald Fonda publica "Management of the patient with subnormal vision" em 1965;

- Samuel Genensky desenvolve um circuito fechado de televisão como um auxílio para leitura, nos Estados Unidos, em 1969;

- Natalie Barraga publica "Visual Efficiency Scale and Teacher's Guide" em 1970;

- Eleanor Faye publica "The Low Vision Patient: Clinical Experiences with Adults and Children" em 1970;

- reabilitação em baixa visão e o conceito de treinamento foram introduzidos por Lindsted, Gertz e Backman, na década de 70;

- categorização de visão subnormal nas recomendações realizadas, no ano de 1972, pelo Grupo de Estudo para a Prevenção da Cegueira da Organização da Saúde e que foram incluídas na $9^{a}$ revisão da Classificação Estatística das Doenças e Problemas Relacionados à Saúde de 1975;

- a Academia Americana de Oftalmologia define sua Seção de Baixa Visão no ano de 1975;

- a partir da segunda metade dos século XX, disseminou-se o uso de auxílios ópticos e, atualmente, uma grande variedade de opções está disponível; 
- na década de 90, o Conselho Internacional de Oftalmologia lança base curricular para formação de oftalmologista na área de baixa visão; (ICO, 2006)

- a OMS e a IAPB lançam a ação "Vision 2020 - The right to sight" para eliminar a cegueira evitável até o ano de 2020. A baixa visão é considerada uma das prioridades;

- o Conselho Internacional de Oftalmologia, sob a liderança do Dr. August Colenbrander, publica no ano de 2002 o "Visual Standards - Aspects and ranges of vision loss" para uniformizar conceitos e definições na área da deficiência visual; (ICO, 2002)

- a OMS publica a Classificação Internacional de Funcionalidade, Incapacidade e Saúde (CIF) no ano de 2001. (OMS, 2001)

No Brasil, historicamente, podemos ressaltar os seguintes aspectos:

- a primeira escola para cegos na América do Sul foi criada no Rio de Janeiro em 1854, pelo Imperador D. Pedro II, com a denominação de Imperial Instituto dos Meninos Cegos. Em 1891 passou a se chamar Instituto Benjamin Constant (IBC); (Bruno, 1997)

- o fato de ser uma Escola de referência para cegos, proporcionou que fossem encaminhados alunos portadores de deficiência visual que não eram cegos e não conseguiam evoluir em escolas regulares. Estes alunos aprendiam o Braille e alguns o liam com os olhos. Era prática comum nas instituições a recomendação de vendar os olhos das crianças com alguma visão, para que não a utilizassem para o Braille; (Costa Filho, 2005) 
- a partir da década de 50 foram criadas no IBC, as Classes de Conservação da Visão $(\mathrm{CCV})$ de $1^{\mathrm{a}}$. a $4^{\mathrm{a}}$. série, nas quais os alunos que não eram considerados cegos tinham Professores videntes, usavam salas com quadro-negro, boa iluminação e cadernos com pauta mais larga. Aos alunos da CCV era sugerido o aprendizado de Braille. A partir do ginásio, as turmas se tornavam mistas (CCV e cegos), com pouca utilização do quadro-negro; (Costa Filho, 2005)

- em 1928 no Estado de São Paulo foi iniciado o atendimento especializado na área de deficiência visual com a Escola Profissional para Cegos, que mais tarde passou a se chamar Instituto Padre Chico; (Bruno, 1997)

- os primeiros atendimentos educacionais a alunos deficientes visuais matriculados no Sistema Estadual de Ensino em São Paulo foram em 1946 com a instalação da Fundação Para o Livro de Cego no Brasil , hoje Fundação Dorina Nowill para Cegos (FDN); (Bruno, 1997)

- no Brasil, a reabilitação de pessoas portadoras de visão subnormal incrementou-se com Vitorino de Araújo Lima no Rio de Janeiro na década de 70. A partir de 1974 surgem as primeiras clínicas de visão subnormal, como o Cetrevis (Centro de Treinamento de Visão Subnormal do Hospital Beneficência Portuguesa de São Paulo). (Kara-José et al., 1988) O Cetrevis contou com o empenho do Dr. Armando de Arruda Novaes, do Dr. Alexandre Costa Lima de Azevedo e da Profa. Dorina de Gouvêa Nowill; (Nowill, 1996) 
- a partir da década de 80 foram implantados os Serviços de Visão Subnormal dentro das Clinicas Oftalmológicas dos Serviços Universitários, destacando-se a Universidade de Campinas, a Universidade de São Paulo, a Universidade Federal de São Paulo , a Santa Casa de Misericórdia de São Paulo, a Universidade Estadual de São Paulo e a Universidade Federal de Minas Gerais;

- nas instituições de atendimento interdisciplinar à deficiência visual também são criados serviços de baixa visão, com a participação de oftalmologistas, entre elas: Laramara, FDN, Instituto de Cegos da Bahia e o IBC;

- no ano de 1995 é fundada a Sociedade Brasileira de Visão Subnormal (SBVSN), filiada ao Conselho Brasileiro de Oftalmologia e que congrega oftalmologistas e profissionais não médicos da área de reabilitação visual;

- no ano de 2001, sob a coordenação do Prof. Dr. Newton Kara-José, é realizado o "Projeto Nacional para Alunos com Baixa Visão",. Esse projeto foi fruto da parceria com a Secretaria de Educação Especial (SEESP), do Fundo Nacional de Desenvolvimento da Educação (FNDE) do Ministério da Educação, Universidade de São Paulo, Universidade Estadual de Campinas e a Associação Brasileira de Educadores de Deficientes Visuais (ABEDEV), Associação Brasileira de Assistência ao Deficiente Visual - Laramara, Fundação Dorina Nowill para Cegos, Secretaria de Estado da Educação de São Paulo e Universidade Estadual de São Paulo. Dentro desse projeto foi 
desenvolvido a "Capacitação de Recursos Humanos na área de Visão Subnormal para Profissionais da área da Saúde e da Educação" para atuação junto à população escolar com baixa visão. Foram capacitados 54 oftalmologistas (2 por unidade da Federação) e 54 educadores ligados aos Centros de Apoio Pedagógico e constituiu-se no maior projeto de capacitação na área de baixa visão com abrangência nacional;

- Sampaio et al (2005) realizaram estudo transversal descritivo mediante a aplicação de questionário estruturado e auto-aplicável enviado a 10.000 oftalmologistas cadastrados no Conselho Brasileiro de Oftalmologia (CBO), inserido em publicação informativa regular do CBO. Responderam à pesquisa 205 (2,05\%) oftalmologistas, sendo que $58(28,3 \%)$ já atuavam na área de baixa visão. Dos $147(81,7 \%)$ oftalmologistas não atuantes na área, $87,8 \%$ tinham interesse em iniciar atendimento a pacientes com baixa visão ${ }^{1}$;

- a formação de oftalmologista na área de baixa visão torna-se obrigatória nos serviços de especialização e de residência médica. O Conselho Brasileiro de Oftalmologia, por meio de sua Comissão de Ensino determina que todos os cursos de especialização credenciados tenham serviços de baixa visão para capacitação do oftalmologista.

\footnotetext{
${ }^{1}$ Sampaio MW, Haddad MAO, Azevedo ACL, Temporini ER (Universidade de São Paulo). Atenção oftalmológica à baixa visão no Brasil. (Apresentado no XXV Congresso Panamericano; 2005; Santiago - Chile)
} 


\subsubsection{A avaliação oftalmológica da criança com baixa visão}

A avaliação oftalmológica da criança com visão subnormal fornece aos profissionais da área da saúde e da área educacional subsídios fundamentais para o trabalho de habilitação visual. A partir do estudo da função visual, o oftalmologista poderá receitar auxílios ópticos adequados e indicar modificações ambientais e de materiais que promoverão a melhor resolução visual e a melhora do desempenho nas atividades diárias. Para o profissional da área educacional, os dados da avaliação permitirão reconhecer as reais limitações visuais da criança e darão subsídios para as intervenções apropriadas no ambiente escolar. (Haddad et al., 2001, Sampaio et al. 2001)

A avaliação inicia-se no primeiro contato com a criança e a família. Devem ser observados a postura, o comportamento, a atenção a estímulos externos e sua exploração, o domínio da mobilidade dentro do ambiente desconhecido e a interação com os pais, familiares ou acompanhantes. (Haddad et al. 2001)

Dados referentes ao início da deficiência, histórico familiar quanto à deficiência visual, desenvolvimento da criança, tratamentos realizados, dados clínicos gerais e desempenho escolar devem ser pesquisados. $O$ oftalmologista deve observar a receptividade dos pais quanto às orientações que possam ser dadas e sua compreensão do real quadro de seu filho com baixa visão.(Haddad et al. 2001) 
A avaliação oftalmológica na área de baixa visão contempla, além do exame oftalmológico, a pesquisa de algumas funções visuais como a acuidade visual, a sensibilidade ao contraste, o campo visual e a visão de cores, que apresentaremos, a seguir:

\subsubsection{Pesquisa da acuidade visual}

A acuidade visual é a medida do poder de resolução do sistema visual e dá informações sobre a integridade do sistema visual. O valor de 1 minuto de arco para valores de acuidade visual normal é arbitrário; muitos indivíduos podem ter capacidade de resolução maior. (Lopez,1994) Há várias maneiras de notação dos valores da acuidade visual: fracionária $(A V=d / D, d=$ distância do observador ao objeto e $D=$ distância em que o objeto forma um ângulo visual de 1 minuto de arco) e em pés ou metros; decimal; mínimo ângulo de resolução (MAR) e logarítimo do mínimo ângulo de resolução (logMAR). (Lopez, 1994)

Para a acuidade visual para perto a notação mais utilizada é a fracionária ou a métrica. Na notação métrica utiliza-se a letra M e o optotipo $1 \mathrm{M}$ corresponde a uma letra cujas dimensões determinam um ângulo visual de 5 minutos de arco a 1 metro. A correspondência entre os valores em M é linear, ou seja, $5 \mathrm{M}$ corresponde a uma letra 5 vezes maior que $1 \mathrm{M}$. A letra utilizada em publicações impressas (revistas e jornais) é do tamanho $1 \mathrm{M}$. (Faye, 1984; Faye, 2000; Rosenthal e Cole, 1996) 
É importante que os valores da acuidade visual não sejam expressos em "conta dedos", que não traduz de maneira objetiva a resolução visual. (Colenbrander e Fletcher, 2003; Faye, 1984)

Os testes para medida da acuidade visual utilizados dependem da faixa etária da criança e de sua capacidade de colaboração e informação. Dessa maneira, crianças em fase pré-verbal ou com dificuldade de informação e interação são avaliadas por testes de resolução, dentro os quais os mais empregados são:

- Os Cartões de Acuidade de Teller (CAT), desenvolvidos a partir de técnicas comportamentais de olhar preferencial. O CAT é composto por 17 cartões de $25,5 \mathrm{~cm} \times 51 \mathrm{~cm}$, dos quais 15 contêm listras pretas e brancas num espaço de $12,5 \times 12,5 \mathrm{~cm}$ dispostas em um dos lados do cartão. As listras modificam-se em espessura com alteração da frequência espacial (mais listras por espaço, maior frequência espacial) de 0,32 ciclos $/ \mathrm{cm}$ a 38 ciclos $/ \mathrm{cm}$ (um ciclo corresponde a uma listra preta e uma branca). Um cartão possui a frequência de 0,23 ciclos/cm e um cartão não possui listras. No centro dos cartões há um pequeno orifício através do qual o examinador observa a reação da criança à apresentação do cartão: a fixação das listras é considerada resposta positiva. As distâncias de avaliação são padronizadas: até 6 meses de idade aplica-se a $38 \mathrm{~cm}$, dos 7 meses aos 36 meses aplica-se a $55 \mathrm{~cm}$ e após 3 anos utiliza-se a distância de $84 \mathrm{~cm}$. Pode ser aplicado atrás de 
uma moldura para que estímulos do ambiente não interfiram com a resposta visual; (Teller, 1989)

- Lea gratings ${ }^{\circledR}$ é outro teste utilizado e tem o mesmo princípio dos Cartões de Acuidade de Teller. (Hyvärinen, 1998)

Para crianças informantes e não alfabetizadas (a partir de 2 anos), são utilizados testes de reconhecimento que utilizam como optotipos figuras simples. Os mais utilizados são os testes com Lea symbols ${ }^{\circledR}$, aplicados a uma distância de 3 metros, 1,5metro e 1 metro. São testes de alta confiabilidade, uma vez que a dificuldade de resolução dos optotipos é muito próxima (casa, quadrado, maçã e círculo). (Hyvärinen, 1998)

Para crianças alfabetizadas são utilizadas as mesmas tabelas empregadas na avaliação do adulto:

- a tabela ETDRS® (early treatment diabetic retinophaty study) Ferris - Bailey modificada apresenta características ideais para a avaliação da acuidade visual nos pacientes com visão subnormal: mesmo número de optotipos por linha, espaço regular entre as linhas e entre os optotipos, cálculo logarítimico, possibilidade de aplicação a 4 metros, 2 metros e 1 metro. Com a tabela ETDRS $®$ é possível utilizar a notação fracionária (em metros ou pés) e logarítimica; (Ferris et al., 1982)

- outras tabelas utilizadas são: Distance Test Chart for the Partially Sighted - Designs for Vision® (utiliza números e possibilita medidas 
de valores muito baixos de acuidade visual), Low Vision Chartr®, que tem os valores já convertidos para distância de 1 metro. (Colenbrander e Fletcher, 2003)

O valor da acuidade visual para perto deve ser pesquisada a fim de que se conheça a necessidade de magnificação e o padrão de leitura . Na criança, a amplitude de acomodação é grande e, na maior parte dos casos, o escolar consegue manter o foco a distâncias muito reduzidas sem que haja indicação de auxílios para perto. (Faye, 1972; Faye, 1984)

As tabelas de pesquisa da acuidade visual mais utilizadas são: Lighthouse Near Visual Acuity Test ${ }^{\circledR}$ para crianças alfabetizadas e tabelas para perto Lea symbols $\circledR$. Trazem os valores da acuidade visual em notação fracionária, em notação métrica $(\mathrm{M})$ e o número de dioptrias necessárias para melhora da resposta visual para perto. Esses valores correspondem ao inverso da acuidade visual em notação fracionária, de acordo com a regra de Kestenbaum. São apenas sugestões para o ponto de partida na adaptação de auxílios ópticos para perto (as dioptrias necessárias dependerão das características funcionais, do estado refracional do paciente e de suas necessidades). (Rosenthal e Cole, 1996; Faye, 1984)

\subsubsection{Pesquisa da sensibilidade ao contraste}

Contraste é a diferença de luminância entre superfícies adjacentes. A acuidade visual mostra a capacidade de resolução de detalhes, é um teste fotópico e que utiliza alto contraste. No entanto, a maior parte das situações 
diárias de um indivíduo requerem sensibilidade a contrastes reduzidos. Algumas pessoas têm baixo desempenho durante essas atividades, pela menor sensibilidade ao contraste, apesar de apresentarem valores normais de acuidade visual. (Hyvarinen, 1998)

A pesquisa da sensibilidade ao contraste é utilizada também na detecção precoce de alterações visuais na suspeita de determinadas doenças oculares como a neurite óptica e o glaucoma; na indicação da ampliação da imagem retiniana necessária; na habilidade para uso de auxílio ópticos e na adequação da iluminação. (Rosenthal e Cole, 1996)

.No escolar, o desempenho pode estar prejudicado pelo uso de material de baixo contraste como pautas de caderno não reforçadas e canetas de escrita fina. Os testes para pesquisa da sensibilidade ao contraste utilizam-se de figuras ou grades senoidais com diminuição progressiva do contraste . (Hyvarinen, 1998)

\subsubsection{Pesquisa do campo visual}

A avaliação do campo visual nos casos de baixa visão tem a finalidade de estudar melhor a funcionalidade do indivíduo e não a detecção ou diagnóstico de doenças oculares. Na maior parte dos casos, a doença já é conhecida e a pesquisa do campo visual é realizada para conhecer alterações que possam interferir no desempenho das atividades diárias. Os achados serão importantes para encaminhamento do paciente a serviços de orientação e mobilidade (principalmente, a partir de campos visuais com amplitudes menores do que 40 graus, mesmo que a acuidade visual esteja 
intacta); para a adaptação de auxílios de magnificação da imagem retiniana (quando a amplitude for menor do que 5 graus, não haverá possibilidade do uso de grandes ampliações e amplitudes de 10 graus levarão a redução da velocidade de leitura durante o uso de auxílios ópticos); para a indicação de auxílios de condensação da imagem retiniana (principalmente nos casos de amplitude menor do que 5 graus) como telescópios reversos, lentes negativas e prismas para relocação da imagem. (Freeman e Jose, 1997) A presença ou ausência de escotomas centrais poderá ser mais preditivo em relação à velocidade de leitura do que os valores de acuidade visual .

A perimetria automática, uma vez que disponível, pode ser empregada desde que haja colaboração por parte do paciente. O perímetro de Goldman é indicado quando há fixação pobre do estímulo visual, fadiga ou limiares menores que os predeterminados pelos programas em uso. Entretanto, a perimetria automatizada fornece uma padronização dos protocolos de teste com menor interferência, é independente do examinador, permite análise estatística dos resultados e comparação com dados normativos, além do seguimento longitudinal do paciente.O Scanning laser ophthalmoscope realiza o estudo do locus retiniano de fixação preferencial. (Rosenthal e Cole, 1996; Faye et al., 2000)

Alguns métodos de custo acessível, no entanto, podem ser úteis para estudo do campo na baixa visão (Jose, 1995; Faye et al., 2000 ):

- o teste de confrontação - teste rudimentar, que deve ser aplicado em todos os pacientes. Estima a existência de defeitos periféricos ou hemianopsias e pode sugerir testes mais sofisticados; 
- o perímetro de disco - com as mesmas finalidades do teste de confrontação;

- a tela de Amsler - estuda os 20 graus centrais e pode estimar a existência de escotomas centrais e paracentrais bem como o desempenho do paciente à leitura e

- a tela tangente - que estuda o campo visual central (geralmente, 30 graus).

\subsubsection{Pesquisa da visão de cores}

Os defeitos de visão de cores podem ser congênitos ou adquiridos. Sua avaliação tem duas principais finalidades: auxiliar no diagnóstico da doença ocular ou investigar a funcionalidade do paciente. Os defeitos congênitos de visão de cores apresentam geralmente alterações para verdevermelho; o sexo masculino é afetado, as alterações são simétricas em ambos os olhos e estáveis. Nos defeitos adquiridos, tanto o sexo masculino quanto o feminino são afetados; podem ser alterações verde-vermelho e azul-amarelo; são assimétricos entre os olhos; não são defeitos estáveis e as repostas dependem da iluminação empregada e do tamanho do estímulo. Os testes podem ser placas pseudoisocromáticas ou testes de arranjo ou pareamento. (Fuller e Birch, 1989, Rosenthal e Cole, 1996)

A acuidade visual e a sensibilidade ao contraste interferem com as respostas nos testes com placas pseudoisocromáticas. Nestas, a acuidade visual não deve ser inferior a 20/200 e o contraste entre a figura/ número e o fundo é pequeno. Os testes de arranjo ou pareamento adaptados (como o 
PV-16 ou o Farnsworth Dichotomous Test - Panel D-15) são os mais utilizados: têm poucas peças de maior diâmetro (melhor para acuidade visual baixa), o que o torna mais rápido; porém, pode não detectar defeitos leves de visão de cores. O teste deve ser monocular quando o objetivo é diagnóstico e binocular quando o objetivo do teste é observar a funcionalidade do paciente. (Rosenthal e Cole, 1996)

Faye (1984) propõe 3 padrões didáticos de correlação clínicofuncional e que dependem dos tipos e da intensidade das alterações nas diversas funções visuais estudadas: diminuição difusa da resolução visual, defeitos de campo visual central e contração generalizada do campo visual.

O perfil da resposta visual, observado na avaliação descrita, deve ser comparado aos valores esperados para a idade. Dessa maneira, é possível reconhecer as dificuldades do escolar e ter parâmetros para auxiliar no processo de habilitação visual, por meio da orientação à família, à escola, aos profissionais de reabilitação; da prescrição da correção óptica da sua ametropia e da prescrição de auxílios ópticos para baixa visão. (Haddad et al., 2001)

\subsubsection{Auxílios para baixa visão}

A maior funcionalidade visual é um dos principais objetivos do atendimento oftalmológico do paciente com visão subnormal. Através da modificação da imagem retiniana, de materiais e das condições ambientais, o aumento da resolução visual é obtido. (Haddad et al. 2001) 
A ampliação da imagem retiniana é o principal recurso utilizado nos pacientes com visão subnormal e pode ser obtida por meio de quatro sistemas (Lopez, 1994; Faye, 1984):

- ampliação pela diminuição da distância relativa (observador objeto) : quanto mais próximo o objeto do observador, maior será a imagem retiniana;

- ampliação linear: aumento real do objeto;

- ampliação angular: obtida com o emprego de lentes ou de combinação de lentes. A imagem parece ser proveniente de um objeto mais próximo;

- ampliação por projeção: a imagem é ampliada pela projeção em uma superfície.

Os sistemas de ampliação podem ser utilizados de maneira isolada ou combinada, de acordo com a necessidade do indivíduo.

Auxílio para baixa visão é qualquer recurso utilizado para melhorar o desempenho da pessoa com baixa visao nas suas diversas atividades. Podem ser ópticos, não ópticos e eletrônicos. (Sampaio et al., 2001)

A indicação dos auxílios pelo oftalmologista deve estar baseada:

- na avaliação oftalmológica com pesquisa das diversas funções visuais. O valor da acuidade visual auxilia na indicação da magnificação necessária; a pesquisa de campo visual dá indícios da dificuldade observada para determinados níveis de ampliação, na dinâmica da leitura e na orientação no ambiente. A avaliação da 
resposta aos diversos níveis de contraste pode mostrar a necessidade de modificação da iluminação empregada, do uso de maior ampliação e de utilização de auxílios não ópticos;

- nas necessidades do paciente. O perfil da criança deve ser considerado: sua idade, escolaridade, atividades, outras deficiências associadas, desenvolvimento global;

- na possibilidade de aumentar as áreas de interesse e atividades, conservando as habilidades já existentes;

- na estabilidade do quadro ocular, para que os auxílios indicados tenham utilidade por períodos maiores. (Sampaio et al, 2001)

\subsection{Auxílios ópticos para baixa visão}

Auxílios ópticos são recursos que, pelas suas propriedades ópticas, levam a uma resolução maior da imagem, seja pela sua capacidade de ampliação, de condensação, de reposicionamento da imagem na retina ou filtração. (Sampaio et al., 2001)

\section{A. Auxílios ópticos para ampliação da imagem retiniana}

Para ampliação da imagem para atividades a curta distância encontram-se disponíveis óculos com lentes convexas, lupas manuais, lupas de apoio e sistemas telescópicos ou telemicroscópios.

Para ampliação para longe temos os sistemas telescópicos.

A determinação da ampliação necessária depende dos valores de acuidade visual longe/ perto detectados durante a avaliação e dos valores da 
acuidade visual necessários para o desempenho de atividades específicas almejadas pelo paciente. É importante lembrar que a acuidade visual de 0,5 permite a realização da maior parte de tarefas do cotidiano.(Lopez, 1994) Para cada atividade e situação podem ser prescritos diferentes auxílios ópticos.

O treinamento para uso funcional do auxílio óptico deve ser realizado antes da sua prescrição, nas diversas atividades e condições ambientais. Desta maneira teremos a garantia de sucesso na adaptação.

\section{Lentes convexas}

São empregadas para ampliação da imagem para tarefas a curta distância. Podem ser montadas em armações de óculos, em lupas manuais ou lupas de apoio. O aumento conseguido depende da distância de refência utilizada (para distância de $25 \mathrm{~cm}$, a fórmula utilizada será $A=D / 4$ e para distância de $40 \mathrm{~cm}$, a fórmula utilizada será $A=D / 2,5$, onde $A=$ ampliação e $\mathrm{D}=$ dioptrias do auxílio óptico). Para que, na comunicação entre profissionais, não haja confusões quanto à real magnificação de um auxílio, deve ser utilizada preferencialmente a descrição em valor dióptrico. (Lopez, 1994)

- Montadas em armações de óculos. O aumento da imagem é conseguido pela diminuição da distância objeto-observador. A lente positiva tem a finalidade de proporcionar o foco da imagem na distância reduzida e evitar o esforço acomodativo. O valor dióptrico necessário para a nitidez de um objeto próximo é dado pela relação: $D=100 / d$ (onde, $D=$ dioptrias necessárias, $d=$ distância do 
objeto ao olho em $\mathrm{cm}$ ). Quanto maior o aumento, menor o campo visual , a distância de trabalho e a velocidade de leitura, o que restringe o número de tarefas em que esses auxílios podem ser empregados. As lentes positivas montadas em óculos podem ser: binoculares:lentes esféricas e lentes esferoprismáticas (lentes esféricas com prismas com base nasal em ambos os olhos). As lentes esferoprismáticas podem ser indicadas a partir de $4 \mathrm{DE}$ associadas a $6 \Delta$ com base nasal a $12 \mathrm{DE}$ associadas a $14 \Delta$ base nasal, montadas em meia-armação e monoculares: A)lentes esféricas até +10 dioptrias $\quad$ B) lentes asféricas de +12 a +20 dioptrias;C) lentes microscópicas e doublets de +24 a +60 dioptrias. D) adições coladas nas lentes, como bifocal, até +32 dioptrias (Faye, 1984; Rosenthal e Cole, 1996; Fonda, 1965)

- Lupas manuais. Lentes convexas ou uma combinação de lentes montadas em armação manual e que aumentam a imagem retiniana. O objeto deve estar posicionado na distância focal da lente e o aumento não depende da distância do auxílio ao observador. Quanto mais próximo o auxílio do olho, maior será o campo de visão. A imagem formada é virtual e situada no infinito. Não é necessário esforço acomodativo. A imagem ampliada pela lente é melhor focada com uso da correção óptica para longe. Há vários modelos e ampliações de +4 dioptrias até +68 dioptrias. Podem ter fonte de iluminação acoplada. (Rosenthal e Cole, 1996; Faye et al, 2000) 
- Lupas de apoio (stand- mounted magnifiers). Montadas num suporte rígido que deve ser apoiado dobre o texto a ser lido. Podem ter de +4 a +60 dioptrias. Fonte de iluminação pode estar acoplada.Podem ter foco fixo ou ajustável. As lupas de apoio com foco fixo requerem esforço acomodativo ou uso de adição para o foco da imagem que é virtual e situada a uma distância finita. As lupas com foco ajustável não requerem esforço acomodativo . (Lopes, 1994; Faye et al, 2000)

\section{Sistemas telescópicos}

São sistemas de lentes que fornecem ampliação angular para distâncias longas, intermediárias e curtas, de acordo com sua composição. A imagem parece proceder de um objeto mais próximo do observador e, portanto, será maior. A ampliação angular é dada pela relação entre o ângulo formado pelo eixo óptico e pelo raio emergente do sistema telescópico e o ângulo formado pelo eixo óptico e o raio incidente ao sistema telescópico. Quanto maior o desvio dos raios obtido, maior a imagem final. (Faye, 1984; Lopez, 1994; Sampaio et al, 2001)

Os sistemas telescópicos são compostos por uma objetiva, um corpo e uma ocular. As lentes na objetiva e na ocular são dispostas de maneira que o foco primário da objetiva coincida com o foco secundário da ocular. Há dois tipos, de acordo com as lentes empregadas (Lopez, 1994):

- Galileu: tem uma lente esférica negativa (côncava) na ocular e uma lente positiva (convexa) no objetiva. Produz uma imagem 
direta. Pode ser focada para o infinito (afocal) ou ter foco ajustável. São encontrados de 2,2X a $4 \mathrm{X}$;

- Kepler ou prismática: utiliza lentes convexas na objetiva e na ocular. Um sistema interno de prismas torna a imagem direta. Apresenta qualidade óptica da imagem superior ao tipo Galileu. Podem ter de 2,5X a 10X de ampliação. Tem foco ajustável e vai do infinito a distâncias curtas.

Os sistemas telescópicos podem ser manuais ou montados em armações (posicionamento central, superior ou inferior); monoculares ou binoculares. A maneira de utilização mais freqüente no escolar é a monocular e manual. Telelupa é a denominação mais encontrada para sistemas telescópicos tipo Galileu. Telemicroscópio é a denominação do sistema telescópico empregado para perto. A principal vantagem do telemicroscópio sobre os outros auxílios para perto é a sua maior distância de trabalho.

Erros refracionais importantes devem ter a correção óptica incorporada ao sistema telescópico ou a correção óptica, na forma de óculos ou lentes e deve ser utilizada durante o emprego do sistema. (Freeman e Jose, 1997)

A criança em idade escolar que tenha indicação para uso do sistema telescópico deve ser submetida a treinamento para o manuseio correto do auxílio e seu conseqüente uso funcional. A partir de condições semelhantes às do seu cotidiano, principalmente escolar, ela deve ser estimulada a utilizar o recurso. (Faye, 1984; Castro, 1994) 


\section{B. Auxílios ópticos para campos visuais reduzidos}

Os auxílios para campos visuais contraídos visam condensar as informações periféricas dentro da ilha de visão e melhorar a eficiência do rastreamento. O método mais utilizado é o de diminuição da imagem por meio de auxílios como: telescópios reversos e lentes negativas. O fator limitante é a diminuição da acuidade visual secundária à diminuição da imagem.

Modelos variados de telescópios reversos foram desenvolvidos. Eles podem ser acoplados a armações ou manuais. Quanto mais potentes, maior será a condensação da imagem e a diminuição da acuidade visual . Entre os telescópios convencionais, os mais utilizados são os de baixo potência, geralmente de 2,5X. Podem dificultar os movimentos oculares para varredura da imagem e este é um dos principais fatores da rejeição do telescópio reverso. (Cole e Rosenthal, 1996; Cohen, 1993)

A diminuição da imagem por lentes negativas é conseguida ao se segurar uma lente de - 5 dioptrias a -10 dioptrias com o braço estendido. A lente é montada em armação monocular de grande diâmetro que o paciente porta pendurada ao pescoço e utiliza, quando uma visão panorâmica é necessária.

Os prismas são utilizados para trazer informações do ambiente para o campo de visão e consequentemente, os movimentos oculares compensatórios para rastreamento não necessitariam ser extensos. Podem ser empregados prismas comuns, de 10 a 15 dioptrias, com a base voltada para o defeito de campo. Prismas de Fresnel podem ser acoplados às lentes dos óculos, em até 4 posições simultaneamente, formando um anel de prismas ao redor do centro da lente. (Cohen, 1993) 
Os espelhos acoplados às armações de óculos têm o objetivo de refletir os objetos situados no campo visual comprometido em direção ao campo visual preservado. Sua adaptação é difícil, uma vez que invertem a imagem, podem sobrepor imagens e são pouco estéticos. (Cohen, 1993)

Os auxílios de reposicionamento e ampliação de campo devem ser exaustivamente testados antes da sua prescrição e sua aplicabilidade deve ser considerada pelo paciente e pelo oftalmologista. (Haddad et al, 2001)

\section{Auxílios ópticos para controle da iluminação}

O espectro de luz visível é composto pela faixa de radiação eletromagnética com ondas com comprimento de $380 \mathrm{~nm}$ a $780 \mathrm{~nm}$. O sistema visual é mais sensível à faixa de $480 \mathrm{~nm}$ a $680 \mathrm{~nm}$ e menos às faixas de 380 a $480 \mathrm{~nm}$ (azul) e de 680 a 780nm (vermelho). A radiações ultravioleta UV-A (400nm a 320nm) e UVB (320 nm a 290nm) são absorvidas pela córnea e pelo cristalino. A radiação infravermelha ultrapassa livremente os meios ópticos e atinge a retina. Além das características da transmissão da luz, a fluorescência nos meios ópticos e a dispersão da luz nos meios com diminuição difusa da transparência (com presença de partículas suspensas) levam ao ofuscamento (glare). As radiações azul e violeta são as que mais sofrem dispersão enquanto as radiações laranja e vermelho são as que menos sofrem. (Cole e Rosenthal, 1996; Castro, 1994; Haddad et al, 2001)

O ofuscamento é o principal efeito adverso da luz sobre o sistema visual; pode levar a um desconforto visual com cefaléia, cansaço, ardor 
ocular, lacrimejamento e blefaroespasmo, ou a uma menor resolução visual, principalmente nos pacientes com baixa visão, pelo menor contraste da imagem retiniana (maior dispersão da luz nos meios ópticos alterados).

Para controle da iluminação, devemos alterar características da fonte de luz e diminuir a fluorescência e a dispersão com uso de filtros. Outros auxílios, os não ópticos, atuam principalmente sobre a luz refletida nas superfícies.

As lentes filtrantes têm o objetivo de diminuir as radiações azul e violeta, diminuir o desconforto visual e o ofuscamento, aumentar o contraste e a resolução da imagem. Para escolha de uma lente filtrante, devemos levar em consideração algumas características do material: coloração, densidade óptica, fotocromaticidade, polarização, filtração seletiva, proteção a UV e presença de superfícies espelhadas. (Cole e Rosenthal, 1996)

A coloração da lente filtrante não é sua principal característica e não deve ser o único parâmetro para a escolha. O melhor filtro é o que não altera a percepção de cor. $O$ filtro verde atua sobre a faixa laranja e vermelha. A lente cinza-claro não leva à alteração de cor e diminui a transmissão de todo o espectro. Lentes amarelas e âmbar eliminam o espectro azul e aumentam o contraste. (Cole e Rosenthal, 1996)

A densidade óptica da lente filtrante está diretamente relacionada à sua capacidade de transmissão; quanto maior a densidade de um filtro, menor a transmissão de luz. (Cole e Rosenthal, 1996)

A polarização de lentes permite o controle da luz ofuscante refletida das superfícies. Lentes polarizadas modificam a direção dos raios refletidos e são muito utilizadas por esquiadores ou velejadores por diminuir o 
ofuscamento da luz na superfície da neve e da água. Podem ser fotocromáticas e em cores variadas.

A escolha da melhor lente filtrante depende da doença ocular, dos sintomas visuais e das necessidades dos pacientes. Deve ser testada e a melhora no conforto visual, no contraste e na resolução deve ser observada. (Haddad et al. 2001)

\section{Auxílios de videomagnificação}

Os sistemas de videomagnificação - CCTV (closed circuit television circuito fechado de televisão) combinam uma câmera, um sistema óptico e um monitor (Haddad et al, 2001); . Existem três tipos:

- de mesa (desktop). Tem um monitor e uma câmera montados acima de uma bandeja móvel. O material a ser lido é posicionado abaixo da câmera e a imagem é projetada na tela do monitor. Esse modelo é pesado, de custo alto e não portátil. Permite o uso para a escrita, uma vez qua a câmera é fixa e possibilita ampliações variadas. O modelo desktop permite ampliação de até 60 vezes;

- manuais. A câmera manual é conectada, através de um cabo, a um monitor de televisão comum. A câmera é deslizada sobre o texto ou material a ser lido. Permite a leitura de superfícies curvas e é portátil. A escrita não é possível como no modelo de mesa. A ampliação máxima obtida é menor que a conseguida com o modelo desktop. Há outro modelo portátil que não necessita ser conectado a um monitor e uma tela pequena é acoplada ao sistema; permite 
aumentos de $6 \mathrm{X}$ e de $13 \mathrm{X}$, a velocidade de leitura é baixa e o deslizamento sobre o texto é difícil;

- montadas em suporte para cabeça. Há dois tipos: a) a câmera é manual e o monitor é montado no suporte para cabeça ; b) tanto a câmera quanto o monitor são montados no suporte para cabeça. 0 monitor é similar ao utilizado para realidade virtual, posicionado à frente dos olhos. Permitem a magnificação para longe e perto. $O$ aumento obtido com esses sistemas depende do tamanho da tela do monitor e do zoom empregado. (Faye, 1984; Faye, 2000)

\subsection{Auxílios não ópticos}

Auxílios não ópticos modificam materiais e melhoram as condições do ambiente com o objetivo de aumentar a resolução visual. (Cole e Rosenthal, 2001; Sampaio e Cibils, 2000) Podem ser empregados isoladamente ou em conjunto com auxílios ópticos com o objetivo de promover a sua adaptação e seu uso funcional. Temos:

- ampliação do tamanho dos objetos. A ampliação de letras em impressos é o auxílio mais comum. Além do aumento da letra, a qualidade da impressão, superfície e coloração do papel, espaçamento entre os caracteres, espaçamento entre as linhas, largura das margens e estilo da letra são características importantes. O aumento máximo geralmente utilizado é o de $2,4 \mathrm{X}$. A vantagem da letra ampliada é favorecer a leitura pela magnificação real, pelo maior contraste dado pela letra ampliada e pela menor frequência 
espacial obtida. A principal desvantagem da impressão com letras ampliadas é o maior volume do material, o que dificulta seu armazenamento e seu transporte; (Cole e Rosenthal, 1996)

- controle da iluminação. Podem ser para controle da fonte de luz (escolha de focos direcionáveis e de lâmpadas) e para diminuição da luz refletida (tiposcópios e acetato amarelo); (Lopez, 1994)

- auxílios para postura e posicionamento. O uso adequado de auxílios ópticos depende do posicionamento do material e da postura do indivíduo durante a atividade. Auxílios ópticos para perto necessitam da manutenção da distância focal, da posição do olhar, da movimentação de cabeça e da postura para maior conforto e eficiência no seu uso. Muitos auxílios ópticos requerem uma distância muito pequena de leitura, o que torna a atividade cansativa e podem levar à falência na adaptação. Pranchas inclinadas e apoio de material de leitura são os auxílios mais utilizados. Ajudam a manter o material num ângulo de 45 graus com o plano da mesa e possibilitam que a linha de visão seja perpendicular ao plano do texto, o que fornece maior conforto e garantia da manutenção do foco com uso do auxílio óptico; (Cole e Rosenthal, 1996)

- auxílios para a escrita. São empregados: guias para escrita (para cheques, por exemplo) confeccionados em cartão preto e com fendas nos locais que devem ser preenchidos; folhas com pauta ampliada e reforçada que favorecem a ampliação das letras e aumentam o contraste da linha com o papel e canetas porosas ou lápis mais macio (3B ou 6B) que aumentam o contraste. 


\subsection{Acesso a serviços de habilitação e reabilitação visual}

Segundo Nallin (1994), instituições de reabilitação podem não contemplar a diversidade cultural, econômica e pessoal do indivíduo com a deficiência.

Do ponto de vista quantitativo, existem poucas instituições de reabilitação e que se localizam principalmente nas capitais; geralmente são de caráter não governamental, mantidas por verbas públicas, por recursos doados pela comunidade e pelo pagamento de parte de sua clientela. De origem pública, tem-se alguns serviços ligados às Universidades. (Nallin, 1994)

Do ponto de vista qualitativo, observa-se que grande parte das instituições objetiva o suprimento de necessidades básicas das pessoas com a deficiência (alimentação e vestuário, por exemplo), apresentando dificuldades em desenvolver atendimento de reabilitação propriamente dito. Em outras instituições, predomina o enfoque médico-científico, com ênfase numa abordagem técnica da deficiência. São estabelecimentos de maior porte, que dispõem de infra-estrutura material e financeira mais estável e incluem centros de formação de pessoal e de tecnologia na área. Estas entidades desenvolvem atendimento de reabilitação propriamente dito. (Nallin, 1994)

A OMS (1992) estima que um centro de atendimento composto por um oftalmologista e um profissional da área de educação especial poderia atender a demanda dentro de uma população de 5 milhões de pessoas. 
A necessidade de serviços de atendimento à baixa visão depende da prevalência da deficiência visual no meio. De acordo com a OMS,da população com baixa visão, $50 \%$ estaria na faixa de deficiência visual moderada (desses, 10\% precisam de suporte de serviços especializados); $25 \%$ estaria na faixa de deficiência visual grave ( dos quais, $50 \%$ necessitaria de algum suporte) e $25 \%$ na faixa de deficiência visual profunda (50\% necessitaria de reabilitação e $50 \%$ de suporte de serviços de baixa visão). De maneira geral, 30\% da população com deficiência visual necessita de atendimento primário, $50 \%$ de atendimento secundário e $20 \%$ de atendimento terciário. Um centro terciário seria necessário para cada 10 milhões de habitantes e centros secundários em número 4 vezes maior. Os centros primários seriam necessários em número de 100 para cada 10.000.000 habitantes .(WHO, 2002)

No Brasil, com uma população estimada de 170 milhões de pessoas, necessitaríamos de 17 centros terciários, 68 centros secundários e 1700 centros primários.

Nos países em desenvolvimento, poderíamos estimar a população infantil com deficiência visual da seguinte forma: prevalência da cegueira ou da deficiência visual grave de 1/1000, prevalência de baixa visão 3/1000. 80\% dessa população teria erros de refração passíveis de correção óptica e $20 \%$ teria realmente baixa visão.

No Brasil, $30 \%$ da população total corresponde à faixa etária de 0 a 14 anos (51 milhões de crianças). A prevalência de cegueira seria de 51.000 crianças e de baixa visão de 153.000 (214.000 crianças com deficiência 
visual). $80 \%$ (122.400) com erros de refração corrigíveis e 20\% (30.600) com baixa visão.

Segundo a OMS nos países em desenvolvimento, a maior parte das crianças com deficiência visual, mesmo graves, não são encaminhadas ao atendimento oftalmológico ou educacional especializados, pelas seguintes razões: nível baixo de instrução dos pais e família; pouca acessibilidade aos serviços de saúde; baixa prioridade do problema ocular da criança no contexto familiar desfavorável; a criança com baixa visão pode ter uma funcionalidade visual adequada dentro de seu meio e cultura e não ser considerada deficiente. (WHO, 1992)

Apesar de diversos estudos apresentarem o impacto positivo das ações desenvolvidas pelos serviços de reabilitação visual na qualidade de vida do indivíduo com deficiência visual, a subutilização desses recursos é observada.(Pollard et al., 2003; Gieser, 2004)

Leonard (2002) sugere que apenas $1 \%$ das pessoas com baixa visão são encaminhadas a serviços de reabilitação visual e que somente 10 a $21 \%$ da população encaminhada tem conhecimento dos recursos existentes em sua comunidade.

Estima-se que atualmente apenas 5 a $10 \%$ da população com baixa visão utilizam serviços de reabilitação visual. (Culham et al., 2002; LovieKitchin, 1990)

A falta de conhecimento, por parte de oftalmologistas, de recursos existentes para a reabilitação visual, é uma das principais barreiras de acesso dos pacientes com baixa visão aos serviços. (Gieser, 2004) 
Estudos quanto às dificuldades de acesso a serviços, percepção e atitudes da população acerca da deficiência visual, aspectos educacionais, aspectos psicossociais e condições ambientais devem ser realizados para melhor compreensão dos diversos aspectos da deficiência visual no nosso meio. (ISLVRR, 2005) 
I. Identificar aspectos clínicos referentes a população com baixa visão em idade escolar atendida no Serviço de Visão Subnormal da Clínica Oftalmológica do Hospital das Clínicas da Faculdade de Medicina da Universidade de São Paulo e no Serviço de Oftalmologia da Associação Brasileira de Assistência ao Deficiente Visual - Laramara, quanto a:

- causas de baixa visão;

- localização da anormalidade;

- classes de comprometimento visual;

- função visual atual;

- prescrição óptica para correção de ametropias e para auxílios para baixa visão;

- necessidades reabilitacionais.

II. Verificar percepções de mães / responsáveis desses escolares quanto a:

- detecção da deficiência visual do escolar;

- encaminhamentos e condutas realizados por profissionais da área médica frente à suspeita da deficiência visual;

- acesso a serviços de atenção oftalmológica especializada à baixa visão;

- acesso a auxílios ópticos prescritos para baixa visão.

III. Fornecer subsídios para desenvolvimento de ações para habilitação/reabilitação da baixa visão na infância. 


\subsection{Tipo de Estudo}

Realizou-se um estudo transversal analítico. Estudou-se a realidade da maneira como se apresentou, sem realizar manipulação de variáveis.

O projeto foi aprovado pela Comissão de Ética em Pesquisa do Hospital das Clínicas da Faculdade de Medicina da Universidade de São Paulo (Protocolo de Pesquisa № 789/05).

\subsection{Populações}

O estudo incluiu duas populações, considerando a natureza dos objetivos:

\subsubsection{População de escolares com baixa visão}

Totalidade de escolares com baixa visão, atendidos no Serviço de Visão Subnormal da Clínica Oftalmológica do Hospital das Clínicas da Faculdade de Medicina da Universidade de São Paulo e no Serviço de Oftalmologia da Laramara (Associação Brasileira de Assistência ao Deficiente Visual), entre fevereiro e novembro de 2005; 


\subsubsection{População de mães ou responsáveis desses escolares}

\subsubsection{Critérios de inclusão}

\subsubsection{Escolar}

idade entre 7 e 16 anos;

não apresentando outra deficiência física,nem sensorial associada à visão;

residente no município de São Paulo, ou em município da Região da Grande São Paulo.

\subsubsection{Mãe ou responsável}

acompanhante do escolar incluído nas características explicitadas; com capacidade de fornecimento de informações.

A população foi identificada durante o atendimento agendado, no período de fevereiro a novembro de 2005 , no Serviço de Visão Subnormal da Clínica Oftalmológica do Hospital das Clínicas da Faculdade de Medicina da Universidade de São Paulo e no Serviço de Oftalmologia da Laramara (Associação Brasileira de Assistência ao Deficiente Visual). Informe sobre o estudo e seus objetivos foram apresentados aos responsáveis. A pesquisa foi realizada mediante o consentimento e autorização para uso dos dados e informações de acordo com o "Termo de Consentimento Livre e Esclarecido", assegurando-se anonimato, sigilo dos dados e ausência de prejuízos para o atendimento. 


\subsection{Local da pesquisa}

3.3.1 O Serviço de Visão Subnormal da Clínica Oftalmológica do Hospital das Clínicas da Faculdade de Medicina da Universidade de São Paulo (SVSN HC FMUSP) presta atendimento aos indivíduos portadores de baixa visão encaminhados pelos outros Serviços da Clínica Oftalmológica. A equipe do SVSN HC FMUSP é formada por oftalmologistas, assistente social, pedagoga, fisioterapeuta, psicóloga, professora de orientação e mobilidade e ortoptista Constituem objetivos desse serviço:

- realizar a avaliação oftalmológica do paciente com visão subnormal e a adaptação e prescrição de auxílios ópticos, não ópticos e eletrônicos pertinentes;

- a partir do levantamento das necessidades individuais, orientar quanto às ações que podem ser realizadas pelas famílias, pais, educadores e comunidade para o uso eficiente da visão e para o desenvolvimento global da criança com baixa visão;

- fornecer orientações para o resgate ou aquisição da independência e da autonomia do indivíduo. Realizar, quando necessário, encaminhamento para outros serviços em centros de habilitação e reabilitação visual;

- capacitar recursos humanos para atuação na reabilitação da população com baixa visão. 
3.3.2 A Associação Brasileira de Assistência ao Deficiente Visual Laramara, localizada na cidade de São Paulo, é uma organização não governamental sem fins lucrativos criada em 7 de setembro de 1991. Seu Centro de desenvolvimento e inclusão da pessoa com deficiência visual (CDIPDV) desenvolve trabalho transdisciplinar em parceria com a família, escola e comunidade, para promoção do desenvolvimento integral, aprendizagem e inclusão social da pessoa com deficiência visual, em uma abordagem sócio-cultural, com perspectiva ecológica. O setor de oftalmologia compõe-se de duas oftalmologistas e duas ortoptistas e tem como objetivo: a avaliação oftalmológica, a prescrição de correção óptica para ametropias e de auxílios ópticos para baixa visão, orientação à família e aos profissionais não médicos da área de reabilitação quanto ao diagnóstico e respostas visuais. 


\subsection{Variáveis selecionadas}

\subsubsection{Variáveis dependentes}

Tendo em vista a multiplicidade de características das variáveis dependentes, realizou-se sua classificação em áreas específicas:

I. Aspectos clínicos referentes ao escolar

Características do quadro visual

- causa da deficiência visual

- etiologia da deficiência visual

- localização anatômica da lesão ocular

- classes de resposta visual

- acuidade visual para longe

- acuidade visual para perto

- sensibilidade ao contraste

- visão de cores

- campo visual

Necessidades ópticas

- prescrição da correção óptica

- prescrição de auxílio óptico

- atualização de auxílio óptico

Necessidade para atendimento multidisciplinar

- encaminhamentos para outras áreas da reabilitação visual 
II. Percepção de mães/responsáveis em relação a:

Detecção da deficiência visual

- Pessoa que suspeitou do problema visual (Q 8)

- Idade quando houve a suspeita da deficiência visual (Q 9)

Atendimento médico para diagnóstico

- Profissional(is) médico (s) consultado(s) sobre o problema visual (Q 11)

- Orientação médica frente a suspeita do problema visual (Q 12)

- Tipo de serviço público/ privado (Q 13)

- Intervalo de tempo entre a suspeita do problema visual e a consulta médica (Q 14)

Atendimento em serviço especializado

- Responsável pelo encaminhamento para o serviço de atendimento da baixa visão $(Q 17)$

- Atendimento prévio em outro serviço (Q 18)

- Conhecimento de outros serviços para baixa visão existentes (Q 19)

Dificuldades escolares

- Tipo de dificuldade escolar (Q 21)

Auxílios ópticos para baixa visão

- Uso de auxílios ópticos para longe (Q 22)

- Uso de auxílios ópticos para perto (Q 23)

- Aquisição do auxílio óptico (Q 24)

Benefícios concedidos pelos órgãos governamentais pela deficiência (Q 25) 


\subsubsection{Variáveis independentes}

Características pessoais do entrevistado (mãe ou responsável)

- relação com o escolar $(Q$ 1)

- exercício de atividade remunerada (pai/mãe) (Q 2 e 3)

- escolaridade (pai/mãe) (Q 4 e 5)

- núcleo familiar da moradia (Q 6)

Características pessoais do escolar

- $\operatorname{sexo}$

- idade

- série cursada (Q 20)

- município de residência

\subsection{Instrumentos da pesquisa}

\subsubsection{Estudo exploratório}

Realizou-se estudo exploratório por meio de entrevista individual, não estruturada com 20 pais ou responsáveis de crianças e adolescentes com baixa visão. Seguiu-se um roteiro de entrevista que contemplou domínios apresentados no componente "atividades e participação" da Classificação Internacional de Funcionalidade, Incapacidade e Saúde (OMS,2003): 
aprendizado e aplicação de conhecimentos, realização de tarefas, comunicação, mobilidade, cuidados pessoais, vida doméstica, interações e relações interpessoais, áreas principais da vida (educação e vida econômica), vida comunitária, cívica e social. As informações assim obtidas foram analisadas, tendo composto as questões do instrumento da pesquisa.

\subsubsection{Teste prévio}

Com base no estudo exploratório foi elaborado um questionário semiestruturado que foi aplicado a 30 pais ou responsáveis por crianças com deficiência visual atendidas na Laramara e no SVSNHC-FMUSP. Correções foram realizadas no questionário e constituiu-se o questionário semiestruturado final (Anexo A). A população entrevistada não foi incluída na presente pesquisa.

\subsubsection{Avaliação oftalmológica da população de escolares com baixa visão}

A avaliação oftalmológica da população em estudo foi composta por:

- Medida monocular e binocular da acuidade visual para longe corrigida. Empregaram-se a tabelas Ferris - Bailey modificadas "ETDRS Distance Acuity Test" aplicadas a 2 metros ou a 1 metro e tabela de Feinbloom a 3 metros, $1,5 \mathrm{~m}$ ou 1 metro para pacientes alfabetizados. As tabelas com optoptipos "' Lea" foram utilizadas para pacientes não alfabetizados e aplicadas a 3 metros, $1,5 \mathrm{~m}$ ou 1 metro; 
- Medida da acuidade visual para perto. Foram utilizadas as tabelas Ferris - Bailey ETDRS "Lighthouse Near Visual Acuity test" para pacientes alfabetizados ecom optopitpos "Lea”, "Lea Symbols Near Vision Card", para pacientes não alfabetizados. O teste foi aplicado a $40 \mathrm{~cm}$ com uso da correção óptica para perto. A avaliação foi monocular e binocular.

- Procurou-se manter as condições de iluminação da sala de exame e da tabela de acuidade visual constantes, em torno de 800 lux, calibrados por luxímetro digital modelo MLM-1010 da marca Minipa;

- Os valores de acuidade visual, de acordo com a Classificação Estatística Internacional de Doenças e Problemas Relacionados à Saúde $10^{\circ}$ Revisão - CID 10 (1993), da Organização Mundial da Saúde, foram classificados em classes de comprometimento visual: Classe $1(0,3<\mathrm{AV} \leq 0,1) ;$ Classe $2 \quad(0,1<\mathrm{AV} \leq 0,05) ;$ Classe 3 $(0,05<\mathrm{AV} \leq$ 0,02); Classe $4(0,02<\mathrm{AV} \leq$ percepção de luz $)$. De acordo com o Conselho Internacional de Oftalmologia (ICO, 2002), as classes 1, 2, 3 e 4 foram denominadas deficiência visual moderada, deficiência visual grave, deficiência visual profunda, próximo à cegueira, respectivamente .

- Teste de sensibilidade ao contraste. Foi empregado o "Lea Symbols Contrast Test" aplicado a distância de $25 \mathrm{~cm}$. A notação utilizada foi o inverso do contraste limiar, e o logarítimo da sensibilidade ao contraste, de acordo com o gráfico e instruções contidos no manual do teste; (Hyvärinen,1992) 
- Teste de cores. Utilizamos o "Quantitative Color Vision Test - PV16" por método de arranjo e pareamento, de acordo com as especificações apresentadas no manual. (Hyvärinen,1993). Foram definidas como respostas: padrão normal de visão de cores, tipo tritan ou tipo I verde-vermelho de Verriest, tipo deutan ou tipo II verde-vermelho de Verriest, tipo tritan ou tipo III azul-amarelo de Verriest e não definida;(Rosenthal e Cole, 1996)

- Estudo da amplitude do campo visual foi realizado por meio de perímetro de disco posicionado a $33 \mathrm{~cm}$ do paciente e utilizou-se como estímulo uma esfera branca com $35 \mathrm{~mm}$ de diâmetro. Quando houve a colaboração do escolar, utilizou-se a tela tangente a 1 metro de distância para estudo dos 30 graus centrais. Empregou-se como estímulo a luz projetada por uma ponteira laser, de acordo com protocolo sugerido por Lee et al. (2003) Utilizou-se a notação sugerida pelo Conselho Internacional de Oftalmologia .(ICO, 2002)

\subsubsection{Registro de dados da avaliação oftalmológica}

Elaborou-se uma ficha para registro de dados da avaliação oftalmológica. (Anexo B). Baseou-se no protocolo para registro de causas de perdas visuais em crianças, sugerido por Gilbert et al. (1993). 


\subsection{Coleta de dados}

A coleta de dados foi realizada em dois dias de avaliação, nos locais de atendimento. No primeiro dia (sessão com 1 hora de duração) foi aplicado o questionário ao responsável e realizada a avaliação oftalmológica. No segundo dia (sessão com 1 hora de duração) realizou-se complementação da avaliação oftalmológica com testes funcionais e, se necessário, testes com auxílios ópticos pertinentes ao caso.

As entrevistas e as avaliações foram realizadas pelo próprio pesquisador. O questionário foi aplicado aos pais ou responsáveis sem a presença do escolar.

\subsection{Procedimentos para análise dos dados}

\subsubsection{Banco de dados}

Foram criados dois bancos de dados com informações coletadas e registrados no questionário e na ficha de dados oftalmológicos. Utilizou-se o programa Access 2003. 


\subsubsection{Análise estatística descritiva e analítica}

A partir dos bancos de dados criados foi realizada a distribuição de freqüências das variáveis categóricas. Foi utilizado o programa estatístico SPSS 10.0 .

Foi utilizado o teste exato de Fischer (Monte Carlo) para verificação da existência ou não de associação entre as variáveis categóricas, tendo sido significativa a associação quando o valor foi $p \leq 0,05$. 


\subsection{Características das populações}

\subsubsection{A população de escolares foi composta por}

- 115 crianças e adolescentes com baixa visão (com valores de acuidade visual corrigida no melhor olho de 0,32 a percepção de luz de acordo definição funcional proposta pela Organização Mundial da Saúde (Programme for the Prevention of Blindness Management of low vision in children - Report of a WHO Consultation. Bangkok,1992 48 p. (WHO/PBL/93.27) e classes 1,2,3 e 4 de deficiência visual do CID-10;

- $23(20 \%)$ crianças avaliadas pelo Serviço de Visão Subnormal do Hospital das Clínicas da Faculdade de Medicina da Universidade de São Paulo 92 (80\%) no Serviço de Oftalmologia da Associação Brasileira de Assistência ao Deficiente Visual - Laramara no período de junho de 2005 a novembro de 2005;

- idade entre 7 anos e 16,1 anos com média de 11,15 anos;

- $53(46,1 \%)$ do sexo feminino e $62(53,9 \%)$ do sexo masculino; 
- Procedentes da cidade de São Paulo ou região da Grande São Paulo: $14(12,2 \%)$ provenientes da região sul, $9(7,8 \%)$ da região oeste, $5(4,3 \%)$ da região norte, $20(17,4 \%)$ da região leste e 63(54,8\%) da Grande São Paulo;

- $21(18,3 \%)$ casos novos e $94(81,7 \%)$ casos em acompanhamento no Serviço de Visão Subnormal da Faculdade de Medicina da Universidade de São Paulo ou no Serviço de Oftalmologia da Associação Brasileira de Assistência ao Deficiente Visual Laramara;

- $5(4,3 \%)$ cursavam a pré-escolar, 58 (50,5\%) cursavam o Ciclo I, $42(36,5 \%)$ cursavam o Ciclo II e $10(8,7 \%)$ cursavam o ensino médio. (Tabela 1)

Tabela 1 - Faixa etária e escolaridade de crianças com baixa visão - Hospital das Clínicas da Faculdade de Medicina da Universidade de São Paulo e Laramara - 2006

\begin{tabular}{lcccccc}
\hline \multicolumn{7}{c}{ ESCOLARIDADE } \\
Idade (anos) & Pré-escola & Ciclo I & Ciclo II & $\begin{array}{c}\text { Ensino } \\
\text { Médio }\end{array}$ & N & $\%$ \\
\hline 7 a 10 & 5 & 56 & 2 & - & 63 & 54,8 \\
11 a 14 & - & 2 & 34 & - & 36 & 31,3 \\
15 a 16 & - & - & 6 & 10 & 16 & 13,9 \\
\hline Total & 5 & 58 & 42 & 10 & 115 & 100 \\
\hline
\end{tabular}




\subsubsection{A população de mães/responsáveis apresentou as características} dispostas, a seguir, nas tabelas 2 a 8 .

As informações foram fornecidas por mães $(81,0 \%)$ e pais $(10,4 \%)$. (Tabela 2)

Em relação à escolaridade dos pais, 50,5\% cursaram ensino fundamental incompleto e 12,2\% completo; $20,9 \%$ cursaram ensino médio completo. (Tabela 3)

Quanto à escolaridade das mães, 53,9\% cursaram o ensino fundamental incompleto e $11,3 \%$ completo e $20,0 \%$ cursaram o ensino médio completo. (Tabela 4)

Os pais tinham atividade remunerada em $77,4 \%$ e as mães em 44,3\%. (Tabelas 5 e 6$)$

O escolar morava com o pai, a mãe e outros familiares em $65,3 \%$ dos casos e $25,2 \%$ moravam com a mãe e outros familiares. (Tabela 7)

O pai era responsável pelo sustento da casa em $40,0 \%$ dos casos. (Tabela 8)

Tabela 2 - Pessoa entrevistada e sua relação com o escolar com baixa visão Hospital das Clínicas da Faculdade de de Medicina da Universidade de São Paulo e Laramara - 2006

\begin{tabular}{lcc}
\hline Entrevistado & $\mathbf{N}$ & $\mathbf{\%}$ \\
\hline Mãe & 93 & 81,0 \\
Pai & 12 & 10,4 \\
Avó & 5 & 4,3 \\
outro parente & 5 & 4,3 \\
\hline Total & 115 & 100,0 \\
\hline
\end{tabular}


Tabela 3 - Escolaridade do pai. Percepção de mães/responsáveis - Hospital das Clínicas da Faculdade de Medicina da Univer sidade de São Paulo e Laramara - 2006

\begin{tabular}{lcc}
\hline Escolaridade do pai & $\mathbf{N}$ & $\%$ \\
\hline não estudou & 5 & 4,3 \\
ensino fundamental incompleto & 53 & 50,5 \\
ensino fundamental completo & 14 & 12,2 \\
ensimo médio incompleto & 2 & 1,7 \\
ensino médio completo & 24 & 20,9 \\
ensino superior completo & 2 & 1,7 \\
esnino superior incompleto & 3 & 2,6 \\
informante não sabe & 12 & 10,4 \\
\hline Total & 115 & 100,0 \\
\hline
\end{tabular}

Tabela 4 - Escolaridade da mãe. Percepção de mães/responsáveis - Hospital das Clínicas da Faculdade de Medicina da Universidade de São Paulo e Laramara - 2006

\begin{tabular}{lcc}
\hline Escolaridade & $\mathbf{N}$ & $\%$ \\
\hline não estudou & 3 & 2,6 \\
ensino fundamental incompleto & 62 & 53,9 \\
ensino fundamental completo & 13 & 11,3 \\
ensimo médio incompleto & 6 & 5,2 \\
ensino médio completo & 23 & 20,0 \\
ensino superior completo & 3 & 2,6 \\
ensino superior incompleto & 1 & 0,9 \\
pós-graduação & 1 & 0,9 \\
informante não sabe & 3 & 2,6 \\
\hline Total & 115 & 100,0 \\
\hline
\end{tabular}

Tabela 5 - Atividade remunerada ou não remunerada do pai. Percepção de mães/ responsáveis - Hospital das Clínicas da Faculdade de Medicina da Universidade de São Paulo e Laramara - 2006

\begin{tabular}{lcc}
\hline \multicolumn{1}{c}{ Atividade remunerada } & $\mathbf{N}$ & $\%$ \\
\hline Sim & 89 & 77,4 \\
Não & 26 & 22,6 \\
\hline Total & 115 & 100,0 \\
\hline
\end{tabular}


Tabela 6 - Atividade remunerada ou não remunerada da mãe. Percepção de mães/ responsáveis - Hospital das Clínicas da Faculdade de Medicina da Universidade de São Paulo e Laramara - 2006

\begin{tabular}{lcc}
\hline Atividade remunerada & $\mathbf{N}$ & $\mathbf{\%}$ \\
\hline Sim & 51 & 44,3 \\
Não & 64 & 55,7 \\
\hline Total & 115 & 100,0 \\
\hline
\end{tabular}

Tabela 7 - Pessoas com quem o escolar mora. Percepção de mães/responsáveis Hospital das Clínicas da Faculdade de Medicina da Universidade de São Paulo e Laramara - 2006

\begin{tabular}{lcc}
\hline Pessoas com quem mora & N & $\%$ \\
\hline Pai e mãe & 75 & 65,3 \\
Mãe e outros familiares & 29 & 25,2 \\
Pai e outros familiares & 3 & 2,6 \\
Apenas outros familiares & 8 & 6,9 \\
\hline Total & 115 & 100,0 \\
\hline
\end{tabular}

Tabela 8 - Responsável(is) pelo sustento da casa. Percepção de mães/ responsáveis - Hospital das Clínicas da Faculdade de Medicina da Universidade de São Paulo e Laramara - 2006

\begin{tabular}{lcc}
\hline Responsável (is) & N & \% \\
\hline Apenas o pai & 46 & 40,0 \\
Apenas a mãe & 14 & 12,2 \\
Pai e mãe & 33 & 28,7 \\
Outros familiares & 11 & 9,6 \\
Pai, mãe e outros familiares & 4 & 3,5 \\
Pai e outros familiares & 3 & 2,6 \\
Mãe e outros familiares & 4 & 3,5 \\
\hline Total & 115 & 100,0 \\
\hline
\end{tabular}




\subsection{Aspectos clínicos referentes aos escolares com baixa visão}

\subsubsection{Características do quadro visual}

As características do quadro visual foram pesquisadas quanto à causa da deficiência visual, à localização da afecção ocular, à etiologia da deficiência visual, aos valores de acuidade visual corrigida, aos valores da sensibilidade ao contraste, à visão de cores e ao campo visual, apresentadas nas tabelas 9 a 15 .

As principais causas da deficiência visual foram a retinocoroidite macular bilateral por toxoplasmose e as doenças hereditárias da retina e mácula, respectivamente em $27,8 \%$ e $22,6 \%$ dos casos. A catarata congênita foi responsável por $11,3 \%$ dos casos e o glaucoma congêntio primário por $6,1 \%$. (Tabela 9 )

A retina foi o principal local da afecção ocular (54,8\%). (Tabela 10)

As causas hereditárias foram responsáveis por $36,6 \%$ dos casos, enquanto que as pré-natais infecciosas por $32,1 \%$. Etiologia não determinada foi observada em $27,8 \%$. (Tabela 11)

As causas infecciosas observadas foram: toxoplasmose congênita $(28,7 \%)$, rubéola congênita $(2,6 \%)$, citomegalovirus $(0,9 \%)$ e toxocaríase $(0,9 \%)$.

Quanto aos valores de acuidade visual não corrigida, $44,4 \%$ dos casos tinham deficiência visual moderada, 45,2\% deficiência grave, 8,7\% 
deficiência visual profunda e 1,7\% valores próximos à cegueira. Quanto à acuidade visual corrigida, a deficiência visual moderada esteve presente em $67,8 \%$ dos casos, a deficiência visual grave em 27,0\%a deficiência visual profunda em 3,5\% e valores próximos à cegueira em 1,7\%. (Tabela 12)

A sensibilidade ao contraste entre 4 e 20 foi observada em 53,9\%. (Tabela 13)

A visão de cores mostrou-se normal em $82,6 \%$ dos casos (Tabela 14) e o campo visual apresentou-se normal em 69,6\%. (Tabela 15) 
Tabela 9 - Causas da deficiência visual de escolares com baixa visão - Hospital das Clínicas da Faculdade de Medicina da Universidade de São Paulo e Laramara - 2006

\begin{tabular}{|c|c|c|}
\hline Causa da deficiência visual & $\mathbf{N}$ & $\%$ \\
\hline Retinocoroidite macular por toxoplasmose & 33 & 27,8 \\
\hline Doenças hereditárias de retina e mácula & 26 & 22,6 \\
\hline Amaurose congênita de Leber & 4 & 3,5 \\
\hline Retinose pigmentar & 7 & 6,1 \\
\hline Albinismo & 9 & 7,8 \\
\hline Doença de Stargardt & 4 & 3,5 \\
\hline Distrofia de cones & 1 & 0,9 \\
\hline Acromatopsia & 1 & 0,9 \\
\hline Retinopatia da prematuridade & 2 & 1,7 \\
\hline Malformação ocular & 12 & 10,4 \\
\hline Coloboma & 5 & 4,3 \\
\hline Microftalmia & 1 & 0,9 \\
\hline Hipoplasia de NO & 2 & 1,7 \\
\hline Aniridia & 2 & 1,7 \\
\hline Persistência de vítreo primário hiperplásico & 1 & 0,9 \\
\hline Anomalia de morning glory & 1 & 0,9 \\
\hline Glaucoma congênito primário & 7 & 6,1 \\
\hline Atrofia óptica & 4 & 3,5 \\
\hline Catarata congênita & 13 & 11,3 \\
\hline Operada - afacia & 12 & 10,4 \\
\hline Operada - pseudofácica & 1 & 0,9 \\
\hline Cristalino ectópico & 6 & \\
\hline Síndrome de Marfan & 6 & 5,2 \\
\hline Alta miopia & 3 & 2,6 \\
\hline Nistagmo congênito idiopático & 5 & 4,3 \\
\hline Retinoblastoma bilateral & 1 & 0,8 \\
\hline Ceratite intersticial & 1 & 0,9 \\
\hline Ceratocone & 1 & 0,9 \\
\hline Retinocoroidite por toxocaríase & 1 & 0,9 \\
\hline Perfuração do globo ocular por arma de fogo & 1 & 0,9 \\
\hline Total & 115 & 100,0 \\
\hline
\end{tabular}


Tabela 10 - Causas da deficiência visual de escolares com baixa visão segundo a localização da afecção - Hospital das Clínicas da Faculdade de Medicina da Universidade de São Paulo e Laramara - 2006

\begin{tabular}{lcc}
\hline Localização & $\mathbf{N}$ & $\%$ \\
\hline Retina & 63 & 54,8 \\
Cristalino & 19 & 16,5 \\
Todo globo ocular & 15 & 13,0 \\
Globo ocular sem anormalidades & 8 & 7,0 \\
Nervo óptico & 6 & 6,1 \\
Úvea & 2 & 1,7 \\
Córnea & 2 & 0,9 \\
\hline Total & 115 & 100,0 \\
\hline
\end{tabular}

Tabela 11 - Principal etiologia da deficiência visual de escolares com baixa visão Hospital das Clínicas da Faculdade de Medicina da Universidade de São Paulo e Laramara - 2006

\begin{tabular}{lcc}
\hline Etiologia & N & \% \\
\hline Hereditária & 42 & 36,5 \\
Pré-natal infecciosa & 37 & 32,1 \\
Etiologia não determinada & 32 & 27,8 \\
Perinatal pela prematuridade & 2 & 1,8 \\
Pós-natal. Acidente com arma de fogo & 1 & 0,9 \\
Pós-natal infecciosa por toxocaríase & 1 & 0,9 \\
\hline Total & 115 & 100,0 \\
\hline
\end{tabular}


Tabela 12 - Valores de acuidade visual de escolares com baixa visão - Hospital das Clínicas da Faculdade de Medicina da Universidade de São Paulo e Laramara - 2006

\begin{tabular}{|c|c|c|c|c|c|c|c|}
\hline $\begin{array}{c}\text { Classes de } \\
\begin{array}{c}\text { comprometimento } \\
\text { visual }^{*}\end{array}\end{array}$ & $\begin{array}{c}\text { Classes de } \\
\text { deficiência } \\
\text { visual }^{* \star}\end{array}$ & $\begin{array}{c}\text { Valores de } \\
\text { Acuidade visual } \\
\text { (escala decimal) }\end{array}$ & $\begin{array}{c}\text { Valores de } \\
\text { Acuidade visual } \\
\text { (log MAR) }\end{array}$ & $\begin{array}{l}\text { Acuidade visual } \\
\text { não corrigida }\end{array}$ & & $\begin{array}{l}\text { Acuidade visual } \\
\text { corrigida }\end{array}$ & \\
\hline & & & & $\mathrm{N}$ & $\%$ & $\mathrm{~N}$ & $\%$ \\
\hline 1 & moderada & $0,32<\mathrm{AV} \leq 0,1$ & $0,5<\mathrm{AV} \leq 0,9$ & 51 & 44,4 & 78 & 67,8 \\
\hline 2 & grave & $0,1<\mathrm{AV} \leq 0,05$ & $0,9<\mathrm{AV} \leq 1,3$ & 52 & 45,2 & 31 & 27 \\
\hline 3 & profunda & $0,05<\mathrm{AV} \leq 0,02$ & $1,3<\mathrm{AV} \leq 1,7$ & 10 & 8,7 & 4 & 3,5 \\
\hline 4 & $\begin{array}{l}\text { próximo à } \\
\text { cegueira }\end{array}$ & $\begin{array}{c}0,02<\mathrm{AV} \leq \\
\text { percepção de luz }\end{array}$ & $\begin{array}{c}1,7<\mathrm{AV} \leq \\
\text { percepção de luz }\end{array}$ & 2 & 1,7 & 2 & 1,7 \\
\hline Total & & & & 115 & 100,0 & 115 & 100,0 \\
\hline
\end{tabular}

* Classificação internacional estatística de doenças e problemas relacionados à saúde - 10ª Revisão (CID-10)

** World Health Organization - Prevention of blindness and deafness: Consultation on development of standards for characterization of vision loss and visual functioning WHO/PBL/ 03.91. Geneva, 4-5 september 2003 
Tabela 13 - Valores de sensibilidade ao contraste de escolares com baixa visão Hospital das Clínicas da Faculdade de Medicina da Universidade de São Paulo e Laramara-2006

\begin{tabular}{lcccc}
\hline $\begin{array}{l}\text { Sensibilidade } \\
\text { ao contraste }\end{array}$ & $\begin{array}{c}\text { Contraste limiar } \\
\mathbf{( \% )}\end{array}$ & $\begin{array}{c}\text { Contraste limiar } \\
(\text { log })\end{array}$ & $\mathbf{N}$ & $\%$ \\
\hline $4<\mathrm{SC} \leq 20$ & $25<$ contraste $\leq 5$ & $0,6<$ contraste $\leq 1,3$ & 62 & 53,9 \\
$20<\mathrm{SC} \leq 50$ & $5<$ contraste $\leq 2$ & $1,3<$ contraste $\leq 1,6$ & 26 & 22,6 \\
$50<\mathrm{SC} \leq 80$ & $2<$ contraste $\leq 1,25$ & $1,6<$ contraste $\leq 1,9$ & 7 & 6,1 \\
$80<\mathrm{SC} \leq 120$ & $1,25<$ contraste $\leq 0,83$ & $1,9<$ contraste $\leq 2,0$ & 2 & 1,7 \\
$120<\mathrm{SC} \leq 160$ & $0,83<$ contraste $\leq 0,62$ & $2,0<$ contraste $\leq 2,2$ & 18 & 15,7 \\
\hline Total & & & 115 & 100,0 \\
\hline
\end{tabular}

Tabela 14 - Visão de cores de escolares com baixa visão. Hospital das Clíninicas da Faculdade de Medicina da Universidade de São Paulo e Laramara - 2006

\begin{tabular}{lcc}
\hline Visão de cores & N & \% \\
\hline Normal & 95 & 82,6 \\
Tipo I verde-vermelho ou tipo protan & 3 & 2,6 \\
Tipo II verde-vermelho ou tipo deutan & - & - \\
Tipo III azul-amarelo ou tipo tritan & 6 & 5,2 \\
Anormal, não especificada & 11 & 9,6 \\
\hline Total & 115 & 100,0 \\
\hline
\end{tabular}

Tabela 15 - Amplitude do campo visual de escolares com baixa visão - Hospital das Clínicas da Faculdade de Medicina da Universidade de São Paulo e Laramara - 2006

\begin{tabular}{lcc}
\hline Amplitude do campo visual $^{*}$ & $\mathbf{N}$ & $\mathbf{\%}$ \\
\hline Amplitude normal & 80 & 69,6 \\
Diminuição moderada & 16 & 13,9 \\
Diminuição grave & 11 & 9,6 \\
Diminuição profunda & 8 & 6,9 \\
\hline Total & 115 & 100 \\
\hline
\end{tabular}

*International Council of Ophthalmology. Visual Standards - Aspects and ranges of vision loss. Sydney, 2002 


\subsubsection{Necessidades ópticas}

As necessidades ópticas foram pesquisadas de acordo com a prescrição de auxílios ópticos (para longe e para perto) e com a prescrição da correção óptica das ametropias, que são apresentadas, a seguir nas tabelas 16 a 21

Quanto aos auxílios ópticos, 40\% usavam algum tipo de auxílio (30,4\% para longe e $9,6 \%$ para perto). Os sistemas telescópicos de $6 \times 16 \mathrm{~mm}$ eram os auxílios para longe mais usados $(37,1 \%)$ enquanto que as lupas de apoio eram os mais empregados para perto (72,7\%). (Tabelas 16 e 17)

Quanto à prescrição, para $57,4 \%$ dos escolares foram indicados auxílios para longe, para $4,3 \%$ foram indicados auxílios para perto e para $30,4 \%$ auxílios para longe e para perto. Não tiveram indicação para uso de auxílios ópticos 7,9\% dos escolares. (Tabela 18)

Dos auxílios ópticos para longe em uso, 23,4\%foram mantidos e 7,0\% atualizados. Novas indicações foram realizadas para $57,4 \%$ dos escolares e 12,2 \% não tinham indicação. O sistema telescópico $6 \times 16 \mathrm{~mm}$ foi o mais indicado $(55,4 \%)$. (Tabela 19$)$

Entre as afecções oculares mais frequentes, os auxílios ópticos para longe foram prescritos em: $93,9 \%$ dos casos de retinocoroidite macular bilateral, em $92,3 \%$ dos casos de catarata congênita operada, em 88,8\% dos casos de albinisno óculocutâneo, em 80,8\% dos casos de doenças hereditárias da retina e mácula, em $71,4 \%$ dos casos de glaucoma congênito,em $83,3 \%$ dos casos de cristalino ectópico, em $66,7 \%$ dos casos de alta miopia e em $50 \%$ dos casos de retinopatia da prematuridade. 
Dos auxílios ópticos para perto em uso, 8,7\% foram mantidos e 0,9\% atualizados. Novas indicações foram realizadas em $25,2 \%$ dos escolares e $65,2 \%$ não tinham indicação. As lupas de apoio foram os auxílios ópticos mais indicados $(67,5 \%)$. (Tabela 20$)$

Entre as afecções mais freqüentes, os auxílios ópticos para perto foram prescritos em $27,3 \%$ dos casos de retinocoroidite macular bilateral, em $66,7 \%$ dos casos de catarata congênita operada, em $50 \%$ das doenças hederitárias de retina e mácula e em $60 \%$ dos casos de glaucoma congênito.

A correção óptica para ametropias foi prescrita em $79,1 \%$ dos casos . Dos escolares com correção óptica prévia ao estudo, 50,4\% tiveram a prescrição mantida, 25,2 \% atualizada. Novas indicações de correção óptica para ametropias foram realizadas em $3,5 \%$ dos casos. Não houve melhora da acuidade visual com correção óptica em $20,9 \%$ dos casos, os quais não receberam a prescrição. (Tabela 21)

Entre as afecções oculares mais freqüentes, observamos que:

- nos casos de retinocoroidite macular bilateral, observamos que todos tiveram a correção óptica prescrita, sendo que $24,2 \%$ das prescrições foram para hipermetropia ou astigmatismo hipermetrópico e 75,8\% para miopia ou astigmatismo miópico;

- todos os casos de afacia após cirurgia para catarata congênita receberam prescrições para correção óptica de hipermetropia. No caso de pseudofacia, foi prescrita a correção óptica para astigmatismo miópico; 
- nos casos de glaucoma congênito, $85,7 \%$ dos escolares tinham indicação para uso da correção óptica, sendo todas para correção de miopia ou astigmatismos miópicos;

- todos os casos de Amaurose Congênita de Leber receberam prescrição para correção óptica de hipermetropia ou astigmatismo hipermetrópico;

- todos os casos de retinose pigmentar receberam prescrição da correção óptica, sendo 57,1\% para hipermetropia ou astigmatismo hipermetrópico e 42,9\% para miopia ou astigmatismo miópico;

- na Doença de Stargardt, todos receberam correção óptica (50\% para miopia ou astigmatismos miópicos e 50\% para hipermetropia ou astigmatismo hipermetrópico);

- no albinismo, observamos que todos os casos receberam a prescrição de óculos, sendo $55,5 \%$ para hipermetropia ou astigmatismo hipermetrópico e 45,4 para miopia ou astigmatismo miópico;

- na retinopatia da prematuridade, foi prescrita a correção óptica para miopia nos 2 casos estudados (100\%);

- nos casos de nistagmo congênito, houve a prescrição da correção óptica para $80 \%$ dos casos, sendo $50 \%$ para hipermetropia e $50 \%$ para miopia.

Os casos de alta miopia apresentaram valores de ametropia entre 10,50 dioptrias esféricas e -22,00 dioptrias esféricas. 
Tabela 16 - Auxílios ópticos para longe em uso por escolares com baixa visão Hospital das Clínicas da Faculdade de Medicina da Universidade de São Paulo e Laramara - 2006

\begin{tabular}{lcc}
\hline Sistema telescópico & $\mathbf{N}$ & $\%$ \\
\hline $2,5 \times 12 \mathrm{~mm}$ & 1 & 2,9 \\
$2,8 \times 26 \mathrm{~mm}$ & 9 & 25,7 \\
$4,2 \times 12 \mathrm{~mm}$ & 2 & 5,7 \\
$4 \times 12 \mathrm{~mm}$ & 7 & 20,0 \\
$6 \times 16 \mathrm{~mm}$ & 13 & 37,1 \\
$8 \times 21 \mathrm{~mm}$ & 3 & 8,6 \\
\hline Total & 35 & 100,0 \\
\hline
\end{tabular}

Tabela 17 - Auxílios ópticos para perto em uso por escolares com baixa visão Hospital das Clínicas da Faculdade de Medicina da Universidade de São Paulo e Laramara - 2006

\begin{tabular}{lcc}
\hline Auxílio óptico & N & \% \\
\hline Lupas de apoio & 8 & 72,7 \\
Lupas manuais & 1 & 9,1 \\
Lentes asféricas (monocular) & 1 & 9,1 \\
Lentes esferoprismáticas (binocular) & 1 & 9,1 \\
\hline Total & 11 & 100,0 \\
\hline
\end{tabular}

Tabela 18 - Indicação/não indicação e tipos de auxílios ópticos nos escolares com baixa visão - Hospital das Clínicas da Faculdade de Medicina da Universidade de São Paulo e Laramara - 2006

\begin{tabular}{lcc}
\hline Auxílios ópticos & $\mathbf{N}$ & $\%$ \\
\hline Indicados: & 66 & 57,4 \\
para longe & 5 & 4,3 \\
para perto & 35 & 30,4 \\
para longe e para perto & 9 & 7,9 \\
Sem indicação de auxílio óptico & 115 & 100 \\
\hline Total & & \\
\hline
\end{tabular}


Tabela 19 - Auxílios ópticos para longe para escolares com baixa visão (indicação e tipos) - Hospital das Clínicas da Faculdade de Medicina da Universidade de São Paulo e Laramara - 2006

\begin{tabular}{|c|c|c|}
\hline Auxílios ópticos & $\mathbf{N}$ & $\%$ \\
\hline \multicolumn{3}{|l|}{ Em uso: } \\
\hline mantidos & 27 & 23,4 \\
\hline atualizados & 8 & 7,0 \\
\hline Indicados & 66 & 57,4 \\
\hline Não indicados & 14 & 12,2 \\
\hline Tipo de sistema telescópico: & \multicolumn{2}{|c|}{$(n=101)$} \\
\hline $2,8 \times 26 \mathrm{~mm}$ & 9 & 8,9 \\
\hline $4,2 \times 12 \mathrm{~mm}$ & 1 & 1,0 \\
\hline $4 \times 12 \mathrm{~mm}$ & 25 & 24,7 \\
\hline $6 \times 16 \mathrm{~mm}$ & 56 & 55,4 \\
\hline $8 \times 21 \mathrm{~mm}$ & 10 & 10,0 \\
\hline
\end{tabular}

Tabela 20 - Auxílios ópticos para perto para escolares com baixa visão (indicação e tipos) - Hospital das Clínicas da Faculdade de Medicina da Universidade de São Paulo e Laramara - 2006

\begin{tabular}{lcc}
\hline Auxílios ópticos & $\mathbf{N}$ & \% \\
\hline Em uso: & 10 & \\
$\quad$ mantidos & 1 & 8,7 \\
$\quad$ atualizados & 29 & 0,9 \\
Indicados & 75 & 25,2 \\
Não indicados & & 65,2 \\
$\quad$ & 27 & $(\mathrm{n}=40)$ \\
$\quad$ Tipo: & 7 & 67,5 \\
$\quad$ Lupas de apoio & 5 & 17,5 \\
$\quad$ Lupas manuais & 1 & 12,5 \\
$\quad$ Lentes asféricas (monocular) & 2,5 \\
$\quad$ Lentes esferoprismáticas (binocular) &
\end{tabular}


Tabela 21 - Correção óptica para ametropias de escolares com baixa visão Hospital das Clínicas da Faculdade de Medicina da Universidade de São Paulo e Laramara - 2006

\begin{tabular}{lcc}
\hline Correção óptica & $\mathbf{N}$ & $\%$ \\
\hline Em uso & 58 & \\
mantida & 29 & 50,4 \\
atualizada & 4 & 25,2 \\
Indicada & 24 & 3,5 \\
Não indicada & 115 & 20,9 \\
\hline Total & & 100,0 \\
\hline
\end{tabular}

Da população estudada, 21 (18,3\%) eram casos novos. Quanto a correção óptica de ametropias, observou-se que 9 (42,9\%) escolares faziam uso de óculos que foram mantidos após a avaliação oftalmológica; 3 (14,3\%) tiveram sua correção óptica atualizada; $2(9,5 \%)$ escolares, que não faziam uso de correção óptica, tiveram indicação para seu uso e $7(33,3 \%)$ não faziam uso e nem tiveram indicação para uso de correção óptica. Quanto ao uso de auxílio óptico para longe, somente 1 $(4,8 \%)$ escolar fazia uso prévio de sistema telescópico, o qual foi mantido; 18 $(85,7 \%)$ não usavam e tiveram indicação para uso; 2 (9,5\%) não faziam uso e não tiveram indicação. Nenhum escolar fazia uso de auxílio óptico para perto, o qual foi indicado em 8 (38\%) casos. 


\subsubsection{Necessidades reabilitacionais}

Quanto aos encaminhamentos a outros profissionais na área de reabilitação visual, observamos que:

- todos os escolares, que não faziam uso do auxílio óptico para longe antes da avaliação e que tiveram indicação para seu uso $(57,4 \%)$, foram agendados para sessões de orientação para uso funcional (treinamento);

- quanto aos auxílios ópticos para perto, $25,2 \%$ dos escolares, que nunca haviam utilizado o recurso, foram encaminhados para sessões de treinamento;

- dos escolares que já tinham o recurso para longe, $48,6 \%$ tinham tinham dificuldade para seu uso e foram encaminhados para o treinamento. Foram descartadas alterações funcionais que pudessem interferir no uso do auxílio;

- dos escolares que já tinham auxílio óptico para perto, $45,4 \%$ apresentavam dificuldades no uso e também foram encaminhados ao treinamento;

- todos os escolares foram encaminhados para avaliação ou reavaliação educacional especializada para baixa visão, tanto na Laramara, quanto no SVSN HCFMUSP;

- os casos com diminuição da amplitude de campo visual $(30,4 \%)$ foram encaminhados para avaliação em programas de orientação e mobilidade. 


\subsection{Percepção de mães/responsáveis.}

Aspectos da percepção de mães/responsáveis quanto à detecção da deficiência visual, ao atendimento médico para diagnóstico, a atendimento em serviço especializado, ao uso de auxílios ópticos, a dificuldades na escola e a benefícios doados por entidade governamental são apresentados, a seguir, nas tabelas 22 a 40 .

\subsubsection{Percepção de mães/responsáveis quanto à detecção da deficiência visual}

Tabela 22 - Pessoa que observou primeiro a dificuldade visual do escolar. Percepção de mães/responsáveis - Hospital das Clínicas da Faculdade de Medicina da Universidade de São Paulo e Laramara - 2006

\begin{tabular}{lcc}
\hline Quem observou & $\mathbf{N}$ & $\%$ \\
\hline Mãe & 61 & 53,0 \\
Médico pediatra & 14 & 12,2 \\
Avó & 12 & 10,4 \\
Outros familiares & 11 & 9,6 \\
Professora & 7 & 6,1 \\
Médico oftalmologista & 6 & 5,2 \\
Pai & 4 & 3,5 \\
\hline Total & 115 & 100,0 \\
\hline
\end{tabular}

Tabela 23 - Idade do escolar em que foi observado o problema visual. Percepção de mães/responsáveis - Hospital das Clínicas da Faculdade de Medicina da Universidade de São Paulo e Laramara - 2006

\begin{tabular}{lcc}
\hline Idade (anos) & $\mathbf{N}$ & $\%$ \\
\hline$\leq 1$ & 93 & 80,9 \\
$2-5$ & 14 & 12,2 \\
$\geq 6$ & 8 & 6,9 \\
\hline Total & 115 & 100,0 \\
\hline
\end{tabular}




\subsubsection{Percepção de mães/responsáveis quanto ao atendimento médico para diagnóstico}

Tabela 24 - Conduta do oftalmologista como primeiro profissional da área da saúde consultado após a identificação do problema visual. Percepção de mães/ responsáveis - Hospital das Clínicas da Faculdade de Medicina da Universidade de São Paulo e Laramara - 2006

\begin{tabular}{lcc}
\hline Condutas & N & $\%$ \\
\hline Não observou problema visual & 8 & 8,5 \\
Orientou aguardar idade para exame & & \\
oftalmológico & 7 & 7,4 \\
Responsável não se lembra & 1 & 1,1 \\
Fez o diagnóstico do problema visual & 78 & 83,0 \\
\hline Total & 94 & 100,0 \\
\hline
\end{tabular}

Tabela 25 - Orientações do pediatra como primeiro profissional da área da saúde consultado após a identificação do problema visual. Percepção de mães/ responsáveis - Hospital das Clínicas da Faculdade de Medicina da Universidade de São Paulo e Laramara - 2006

\begin{tabular}{lcc}
\hline Orientações & N & $\%$ \\
\hline Ausência de problema visual & 5 & 23,8 \\
Criança com deficiência mental & 1 & 4,8 \\
Aguardar idade para exame oftalmológico & 7 & 33,3 \\
Encaminhamento ao oftalmologista & 8 & 38,1 \\
\hline Total & 21 & 100,0 \\
\hline
\end{tabular}

Tabela 26 - Local do primeiro atendimento oftalmológico. Percepção de mães/ responsáveis - Hospital das Clínicas da Faculdade de Medicina da Universidade de São Paulo e Laramara - 2006

\begin{tabular}{lcc}
\hline Local do atendimento & $\mathbf{N}$ & \% \\
\hline Serviço público & 59 & 51,3 \\
Convênio & 29 & 25,2 \\
Particular & 22 & 19,1 \\
Serviço de Oftalmologia da Laramara & 5 & 4,3 \\
\hline Total & 115 & 100,0 \\
\hline
\end{tabular}


Tabela 27 - Intervalo de tempo entre a identificação do problema visual e a primeira consulta oftalmológica. Percepção de mães/responsáveis - Hospital das Clínicas da Faculdade de Medicina da Universidade de São Paulo e Laramara - 2006

\begin{tabular}{lcc}
\hline Intervalo de tempo & $\mathbf{N}$ & $\%$ \\
\hline Até 6 meses depois & 71 & 61,7 \\
Mais de 6 meses & 44 & 38,3 \\
\hline Total & 115 & 100 \\
\hline
\end{tabular}

Tabela 28 - Razões do retardo da avaliação oftalmológica do escolar com baixa visão. Percepção de mães/responsáveis - Hospital das Clínicas da Faculdade de Medicina da Universidade de São Paulo e Laramara - 2006

\begin{tabular}{lcc}
\hline Razão & $\mathbf{N}$ & $\%$ \\
\hline Não conseguia agendar com oftalmologista do serviço público & 17 & 38,6 \\
Aguardou a orientação/encaminhamento do pediatra & 13 & 29,5 \\
Não achava que a criança tivesse problema visual & 8 & 18,2 \\
Na cidade em que morava não havia oftalmologista & 4 & 9,1 \\
Por problemas financeiros & 1 & 2,3 \\
Não sabia que criança pequena podia ser submetida a exame & & \\
oftalmológico & 1 & 2,3 \\
\hline Total & 44 & 100,0 \\
\hline
\end{tabular}

Tabela 29 - Grau de dificuldade para conseguir a primeira consulta oftalmológica para o escolar com baixa visão. Percepção de mães/responsáveis - Hospital das Clínicas da Faculdade de Medicina da Universidade de São Paulo e Laramara - 2006

\begin{tabular}{lcc}
\hline Grau de dificuldade & $\mathbf{N}$ & $\mathbf{\%}$ \\
\hline Muito fácil & 63 & 54,8 \\
Mais ou menos fácil & 24 & 20,8 \\
Pouco fácil & 13 & 11,3 \\
Nada fácil & 15 & 13,0 \\
\hline Total & 115 & 100,0 \\
\hline
\end{tabular}

Tabela 30 - Idade em que foi realizado o diagnóstico de baixa visão. Percepção de mães/responsáveis - Hospital das Clínicas da Faculdade de Medicina da Universidade de São Paulo e Laramara - 2006

\begin{tabular}{lcc}
\hline Idade (anos) & $\mathbf{N}$ & $\mathbf{\%}$ \\
\hline$\leq 1$ & 73 & 63,5 \\
$2-6$ & 30 & 26,1 \\
$7-13$ & 12 & 10,4 \\
\hline Total & 115 & 100,0 \\
\hline
\end{tabular}




\subsubsection{Percepção de mães/responsáveis quanto ao atendimento em serviço especializado}

Tabela 31 - Idade do escolar ao encaminhamento a serviço de baixa visão. Percepção de mães/responsáveis - Hospitaldas Clínicas da Faculdade de Medicina da Universidade de São Paulo e Laramara- 2006

\begin{tabular}{lcc}
\hline Idade (anos) & $\mathbf{N}$ & $\mathbf{\%}$ \\
\hline$\leq 1$ & 14 & 12,2 \\
$2-6$ & 39 & 33,9 \\
$7-14$ & 62 & 53,9 \\
\hline Total & 115 & 100,0 \\
\hline
\end{tabular}

Tabela 32 - Responsável pelo encaminhamento do escolar com baixa visão ao serviço de visão subnormal ou à instituição. Percepção de mães/responsáveis Hospital das Clínicas da Faculdade de Medicina da Universidade de São Paulo e Laramara - 2006

\begin{tabular}{lcc}
\hline Responsável pelo encaminhamento & N & \% \\
\hline Médico oftalmologista & 69 & 60,0 \\
Professora & 13 & 11,3 \\
Conhecidos da família & 13 & 11,3 \\
Pediatra & 4 & 3,5 \\
Mãe & 4 & 3,5 \\
Ortoptista & 3 & 2,6 \\
Assistente social & 3 & 2,6 \\
Familiares & 2 & 1,7 \\
Prefeito da cidade & 1 & 0,9 \\
Fisioterapeuta & 1 & 0,9 \\
Ótico & 1 & 0,9 \\
Não se lembra & 1 & 0,9 \\
\hline Total & 115 & 100,0 \\
\hline
\end{tabular}


Tabela 33 - Atendimento anterior dos escolares com baixa visão em outro serviço de reabilitação visual. Percepção de mães/responsáveis- Hospital das Clínicas da Faculdade de Medicina da Universidade de São Paulo e Laramara - 2006

\begin{tabular}{lcc}
\hline Antendimento anterior & $\mathbf{N}$ & $\mathbf{\%}$ \\
\hline Sim & 27 & 23,5 \\
Não & 88 & 76,5 \\
\hline Total & 115 & 100,0 \\
\hline
\end{tabular}

Tabela 34 - Conhecimento da existência de outros serviços de baixa visão. Percepção de mães/responsáveis - Hospital das Clínicas da Faculdade de Medicina da Universidade de São Paulo e Laramara- 2006

\begin{tabular}{lcc}
\hline Conhecimento de outros serviços & N & \% \\
\hline Sim & 38 & 33,0 \\
Não & 77 & 67,0 \\
\hline Total & 115 & 100,0 \\
\hline
\end{tabular}

\subsubsection{Percepção de mães/responsáveis quanto ao uso de auxílios ópticos para baixa visão}

Tabela 35 - Tipo de auxílio óptico em uso por escolar com baixa visão. Percepção de mães/responsáveis - Hospital das Clínicas da Faculdade de Medicina da Universidade de São Paulo e Laramara - 2006

\begin{tabular}{lcc}
\hline Tipo de auxílio óptico & N & \% \\
\hline Para longe & 27 & 71,1 \\
Para perto & 3 & 7,9 \\
Para longe e para perto & 8 & 21,0 \\
\hline Total & 38 & 100,0 \\
\hline
\end{tabular}


Tabela 36 - Dificuldade de escolares com baixa visão para uso do auxílio óptico para longe. Percepção de mães/responsáveis - Hospital das Clínicas da Faculdade de Medicina da Universidade de São Paulo e Laramara - 2006

$\mathrm{n}=35$

\begin{tabular}{lcc} 
Dificuldade para uso do auxílio óptico para longe & $\mathbf{N}$ & $\%$ \\
\hline Não & 18 & 51,4 \\
Sim & 17 & 48,6 \\
Razão: & \multicolumn{2}{c}{$(\mathrm{n}=17)$} \\
$\quad$ Vergonha de usar & 9 & 53 \\
Acha desnecessário & 2 & 11,7 \\
Dificuldade de manuseio & 2 & 11,7 \\
Mãe não deixa levar para a escola & 1 & 5,9 \\
É mais fácil copiar do caderno do colega & 1 & 5,9 \\
É mais fácil que o professor dite a lição & 1 & 5,9 \\
Acha que não ajuda & 1 & 5,9 \\
\hline
\end{tabular}

Tabela 37 - Uso de auxílio óptico para perto por escolares com baixa visão. Percepção de mães/responsáveis - Hospital das Clínicas da Faculdade de Medicina da Universidade de São Paulo e Laramara - 2006

\begin{tabular}{llc} 
& & $\mathrm{n}=11$ \\
\hline Uso do auxílio óptico & N & $\%$ \\
\hline Sim, usa bem & 6 & 54,6 \\
Não usa bem & 5 & 45,4 \\
$\quad$ & & \\
$\quad$ Razão: & 2 & $(\mathrm{n}=5)$ \\
$\quad$ Acha feio, tem vergonha & 2 & 40,0 \\
$\quad$ Não ajuda & 1 & 40,0 \\
$\quad$ Acha desnecessário & & 20,0 \\
\hline
\end{tabular}


Tabela 38 - Dificuldade de aquisição do auxílio óptico prescrito ao escolar. Percepção de de mãesresponsáveis - Hospital das Clínicas da Faculdade de Medicina da Universidade de São Paulo e Laramara - 2006

$\mathrm{n}=41$

\begin{tabular}{lcc}
\hline Dificuldade & N & \% \\
\hline Não & 8 & 19,5 \\
Sim, mas recebeu doação & 18 & 44,0 \\
Sim, mas adquiriu & 12 & 29,2 \\
Sim, não adquiriu ou recebeu doação & 3 & 7,3 \\
$\quad$ & & \\
$\quad$ Razão da dificuldade: & $(\mathrm{n}=33)$ & \\
$\quad$ Custo & 25 & 75,8 \\
$\quad$ Não encontrou & 8 & 24,2 \\
\hline
\end{tabular}

\subsubsection{Percepção de mães/responsáveis quanto à dificuldade na escolar}

Tabela 39 - Presença e tipo de dificuldade na escola de crianças com baixa visão. Percepção de mães/responsáveis - Hospital das Clínicas da Faculdade de Medicina da Universidade de São Paulo e Laramara - 2006

\begin{tabular}{lcc} 
& & $\mathrm{N}=115$ \\
\hline Dificuldade na escola & $\mathbf{N}$ & $\%$ \\
\hline Sim & 84 & 73,0 \\
Não & 31 & 27,0
\end{tabular}

Tipo de dificuldade:

$$
(\mathrm{n}=84)
$$

Dificuldade para enxergar a lousa

Falta de compreensão do quadro visual por parte do professor e falta de colaboração do mesmo

Dificuldade para leitura de letras pequenas no livro/caderno

Falta de motivação para ir à escola

6

Necessidade de tempo maior para realização de tarefa

Dificuldade de alfabetização

Excesso de claridade na sala de aula 


\subsubsection{Percepção de mães/responsáveis quanto a benefícios concedidos pelos órgãos governamentais pela deficiência}

Tabela 40 - Recebimento de benefício doado por entidade governamental ao escolar de baixa visão. Percepção de mães/responsáveis - Hospital das Clínicas da Faculdade de Medicina da Universidade de São Paulo e Laramara - 2006

\begin{tabular}{lcc}
\hline & $\mathbf{N}$ & $\mathbf{\%}$ \\
\hline Sim & 71 & 61,7 \\
Não & 44 & 38,3 \\
\hline Total & 115 & 100,0 \\
\hline
\end{tabular}

\subsection{Resultados analíticos}

\subsubsection{Idade}

Tabela 41 - Quem percebeu a dificuldade para enxergar segundo a idade no diagnóstico. Percepção de mães/responsáveis - Hospital das Clínicas da Faculdade de Medicina da Universidade de São Paulo e Laramara - 2006

\begin{tabular}{lcccc}
\hline & \multicolumn{4}{c}{ Idade no diagnóstico } \\
\cline { 2 - 5 } Quem percebeu primeiro & \multicolumn{3}{c}{$\mathbf{0}$ a 11 meses } & $\mathbf{1 2}$ meses e mais \\
\cline { 2 - 5 } & $\mathbf{N}$ & $\mathbf{\%}$ & $\mathbf{N}$ & $\mathbf{\%}$ \\
\hline Mãe & 27 & 52,9 & 34 & 53,0 \\
Pai & 3 & 5,9 & 1 & 1,6 \\
Avó & 3 & 5,9 & 9 & 14,1 \\
Professora & - & - & 7 & 10,9 \\
Pediatra & 13 & 25,5 & 1 & 1,6 \\
Oftalmologista & 5 & 9,8 & 1 & 1,6 \\
Outra pessoa & & & 11 & 17,2 \\
Total & 51 & 100,0 & 64 & 100,0 \\
\hline
\end{tabular}

Teste exato de Fisher (Monte Carlo) $p=0,0279$ 


\subsubsection{Classe de deficiência visual}

Tabela 42 - Indicação/não indicação de auxílios ópticos para longe segundo a classe da deficiência visual de escolares com baixa visão - Hospital das Clínicas da Faculdade de Medicina da Universidade de São Paulo e Laramara - 2006

\begin{tabular}{lcccccc}
\hline Deficiência visual & \multicolumn{2}{c}{ Indicado } & \multicolumn{2}{c}{ Não indicado } & \multicolumn{2}{c}{ Total } \\
\cline { 2 - 7 } & $\mathbf{N}$ & $\%$ & $\mathbf{N}$ & $\%$ & $\mathbf{N}$ & $\%$ \\
\hline Moderada & 69 & 88,5 & 9 & 11,5 & 78 & 100,0 \\
Grave & 30 & 97,0 & 1 & 3,0 & 31 & 100,0 \\
Profunda & 2 & 50,0 & 2 & 50,0 & 4 & 100,0 \\
Próximo à cegueira & - & - & 2 & 100,0 & 2 & 100,0 \\
\hline
\end{tabular}

Teste de Fischer (Monte Carlo) $p=0,0005$

Tabela 43 - Indicação/ não indicação de auxílios ópticos para perto segundo a classe da deficiência visual de escolares com baixa visão - Hospital das Clínicas da Faculdade de Medicina da Universidade de São Paulo e Laramara-2006

\begin{tabular}{lcccccc}
\hline Deficiência visual & \multicolumn{2}{c}{ Indicado } & \multicolumn{2}{c}{ Não indicado } & \multicolumn{2}{c}{ Total } \\
& N & $\%$ & N & $\%$ & N & $\%$ \\
\hline Moderada & 22 & 28,2 & 56 & 71,8 & 78 & 100,0 \\
Grave & 17 & 54,8 & 14 & 45,2 & 31 & 100,0 \\
Profunda & 1 & 25,0 & 3 & 75,0 & 4 & 100,0 \\
Próximo à cegueira & - & - & 2 & 100,0 & 2 & 100,0 \\
\hline
\end{tabular}

Teste de Fischer (Monte Carlo) $p=0,0365$ 
A perda visual leva a conseqüências na vida pessoal, econômica e social de um indivíduo e, quando a prevalência da deficiência visual é alta, tornam-se problemas de saúde pública. (West e Sommer, 2001) A prevenção da cegueira na infância e a reabilitação visual na baixa visão encontram-se entre as prioridades da Organização Mundial da Saúde na iniciativa global "Vision 2020: The right to sight".( Pizzarello et al., 2004) Apesar da população infantil com deficiência visual ser comparativamente menor que a população idosa, considera-se a incapacidade ao longo da vida como a principal justificativa para ações de prevenção e reabilitação visual nessa população. A habilitação visual de uma criança cega por catarata congênita equivaleria à reabilitação visual de 10 idosos cegos por catarata. A cegueira infantil segue-se à cegueira por catarata, no âmbito mundial, a principal causa da deficiência visual. (Gilbert e Foster, 2001)

Segundo Temporini e Kara-José (2004), o atual conceito de prevenção da cegueira ampliou-se e enfatiza-se a preservação da visão. Nesse sentido, relaciona-se estreitamente à qualidade de vida do ser humano, na qual desempenha importante função a capacidade visual.

O impacto de ações para preservação da visão engloba, portanto, toda a população em via de sofrer agravos visuais e, particularmente, aqueles já com a deficiência visual estabelecida no sentido evitar a incapacidade. 
O planejamento de programas preventivos deve estar baseado no conhecimento da situação epidemiológica do problema, na disponibilidade e formação de recursos humanos, na infraestrutura existente e necessária e nos fatores psicossocioculturais.(Temporini e Kara-José, 2004) Portanto, o estudo da população escolar com baixa visão deve ser realizado sob todas essas perspectivas.

A deficiência visual na idade escolar tem sido objeto de importantes estudos que trazem contribuições para a promoção da inclusão da criança com deficiência visual. (Temporini, 1988; Temporini, 1990; Kara-José, 1994; Kara-José, 2006; Montilha, 2001; Gasparetto, 2001; Nobre, 2001)

A população do município de São Paulo (IBGE,2006) é estimada em 10.927.985 pessoas, sendo $30 \%$ composta pela faixa etária de 0 a 14 anos. De acordo com dados da Secretaria da Educação do Município de São Paulo, no ano de 2005 encontravam-se matriculados na rede municipal de ensino 1.109.226 alunos, sendo $2031(0,18 \%)$ escolares com deficiência visual (cegueira e baixa visão).

Desse universo estudou-se a população de 115 escolares com baixa visão atendidos no Serviço de Visão Subnormal do Hospital das Clínicas da Universidade de São Paulo e no Serviço de Oftalmologia da Associação Brasileira de Assistência ao Deficiente Visual, ambos localizados na cidade de São Paulo. Estudaram-se aspectos médicos e sociais da deficiência visual, por meio da avaliação oftalmológica e do ponto de vista da família. Assim, verificou-se a percepção quanto: à dificuldade visual, ao problema visual, ao diagnóstico do problema ocular, ao acesso ao atendimento 
oftalmológico, ao acesso a serviços de reabilitação visual, ao uso de correção óptica, às dificuldades escolares secundárias à deficiência visual, indicação, ao uso e aceitação de auxílios ópticos para baixa visão. Foram investigados aspectos da baixa visão, geralmente não pesquisados pelo oftalmologista, que colaboraram para uma revisão crítica e aprimoramento da abordagem oftalmológica na área da baixa visão, tendo em vista a política de inclusão escolar.

A pesquisa da condição de saúde e de funcionalidade nos diversos domínios de uma população infantil tem no emprego de questionários aplicados a pais ou responsáveis um dos principais instrumentos tanto para a avaliação clínica quanto para pesquisa (Goodman, 1997; Rosenbaum et al., 1995). Os pais conhecem bem seus filhos e as informações por eles fornecidas em geral refletem o comportamento e habilidades da criança de modo mais fidedigno que testes aplicados por pessoas estranhas.

No presente estudo, as mães foram as principais informantes. (Tabela 2) Na maioria das vezes, o pai era o responsável único pelo sustento da casa (Tabela 8), o que reflete a sociedade brasileira, onde, tradicionalmente, o homem é o responsável pelo sustento da família, cabendo sobretudo à mulher a responsabilidade da educação dos filhos e dos afazeres domésticos.(Nobre, 1997) Pode-se supor que a existência de um filho com deficiência reforça essa divisão de atribuições.

Apesar da mãe ter atividade remunerada sendo, por vezes, responsável única pelo sustento do lar, constituiu-se na pessoa mais presente à entrevista, do que o pai ou outro responsável (Tabela 2). Esse 
fato corrobora a afirmação de que um dos traços socioculturais da sociedade brasileira confere à mulher a responsabilidade pelos cuidados dos filhos, desconsiderando o fato de que ela exerça trabalho remunerado. (Nobre, 1997) Segundo o IBGE (2006), na população brasileira o homem é o provedor da família em $74 \%$, a mulher é a provedora em $26 \%$ e tem atividade remunerada crescente, atualmente,em torno de 58,2\%. Essas freqüências são próximas às observadas no presente estudo, onde o pai do escolar tem atividade remunerada em $77,4 \%$, enquanto que a mãe em $44,3 \%$; o pai é responsável pelo sustento do lar em $74,8 \%$ e a mãe em $47,9 \%$ dos casos(Tabelas 5,6 e 8 ).

Quanto à escolaridade do pai e da mãe foi observada a predominância do ensino fundamental completo, apontada também por dados do IBGE (2006), evidenciando que a população brasileira de 25 anos ou mais de idade apresenta a média de anos de escolaridade de 6,0. A baixa escolaridade dos pais pode afetar a detecção e tratamento de problemas visuais, a compreensão da deficiência visual e a conduta da família para a reabilitação da criança.

Os efeitos secundários da perda visual podem não ser tão evidentes aos oftalmologistas. Esses efeitos incluem, além das limitações funcionais, a incapacidade, as reações emocionais e a menor qualidade de vida. (Gieser, 2004) Alguns efeitos serão também observados nos membros do núcleo familiar, que poderão ter diferentes sentimentos e atitudes frente à constatação de ter um filho deficiente: frustração, culpa, vergonha, negação, rejeição, de maneira geral vividos pelos pais e irmãos da criança. (Amiralian, 
1997) Daí, a importância, por parte dos oftalmologistas, da compreensão e apoio à família no momento do diagnóstico da deficiência visual. Nobre(2001) aponta que a mãe da criança portadora de deficiência visual, quando recebe o diagnóstico necessita de suporte emocional, antes de qualquer informação técnica, pois, as angústias poderão ser causadas ou agravadas pelo desconhecimento do diagnóstico e pelo distanciamento dos profissionais da área médica.

Segundo Nobre (1997), se o nascimento de qualquer criança afeta um casamento de várias maneiras, o nascimento de uma criança com deficiência visual pode acarretar problemas especiais e o impacto da nova situação obriga a mãe a efetuar um redimensionamento de seus planos, projetos, ideais e, até mesmo, a união com seu companheiro.

Apesar dos problemas emocionais e de relacionamento expostos, no presente estudo a maioria das crianças morava com o pai e a mãe conjuntamente. Quando o casal não vive junto, a criança reside, em geral, somente com a mãe (Tabela 7), o que segue padrão da sociedade brasileira quanto ao papel da mãe no cuidado do filho, com ou sem deficiência.

Morar com o pai e a mãe conjuntamente é uma situação desejável para que toda criança, em especial a criança com deficiência, possa contar com uma família nuclear estruturada que será sua referência frente às diversas situações da vida. Segundo Siaulys (2006), e na relação com as pessoas da sua família e com o mundo que a cerca que a criança desenvolve suas potencialidades e se estrutura como pessoa. A família tem papel fundamental no processo de desenvolvimento e aprendizagem das 
pessoas com deficiência visual como mediadora nas interações, nas formas de comunicação, nas relações da criança com mundo e no processo de construção do conhecimento. (Amiralian, 1997; Bruno, 1999)

A inexistência de estudos populacionais ou de registros de cegueira na América Latina determina que sejam realizadas estimativas com base em instituições de atendimento à população cega. Nesses casos, não serão contabilizadas: as crianças que não tiveram acesso aos serviços (pela baixa renda ou por serem residentes em área rural), as crianças com múltiplas deficiências ou crianças com baixa visão não detectadas; porém, maior número de crianças com deficiência visual poderá ser estudado e poderá haver padronização do exame que será feito por um número restrito de oftalmologistas daquele serviço. (Gilbert et al, 1994).

Estudos realizados no SVSN HC HMUSP, no Serviço de Visão Subnormal da Universidade de Campinas, na Laramara, no Serviço de Visão Subnormal da Universidade Federal de São Paulo e Fundação Altino Ventura contribuíram para o conhecimento de aspectos da deficiência visual no nosso meio. (Kara-José et al, 1988; Tartarella et al, 1991; Leal et al, 1995; Carvalho et al, 1996; Haddad et al, 2000; Haddad et al, 2006a; Haddad et al, 2006b)

Além dos aspectos sociais, o presente estudo contribuiu para o conhecimento de características visuais e de reabilitação de uma população em idade escolar na cidade de São Paulo.

Quanto à etiologia da deficiência visual, houve predominância de doenças hereditárias $(34,6 \%)$ e pré-natais infecciosas $(33,2 \%)$. Dessa 
maneira, muitos dos quadros de deficiência visual, por estarem presentes ao nascimento, foram observados nos primeiros 12 meses de vida $(80,9 \%)$. Doenças degenerativas da retina, como a retinose pigmentar, a Doença de Stargardt e a distrofia de cones manifestam-se no decorrer da primeira década de vida, o que colaborou, provavelmente, para a detecção tardia dos casos de deficiência visual, observados entre 2 e 5 anos e após os 6 anos de idade. Possíveis causas genéticas e hereditárias tornam necessários serviços de aconselhamento genético.

Não foram observados casos de deficiência visual secundários a hipovitaminose $A$, causa mencionada em regiões com menor desenvolvimento socioeconômico; porém, não relatado em outros estudos realizados no Brasil. (Kara-José et al, 1888; Carvalho et al.,1996; Moreira et al., 1991, Tartarella et al., 1991; Leal et al.,1995; Haddad et al., 2000a; Haddad et al. 2006a).

As causas infecciosas das afecções oculares (Tabela 11) evidenciam necessidade de programas de prevenção primária, como programas educacionais e imunização, em particular, para a rubéola congênita, importante causa de catarata congênita. Foster et al.(1997) propõem que a vacinação contra a rubéola (assim como para outras doenças infecciosas) em meninas de 12 a 13 anos ou de todas as crianças menores de 1 ano deva ser considerada, medida preventiva adotada em âmbito nacional.

A retinocoroidite macular bilateral por toxoplasmose, as doenças hereditárias da retina, a malformação ocular, catarata congênita, a retinopatia da prematuridade, o glaucoma congênito primário, a atrofia 
óptica, a alta miopia e o nistagmo congênito idiopático foram as principais causas da baixa visão, também observadas em outros estudos de serviços de baixa visão no Brasil. (Carvalho et al.,1996; Carvalho et al., 1998; Moreira et al., 1991, Tartarella et al., 1991; Leal et al.,1995; Haddad et al., 2000a; Haddad et al.,2006a).

A retinocoroidite macular cicatrizada bilateral por toxoplasmose congênita foi a afecção ocular predominante em $27,8 \%$ dos casos (Tabela 9). A toxoplasmose é responsável por cerca de $50 \%$ dos casos de uveítes no Brasil (Abreu et al., 1987) e é considerada uma das principais causas de baixa visão. Kara-José et al. (1988), Carvalho et al. (1996) e Carvalho et al (1998) observaram a lesão macular por toxoplasmose ocular congênita como principal afecção ocular em serviços de baixa visão de 30,7\%, 20,6\% e $46,7 \%$, respectivamente.

Quanto à prescrição de auxílios ópticos, foram prescritos para longe em $93,9 \%$ e auxílios ópticos para perto em $27,3 \%$ dos casos de retinocoroidite macular bilateral. Não necessitavam de auxílio óptico para longe $6,1 \%$ dos casos (apresentavam valores de acuidade visual adequados para o desempenho de suas tarefas). É a afecção ocular que apresenta respostas mais efetivas aos recursos para ampliação da imagem retiniana, como os auxílios ópticos. Lobato et al.( 2003) observaram que 53,9\% de escolares com retinocoroidite macular bilateral tinham indicação para uso de auxílios ópticos para longe e $15,4 \%$ para perto. Carvalho et al.(1998) observaram a prescrição de auxílios ópticos para longe em 37,8\% e para perto em $18,8 \%$ e Haddad et al (2006b) em $62,5 \%$ dos casos para longe e 
$13 \%$ para perto. Observa-se, portanto, alta freqüência de prescrição de auxílios ópticos para longe.

Na retinocoroidite macular bilateral ocorrem: diminuição da acuidade visual e defeitos campimétricos centrais ou paracentrais, cuja intensidade dependerá da extensão e da profundidade da lesão retiniana. (Haddad et al., 2000b). A possibilidade de novos focos de retinocoroidite peripapilares levará a escotomas absolutos (lesões profundas) e maior defeito do campo visual periférico pelo acometimento das arcadas maculares. (Stanford et al., 2004) O desempenho visual decorre da existência de campo visual paracentral e periférico preservado e também da habilidade do paciente em utilizar áreas parafoveais ao redor da cicatriz. (Faye, 1984)

Quanto à correção óptica de ametropias, houve a sua prescrição para todos os casos de retinicoroidite macular, sendo $24,2 \%$ para hipermetropias ou astigmatismos hipermetrópicos e $75,8 \%$ para miopia ou astigmatismos miópicos. Moribe e Veitzman (1994) observaram correlação entre cicatrizes retinianas secundárias a toxoplasmose e maior freqüência de miopia. Portanto, a refração deverá ser realizada e a melhora da resposta visual com uso da correção óptica observada.

A freqüência de adaptação de auxílios ópticos para perto foi menor na população com retinocoroidite macular bilateral. Esse fato explica-se pela existência do poder acomodativo suficiente para focar a imagem a curtas distâncias (quando a ampliação da imagem retiniana por aproximação do objeto ao olho) e também pela presença da miopia, uma vez que para perto a retirada da correção óptica funcionaria como uma adição no caso do míope. 
A catarata congênita operada foi observada em $11,3 \%$ dos casos, sendo afácicos 10,4\% e pseudofácicos 0,9\%. (Tabela 9). Foi também observada por outros estudos brasileiros com freqüência variável entre 4,9\% e 28,6\% . (Kara-José et al.,1984; Kara-José et al.,1988; Carvalho et al.,1998; Leal et al.,1995; Gilbert at al.,1994; Leite et al.,1997; Tartarella et al.,1991; Moreira et al.,1991; Haddad et al.,2000; Carvalho et al., 2002Merula et al.,2005).

A prevalência da catarata congênita é de 1 a 4/10.000 nos países em desenvolvimento e de 0.1 a $0.4 / 10.000$ nos países desenvolvidos. Globalmente, cerca de 200.000 crianças são cegas por catarata. Quanto à incidência, nos países em desenvolvimento é de 10 crianças/milhão da população e nos países desenvolvidos de 4 crianças/ milhão da população por ano. (Foster et al., 1997)

Segundo Foster et al. (1997), a etiologia da catarata congênita, nos países desenvolvidos, pode não ser definida em $50 \%$ dos casos, pode ser hereditária em 20\% e, em 30\%, secundária a anormalidades cromossômicas, doenças metabólicas, infecções intrauterinas, prematuridade ou associada com outras anormalidades oculares. Rahi (2000) observou $1 \%$ de catarata congênita secundária à rubéola congênita no Reino Unido. No Brasil, estudos evidenciaram maior correlação com causas infecciosas - entre 15 a $38 \%$ dos casos, secundários à rubéola congênita. (Kitadai et al.,1994; Haddad et al, 2006a)

A detecção e o tratamento cirúrgico devem ocorrer o mais cedo possível para minimizar os efeitos da perda visual pela ambliopia. (Foster et 
al.,1997). A cirurgia deve ser realizada até a oitava semana de vida para que os efeitos da privação visual sobre o sistema visual sejam menos profundos e mais reversíveis. (Regensteiner et al., 1987) A criança com a catarata congênita deve ser encaminhada ao centros terciários de atendimento oftalmológico para que sejam asseguradas a cirurgia, a correção óptica, o controle da ambliopia e a estimulação precoce.

Programas educacionais voltados para pediatras neonatologistas para a realização da pesquisa do reflexo vermelho, para detecção de opacidades dos meios oculares transparentes, devem ser desenvolvidos. (Arieta et al., 1987). A capacitação de oftalmologistas, acesso a instrumental cirúrgico, disponibilidade de correção óptica e possibilidade de acompanhamento dos casos operados devem ser considerados nos países em desenvolvimento.

No presente estudo, todos os casos de catarata congênita foram encaminhados ao serviço de baixa visão após a realização da cirurgia bilateralmente. Dos 13 casos estudados, 1 era pseudofácico $(7,7 \%)$. Foster et al (1997) observaram a necessidade de outros estudos para a indicação de implante de lentes nos países em desenvolvimento, onde, a menor observância às orientações pós-operatórias, ao uso de correção óptica, à necessidade de acompanhamento e baixa renda familiar justificariam o uso da lente intraocular como garantia de maior resolução e desenvolvimento visual.

Todos os casos de catarata congênita operada, no presente estudo, faziam uso da correção óptica, o que revela o cuidado do oftalmologista para a melhor resolução e desenvolvimento visuais. Quanto ao uso de auxílios 
ópticos, 92,3\% tiveram a prescrição para uso de auxílios para longe e 61,5\% para perto. Nesses casos, a falta da acomodação (após a cirurgia da catarata) contribuiu para que mais auxílios para perto fossem prescritos.

Os avanços das técnicas cirúrgicas para o tratamento da catarata congênita têm reduzido os índices de complicações. Contudo, ações mais efetivas devem ser instituídas buscando prevenção, diagnóstico e tratamento precoces, adequada correção óptica, tratamento de ambliopia e serviços de intervenção precoce. (Mérula et al., 2005)

Entre as doenças hereditárias de retina e mácula $(22,6 \%)$, o albinismo oculocutâneo foi a afecção mais freqüente. É importante salientar que, pelas características fenotípicas da criança, o diagnóstico do albinismo oculocutâneo pode ser realizado precocemente; portanto, o conhecimento das repercussões dessa afecção na visão por parte dos pediatras é fundamental para que a família seja prontamente orientada e encaminhada ao oftalmologista. No entanto, observamos que os casos de albinismo oculocutâneo estudados, o encaminhamento ocorreu entre 6 meses e 14 anos, com média de 7,4 anos.

As doenças hereditárias da retina podem ser estacionárias ou progressivas. (Maestrini et al., 2004) A doença de Stargardt, a retinose pigmentar, a distrofia de cones e bastonetes, a amaurose congênita de Leber são progressivas e têm diferentes quadros de evolução, de acordo com as características genéticas presentes em cada indivíduo. Segundo Unonius et al. (2003), é importante a classificação dessas doenças, quanto ao padrão de herança, para o avanço nas pesquisas da terapia genética. Os 
diferentes aspectos evolutivos e funcionais de cada doença irão determinar as demandas de cada paciente e cabe ao oftalmologista estar atento para realizar as prescrições ópticas possíveis e encaminhamentos a serviços de reabilitação.

As distrofias retinianas da infância são doenças raras e de difícil diagnóstico, podendo ter múltiplas manifestações clínicas e diferentes tipos de herança. Diante de uma criança com baixa visão, deve-se lançar mão de vários recursos diagnósticos, dentre eles a anamnese cuidadosa, o exame oftalmológico completo e os exames complementares (eletrorretinografia, testes de visão de cores e campo visual). Em alguns casos, o diagnóstico correto será definido de acordo com a evolução da doença, ao longo do tempo. O diagnóstico determinará o prognóstico e auxiliará no aconselhamento aos pais e na conduta frente a cada paciente. (Maestrini et al., 2004)

Os erros refrativos são descritos, com maior freqüência, em doenças hereditárias da retina, em particular na amaurose congênita de Leber, na retinose pigmentar, no albinismo e na acromatopsia. No presente estudo, todos os escolares com essas afecções receberam prescrição de correção óptica da ametropia. Quanto à prescrição de auxílios ópticos, 80,8\% tiveram prescritos auxílios para longe e $50 \%$ para perto.

A amaurose congênita de Leber tem manifestação no primeiro ano de vida e está relacionada a presença de hipermetropia, ausência de respostas ao eletrorretinograma, ausências de alterações fundoscópicas ao nascimento e compressão óculo-digital (sinal de Franceschetti). Apesar da 
baixa acuidade visual presente, deve-se considerar a correção da ametropia, geralmente hipermetropia alta e também realizar o acompanhamento do caso, uma vez que ceratocone e catarata traumática podem estar presentes ao longo dos anos. (Catalano e Nelson, 1994)

No presente estudo, os escolares com amaurose congênita de Leber não apresentavam outra doença sistêmica ou deficiência associada à visual; porém alterações cognitivas, acometimentos neurológicos ou sistêmicos podem estar presentes, como, por exemplo, rins policísticos e a osteopetrose . (Mets, 1990). O oftalmologista deve estar atento, portanto, quanto à necessidade de encaminhamento da criança a outras especialidades e serviços.

A malformação ocular foi observada em $10,4 \%$ dos casos. A principal afecção observada foi o coloboma ocular ( 4,3\%). (Tabela 9). Decorrente da fusão incompleta das margens da fissura embrionária, o quadro clínico observado será decorrente do envolvimento de diversas estruturas (íris, corpo ciliar, retina e nervo óptico). Quando a retina é acometida, podemos observar defeitos de campo visual correspondentes à lesão retiniana, induzindo à posições de cabeça e do olhar para melhor posicionamento do campo visual. Podem haver com alterações sistêmicas, como, por exemplo, a associação CHARGE (coloboma, afecções cardíacas, atresia de coanas, atraso cognitivo, e anomalias genitais), condição multifatorial e de maior prevalência nos quadros de coloboma.

A aniridia esteve presente em $1,7 \%$ dos casos (Tabela 9). Sua etiologia é genética e pode estar associada a tumor de Wilm's. atraso 
cognitivo, atraso no desenvolvimento, anormalidades genitourinárias e alterações faciais. Pode ter manifestações variadas, com diminuição da acuidade visual, opacificações do cristalino e glaucoma. O encaminhamento a profissionais e serviços de pediatria para pesquisa de possíveis envolvimentos sistêmicos deve ser realizado. $O$ acompanhamento oftalmológico para a prescrição óptica e controle do glaucoma é necessário.

A hipoplasia do nervo óptico foi observada em $1,7 \%$ dos casos. Pode estar associada a distúrbios do sistema nervoso central e a alterações endócrinas. O diagnóstico da hipoplasia do nervo deve ser um alerta para pesquisa de possíveis alterações sistêmicas. As causas são esporádicas e idiopáticas. (Weiss, 1990)

O glaucoma congênito primário foi responsável por $6,1 \%$ dos casos de baixa visão. Apesar da incidência na população infantil ser de apenas 0,02\% (Catalano e Nelson, 1994), essa doença ocular leva a menor resposta visual em conseqüência da ambliopia ou da lesão do nervo óptico e os casos serão encaminhados com maior freqüência aos serviços de baixa visão. Dessa maneira, estudos nacionais apresentaram freqüência entre $1,1 \%$ a $15 \%$ do glaucoma congênito como causa da deficiência visual em serviços de reabilitação. (Carvalho et al., 1998; Carvalho et al., 1996; Haddad et al., 2000; Haddad et al., 2006a.; Haddad et al., 2006b; Tartarella et al., 1991). No presente estudo, o maior encaminhamento foi realizado pelo Serviço de Glaucoma Congênito do Hospital das Clínicas da Universidade de São Paulo, conceituado serviço nacional de referência para o tratamento dessa afecção. 
O prognóstico visual da criança com glaucoma congênito depende da época do diagnóstico e do tratamento. Opacidades corneais, erros refracionais não corrigidos e lesão do nervo óptico são indicativos do grau de comprometimento visual. O edema corneal, se presente nos primeiros 3 meses de vida, pode levar à acuidade visual menor que 20/200 em aproximadamente $50 \%$ das crianças.(Catalano e Nelson, 1994)

Segundo Betinjane (1999), é necessário corrigir as ametropias para garantir, além do controle da pressão intraocular, melhor resolução visual. Um método alternativo para cálculo da refração ocular dessas crianças seria a fórmula de regressão, que leva em consideração valores da ceratometria e do diâmetro axial obtido pela ultrassonografia. (Carani et al., 1994)

As ametropias foram corrigidas em $85,7 \%$ dos escolares, sendo todas para correção de miopia ou astigmatismos miópicos. Haddad et al .(2003) estudaram a população infantil com baixa visão secundária ao glaucoma congênito observaram necessidade de correção óptica em $68 \%$ dos pacientes, das quais $80 \%$ eram para correção de miopia ou astigmatismo miópico e $20 \%$ para hipermetropia ou astigmatismo hipermetrópico.

A presença de valores de acuidade visual maiores do que 0,05 permitiu que, nos casos de glaucoma congênito, $71,4 \%$ dos casos tivessem adaptação de auxílios ópticos para longe e em $42,8 \%$ auxílios ópticos para perto. Haddad et al.(2003) observaram na idade escolar, 69,3\% dos pacientes com auxílios ópticos para longe e 12,2\% com auxílios ópticos para perto coerente com padrões observados nesse grupo etário. 
A retinopatia da prematuridade foi observada em $1,7 \%$ dos casos Nos países em desenvolvimento, como no Brasil, os avanços tecnológicos levam a melhoria dos serviços de neonatologia com aumento da sobrevida de prematuros com muito baixo peso, o que resulta num maior número de casos de retinopatia da prematuridade. Faz-se necessário o conhecimento do pediatra neonatologista para a indicação da avaliação oftalmológica para a prevenção da perda visual programas de detecção e tratamento precoces.

Como conseqüência das melhores condições de atendimento neonatal intensivo, dados norte-americanos revelaram diminuição na freqüência de retinopatia da prematuridade representando, entre 8 e $18 \%$ das causas de deficiência visual na infância. Entretanto, na América Latina, taxas crescentes têm sido relatadas: na Argentina e no Paraguai, a retinopatia da prematuridade é a causa de cegueira infantil em mais de $30 \%$ dos casos. (Muñoz e West, 2002). No Brasil, taxas entre 11,8\% e 1,3\% foram observadas como causas de perda visual nos diversos estudos no nosso país (Kara-José et al. 1988; Carvalho et al. 1998; Haddad et al. 2000; Haddad et al., 2006a; Haddad et al., 2006 b) Procianoy (1997) estimou que cerca de 16.000 recém-nascidos, no Brasil, desenvolvam a retinopatia da prematuridade anualmente, dos quais aproximadamente 1.600 podem ficar cegos se não detectados e tratados precocemente. Portanto, o estudo da prevalência de ROP e a avaliação dos programas de prevenção da cegueira quanto à sua eficiência fazem-se necessários.

A retinopatia da prematuridade, nos estágios mais avançados, tem efeito deletério sobre o sistema visual e deficiência visual profunda é 
observada. Entretanto, cerca de $90 \%$ dos casos apresentam resolução espontânea (Catalano e Nelson, 1994) e, portanto, os pacientes que chegam a serviços especializados de atendimento à deficiência visual corresponderiam a uma parcela do total de crianças que desenvolveram a retinopatia da prematuridade. Haddad et al. (2004) estudaram uma população de 210 crianças com baixa visão secundária à retinopatia de prematuridade e observaram maior freqüência de histórico de gestações múltiplas $(13,7 \%)$ como fator da prematuridade; $64,8 \%$ tiveram seu diagnóstico realizado tardiamente e não tiveram nenhuma indicação de tratamento; o encaminhamento à instituição para atendimento à deficiência visual foi realizado em $45,2 \%$ por oftalmologistas; $16,6 \%$ estavam associados com outras deficiências físicas, cognitivas ou sensoriais; somente $13,7 \%$ tinham valores de acuidade maiores que 0,05 . Portanto, a freqüência de somente 2 casos no presente estudo estaria relacionada à maior prevalência de ausência de respostas visuais nessa população .

A baixa acuidade visual dificultará a eficiência na adaptação dos auxílios ópticos. No presente estudo, 2 casos tinham deficiência visual moderada e em 1 caso foi indicado o uso de um auxílio óptico para longe de $4 \times 12 \mathrm{~mm}$. Ambos eram míopes e tinham melhora da resposta visual com uso de seus óculos. A miopia parece estar presente até em $80 \%$ de retinopatia da prematuridade, seja pelo deslocamento do diafragma iridocristaliniano, seja pela realização da crioterapia. (Catalano e Nelson, 1994; Ricci, 1999) 
A necessidade da avaliação oftalmológica para o diagnóstico, coloca o oftalmologista numa posição estratégica como o principal agente de encaminhamento na comunidade. A perda visual profunda e irreversível, na maior parte dos casos, não permite dúvidas quanto à necessidade da reabilitação visual. No presente estudo, 1 caso foi encaminhado pelo oftalmologista do berçário ao serviço de visão subnormal.

A retina foi a estrutura ocular mais acometida $(54,8 \%)$, seguida pelas alterações no cristalino (16,5\%). A córnea foi a estrutura atingida em 0,9\%. Dados mundiais de deficiência visual na infância apontam a retina em $25 \%$ das causas, a córnea em $20 \%$, o cristalino em $13 \%$. A inexistência de casos de lesões corneais por hipovitaminose A na nossa região e a prevalência maior de retinocoroidite macular bilateral podem justificar essa diferença em relação aos dados apontados por Gilbert e Foster (2001b).

De acordo com a definição de visão subnormal e cegueira da CID-10 (OMS, 1993), foram registrados $94,8 \%$ dos casos com baixa visão (categorias 1 e 2 ) e 5,2\% de escolares cegos (categorias 3 e 4). Porém, se considerada a definição proposta pela OMS (WHO, 1992) e também as categorias propostas pelo Conselho Internacional de Oftalmologia (ICO, 2002), observam-se $67,8 \%$ com deficiência visual moderada, $27 \%$ com deficiência visual grave, 3,5\%com deficiência visual profunda e 1,7\% com valores de acuidade visual próximos à cegueira (Tabela 11). É importante ressaltar que, para os profissionais de reabilitação visual, valores de acuidade inferiores a 0,05 até percepção de luz são importantes na 
funcionalidade de uma pessoa. Ressalta-se a necessidade de uniformidade de definições para melhor comunicação entre profissionais e serviços.

Os valores de acuidade visual corrigida observados mostram uma freqüência maior de deficiência visual moderada e grave $(94,8 \%)$ em relação aos apontados por outros estudos (em torno de 50\%) e também em estudos realizados previamente nos mesmos serviços em populações de 0 a 16 anos de idade. (Leal et al, 1995; Carvalho et al, 1996; Carvalho et al, 1998; Haddad et al, 2000; Haddad et al, 2006a; Haddad et al, 2006b)

Auxílios ópticos para longe foram prescritos em $88,5 \%$ dos casos com deficiência visual moderada, em $97 \%$ dos casos com deficiência visual grave e em $50 \%$ dos casos com deficiência visual profunda, correlação estatisticamente significativa (Tabela 42). Os auxílios ópticos para perto, de modo significativo, foram prescritos em $28,2 \%$ na deficiência moderada, em $54,8 \%$ na grave e $25 \%$ na profunda (Tabela 43 ). Apesar dos resultados na adaptação de auxílios ópticos serem mais efetivos para valores de acuidade visual até 0,05, deve-se observar se há respostas positivas, com recursos de ampliação da imagem retiniana, para valores mais baixos. Procura-se promover o uso máximo da visão remanescente de acordo com as necessidades do indivíduo, da sua condição funcional e seus interesses.

A avaliação da sensibilidade ao contraste mostrou redução da função, de forma acentuada, em $76,5 \%$ dos casos (Tabela 13). Reforçam-se, dessa maneira, as orientações para aumento do contraste de materiais didáticos utilizados pelo escolar com baixa visão. Os auxílios não ópticos para aumento do contraste são, de maneira geral, simples e de custo acessível 
(por exemplo, canetas de ponta porosa, lápis com grafite 3B ou 6B, pautas reforçadas nos cadernos) e podem contribuir para melhor desempenho do aluno.(Min et al, 2001; Sampaio et al 2001; Haddad et al 2001)

Os defeitos de visão de cores estiveram presentes em 17,4\% (Tabela 14) e foram decorrentes de doenças distróficas da retina em $70 \%$ dos casos. Justifica-se a pesquisa dessa função como diagnóstico diferencial de dificuldades cognitivas, uma vez que alguns escolares podem apresentar dificuldades para nomear cores como decorrência de defeitos congênitos ou adquiridos da visão de cores. Os defeitos de visão de cores terão importância nas atividades laborativas que o escolar venha a ter e poderá ser fator limitante no desempenho de tarefas. (Min, 2001) É importante ressaltar que pode haver sobreposição, nos casos estudados, de defeitos congênitos e adquiridos da visão de cores. Os defeitos adquiridos mudarão de acordo com a progressão da afecção ocular.(Rosenthal e Cole, 1996)

A pesquisa da amplitude do campo visual mostrou valores normais para $69,6 \%$ dos escolares não apresentavam alteração; porém, redução importante foi observada em 16,5\% (Tabela 15).

Segundo Faye (1984) um campo visual central de 20 graus é necessário para que haja uma rápida orientação espacial num ambiente familiar. Uma vez que a diminuição da amplitude do campo visual ocorre de maneira lenta e progressiva em algumas doenças oculares (como o glaucoma ou a retinose pigmentar), o indivíduo desenvolve mecanismos compensatórios, como balanço de cabeça e movimentação rápida dos olhos, para varredura do campo periférico. Dessa maneira, o indivíduo com 
redução da amplitude de campo visual consegue dimensionar e reconhecer o ambiente. Esses mecanismos são involuntários e imperceptíveis e, assim, o paciente não toma conhecimento da alteração visual até que o campo visual seja reduzido a 10 graus ou menos. Cohen (1993) relata que um campo de 10 graus à perimetria seria equivalente a 50 graus em termos de funcionalidade, como conseqüência desse mecanismo compensatório.

Todos os escolares com diminuição da amplitude do campo visual $(30,4 \%)$ foram encaminhados a programas de orientação e mobilidade (Tabela 15). O escolar com campo visual reduzido necessitará realizar a varredura de seu ambiente, o que fará com que necessite de maior tempo para realização de tarefas. Programas na área de orientação e mobilidade são necessários para os casos com diminuição importante da amplitude do campo visual. Procura-se proporcionar a mobilidade segura e a independência dentro e fora de seu ambiente escolar.

No contexto escolar, Garcia (2001) observou que os professores de Salas de Recursos da Secretaria da Educação de São Paulo declararam-se desinformados, sem orientação, sem supervisão, sem formação contínua para o desenvolvimento de programas de orientação e mobilidade para os alunos com deficiência visual. Apontou-se a necessidade de maior capacitação, parcerias e envolvimento da comunidade.

Ressalta-se, ainda, a importância de investigação do campo visual, como instrumento legal, para confecção de laudos médicos para a solicitação de benefícios e isenções, previstos pela legislação de cada país, às pessoas com deficiência visual, classificadas de acordo a legislação 
vigente. No Brasil, o Decreto № 3.298 - de 20 de dezembro de 1999, alterado pelo Decreto № 5.296 de 2 de dezembro de 2004 que regulamenta a Lei № 7.853 de 24 de outubro de 1989 que dispõe sobre a Política Nacional para a Integração da Pessoa Portadora de Deficiência, utiliza os seguintes parâmetros para definir legalmente a pessoa com deficiência visual: 1) cegueira, na qual a acuidade visual é igual ou menor que 0,05 no melhor olho, com a melhor correção óptica; 2) baixa visão, com acuidade visual entre 0,3 e 0,05 no melhor olho, com a melhor correção óptica; 3) somatória da medida do campo visual em ambos os olhos igual ou menor que $60^{\circ}$; 4) ou a ocorrência simultânea de quaisquer das condições anteriores.(Sicorde, 2006; Bolonhini, 2004)

Os auxílios ópticos eram usados por $40 \%$ dos escolares com baixa visão. Após a avaliação realizada, 92,1\% tiveram indicação para uso de auxílios ópticos. Essa maior freqüência na prescrição dos auxílios ópticos pode ser justificada pela presença de valores de acuidade visual maiores do que 0,05 em $94,8 \%$ dos casos, o que permite melhores resultados à adaptação (Tabela 12). Ressalta-se que algumas crianças haviam sido avaliadas nos serviços antes da idade escolar, quando não houve indicação ou condições de desenvolvimento para manuseio de auxílios ópticos ou também dificuldades para sua aquisição.

Dentre os auxílios ópticos, foram mais prescritos os auxílios para longe (sistemas telescópicos) em $87,8 \%$ da população (Tabela 18). A criança por apresentar acomodação, utiliza-se da ampliação da imagem retiniana para perto por meio da aproximação do objeto (material escolar, 
por exemplo) ao olho. Não há, portanto, na maior parte dos casos, necessidade de adição ou de auxílios ópticos para perto.

Lindsted (1986) relatou dificuldades acomodativas em crianças com baixa visão; Gwiazda et al (1993)observaram insuficiência de acomodação em crianças com miopia e Woodhouse et al (1993) relataram redução da acomodação em crianças com Síndrome de Down. No que se refere ao escolar com baixa visão deve-se, portanto, pesquisar sua condição acomodativa e realizar a prescrição necessária. No presente estudo, houve a indicação de adição ou auxílios ópticos para perto a escolares com baixa visão em $34,7 \%$ dos casos (Tabela 18).

O auxílio óptico para perto mais prescrito foi a lupa de apoio de $2 x$ de ampliação (tipo barra) pela facilidade de manipulação em seguimento às linhas dos livros e pautas dos cadernos escolares. Haddad et al. (2006b) relataram ter sido a barra de leitura de $2 \mathrm{X}$ o auxílio ópticos para perto mais prescrito numa população escolar com baixa visão.

O sistema telescópico mais prescrito foi o de 6 X $16 \mathrm{~mm}$ de ampliação seguido pelo de $4 \times 12 \mathrm{~mm}$ e pelo de $2,8 \times 26 \mathrm{~mm}$ em $55,4 \%, 24,7 \%$ e $8,9 \%$, respectivamnete. A acuidade visual a ser atingida com o emprego do sistema telescópico dependerá das atividades a serem realizadas pela pessoa com baixa visão. A acuidade visual almejada e a acuidade visual corrigida observada no olho de melhor visão do escolar definirão a escolha do poder de ampliação do auxílio óptico. (Sampaio et al., 2001) A acuidade visual de 1,0 é desejável; porém, muitas vezes, não necessária, pois a acuidade visual de 0,5 permite a uma pessoa ler números de ônibus e ler 
placas (Lopez, 1994) Sei (1998) relatou que o uso de sistemas telescópicos, com poder de ampliação de 2,8X ,colaborou para a realização de atividades escolares em 28 estudantes com valores de acuidade visual variadas.

Devido à diminuição do campo visual, diminuição da iluminação da imagem retiniana, mudança de profundidade de campo e efeitos de paralaxe, presentes em todos os sistemas telescópicos, a pessoa com baixa visão deverá receber orientação para uso funcional desse recurso. (Sampaio et al., 2001) Essa orientação visa comparar a eficiência no uso do auxílio em atividades similares às do indivíduo na sua vida diária, uma vez que os testes durante a avaliação oftalmológica têm parâmetros controlados (como iluminação, distância do objeto e contraste) e não evidenciam as dificuldades que possam existir durante o uso de auxílio na vida real. (Sampaio et al, 2001)

Todos os sistemas telescópicos prescritos foram manuais, monoculares e com ajuste de foco. Os auxílios manuais e monoculares são mais estéticos e permitem uma aceitação maior para seu uso por parte do escolar. O foco ajustável permite, de acordo com a profundidade de foco do recurso, a utilização do mesmo para atividades e distâncias variadas. (Hadddad et al, 2001)

Pode-se promover o uso do sistema telescópico na idade escolar em atividades lúdicas e prazerosas para que a criança entenda a necessidade do uso do recurso para o desempenho de suas atividades cotidianas. (Min et al., 2001)

A população estudada era composta por escolares que já haviam sido submetidos à avaliação oftalmológica em um dos serviços da presente 
pesquisa $(81,7 \%)$ e por escolares que iriam passar pela primeira avaliação em um dos serviços (18,3\%). Podem-se observar que, dentre os casos novos, somente $1(4,8 \%)$ fazia uso do auxílio óptico para longe enquanto que 18 casos $(85,7 \%)$ que não faziam uso do sistema telescópico tiveram prescrição para uso do mesmo. Somente 1 caso havia sido avaliado previamente por outro serviço de baixa visão. Quanto aos auxílios ópticos para perto, nenhum caso novo utilizava e 8 (38\%) tiveram indicação de uso após a primeira avaliação. A dificuldade de acesso a serviços de baixa visão poderia estar comprometendo a prescrição óptica e, em conseqüência, o desempenho escolar do aluno.

A correção óptica de ametropias já era usada por $75,6 \%$ dos pacientes; dessas, foram atualizadas $25,2 \%$ e mantidas $50,4 \%$ (Tabela 20 ). Novas indicações de correção óptica foram realizadas em 3,5\% dos casos. No total, $79,1 \%$ dos escolares necessitaram usar correção óptica para ametropias. As afeç̧ões oculares que levam à baixa visão também são responsáveis pelas ametropias existentes. Desse modo, temos a retinocoroidite macular bilateral (para os quais são referidos maior freqüência de miopia; a amaurose congênita de Leber (geralmente, nesses casos, há hipermetropia alta); crianças afácicas após cirurgia para catarata congênita; retinopatia da prematuridade; cristalino ectópico na Síndrome de Marfan e a alta miopia . Du et al (2005) realizaram estudo retrospectivo numa população infantil com deficiência visual e observaram que somente $25 \%$ tinha ametropias menores que \pm 1 dioptria (em equivalente esférico) e associação significante entre determinadas afecções oculares e tipos de 
ametropias: hipermetropia baixa ou moderada no albinismo, na hipoplasia de nervo óptico, no coloboma, na atrofia óptica e na acromatopsia; hipermetropia alta na afacia; alta miopia na retinose pigmentar e na retinopatia da prematuridade.

Schimiti et al (1989) estudaram uma população escolar na cidade de Ibiporã (PR) e observaram 4,5\% de crianças com necessidade de correção óptica para ametropias; dentre essas, $46,5 \%$ de hipermetropia ou astigmatismo hipermetrópicos, $33,5 \%$ de miopia ou astigmatismos miópicos e $20,2 \%$ de astigmatismos. Portanto, a necessidade da correção óptica de ametropias é mais evidente numa população escolar com baixa visão do que na população escolar geral.

No presente estudo, entre os casos novos, $57,2 \%$ já faziam uso da correção óptica e ao final da avaliação $66,7 \%$ necessitavam dos óculos, o que pode apontar que, mesmo o oftalmologista que não realiza $\circ$ atendimento em serviços de baixa visão teria a preocupação em corrigir as ametropias na população infantil.

Segundo Fonda(1986), uma refração cuidadosa pode melhorar a visão em cerca de $15 \%$ dos pacientes. Portanto, faz-se necessário que o oftalmologista dedique um tempo maior à refração do paciente com baixa visão, no qual, uma pequena melhora quantitativa pode significar um ganho qualitativo no desempenho de tarefas.

No presente estudo, a percepção da dificuldade visual foi feita pela mãe, em $53 \%$ dos casos. Resultados similares foram observados por Nobre (1997), em 48\% de uma população, de 0 a 4 anos de idade, com deficiência 
visual. De outro lado, Nobre (2001) observou que em 58,3\% de escolares, a dificuldade visual foi detectada pelo professor.

As causas da deficiência visual mais freqüentes foram as afecções pré-natais, perinatais e hereditárias, em $70,4 \%$ dos casos (Tabela 11), que levaram a manifestações oculares precoces, tornando a dificuldade visual perceptível. Dessa forma, a dificuldade visual foi observada no primeiro ano de vida em $80,9 \%$ dos casos. (Tabela 23 )

A mãe, pelo seu vínculo com os filhos, é a pessoa que pode perceber primeiro a dificuldade visual. Nos casos em que não houve a observação pela mãe, ela foi realizada pela avó ou pelo pai ou pelo pediatra, durante a consulta de puericultura de rotina. Até os 11 meses de vida, a mãe foi a observadora em $52,9 \%$, enquanto que o pediatra em $25,5 \%$, o oftalmologista em $9,8 \%$, o pai em 5,9\% e avó em 5,9\%. Possivelmente, houve indicação do pediatra para a consulta oftalmológica; uma vez que, na nossa cultura não é usual a avaliação oftalmológica de rotina para todos os lactentes; portanto, considera-se que a participação do pediatra possa ter sido mais pronunciada.

Após os 12 meses de vida, a mãe foi ainda a principal observadora (53\%), porém, registra-se maior participação da professora e do pediatra. Os casos não observados pelos familiares podem ter decorrido de manifestação mais tardia do problema visual ou devido ao contexto familiar de baixa escolaridade. Dos 2 aos 5 anos, a observação ocorreu em 12,2\% dos casos enquanto que dos 6 anos em diante, o problema visual foi percebido em $6,9 \%$ dos casos (Tabela 23 ). 
$\mathrm{Na}$ idade escolar o professor e outras pessoas da comunidade terão maior importância na detecção de problemas visuais. Temporini (1988) ressalta o papel do professor como observador da condição de saúde de seus alunos devido ao seu contato diário e prolongado com os mesmos. Porém, o professor necessita estar instrumentalizado e ter conhecimentos básicos de saúde ocular para que suas condutas e encaminhamentos sejam apropriados e efetivos. Armond e Temporini (2000) observaram, a partir dos conhecimentos e mitos relacionados à saúde ocular, a necessidade de prover orientação a professores para o desenvolvimento de ações de oftalmologia sanitária nas escolas de primeiro grau.

A população estudada por Nobre(2001) teve a deficiência visual detectada durante a Campanha Olho no Olho, iniciativa de caráter preventivo implementada nas escolas públicas do sistema público de ensino. Deve-se ressaltar, portanto, a importância de programas de Saúde Escolar, uma vez que na faixa de 7 a 14 anos, o acesso à escola está praticamente universalizado $(95,7 \%)$, incluindo as áreas rurais, onde $94,7 \%$ das crianças freqüentam alguma instituição de ensino (IBGE, 2006) Assim, a abrangência da Campanha Olho no Olho permitiu que os casos não detectados, anteriormente à idade escolar, pudessem ser identificados.

O pediatra, no presente estudo, teve importante papel de observador da condição visual da criança. Porém, Manica (2003) aponta que os pediatras têm conhecimento insuficiente para diagnosticar e tratar afecções oculares prevalentes na infância, assim como, para orientar a família dessa criança. O pediatra deve ter mais informações de saúde ocular durante sua 
especialização e deve conhecer procedimentos específicos como, por exemplo, o teste do reflexo vermelho, para a detecção precoce de problemas visuais. (Arieta e Kara-José, 1987). Pode-se ilustrar a falta de informação com as condutas tomadas pelo pediatra como primeiro profissional da área da saúde a ser consultado após a observação da dificuldade visual: não percebeu a dificuldade visual (23,8\%); solicitou aguardar maior idade da criança para que essa fosse submetida a avaliação oftalmológica (33,3\%); ponderou tratar-se de deficiência mental( $4,8 \%)$ e encaminhou ao oftalmologista (38,1\%). (Tabela 25$)$

Quanto à avaliação oftalmológica, após a percepção do problema visual, $83 \%$ dos oftalmologistas fizeram o diagnóstico. Positivamente, revelase o preparo do profissional para a avaliação de crianças com problemas visuais. O oftalmologista foi o primeiro profissional médico consultado em $81,7 \%$ dos casos.

O serviço público prestou atendimento em $51,3 \%$, enquanto que a clínica particular foi responsável por $44,3 \%$ (consultas particulares e por convênios). Discute-se a possibilidade de dificuldade de acesso a serviços públicos e procura pelo serviços privados numa situação emergencial. Da população estudada, 5 casos tiveram acesso ao serviço de baixa visão pela relação familiar com outro paciente com baixa visão e pela maior possibilidade de ter o mesmo diagnóstico. (Tabela 26)

A primeira avaliação oftalmológica ocorreu até 6 meses após a observação do problema visual em 61,7\%. (Tabela 27) Acharam fácil conseguir o agendamento $54,8 \%$ dos responsáveis .(Tabela 29) 
As justificativas mais freqüentes por não conseguir a avaliação oftalmológica foram a falta de vagas $(38,6 \%)$ e o aguardo na orientação do pediatra(29,5\%).(Tabela 27 ) Discute-se novamente o acesso a atendimento oftalmológico em serviços públicos, onde a espera maior do que 6 meses poderia levar a perdas irreversíveis da função visual da criança. O pediatra, por desconhecimento de saúde ocular, constituiu-se num fator de diagnóstico e tratamento tardios de problemas oculares da criança.

Em 18,2\% dos casos, o responsável considerou que houvesse dúvida quanto à existência do problema visual e, por esse motivo, o médico não foi procurado. (Tabela 27) Herring (1996) ressaltou que os familiares, quando são notificados da deficiência da criança, podem ter sentimentos como tristeza, culpa, medo, ansiedade, ressentimento, negação e raiva que, em parte, são superados e, em parte, são recorrentes ao longo da vida. No presente caso, o atraso na procura por auxílio médico deveu-se ao desconhecimento, à falta de informação ou à negação do problema. Segundo Faye (1984), os pais devem trabalhar suas reações pelo bem da criança, para aceitar o futuro com expectativas realistas e para preparar seu filho contra os desapontamentos por ter uma visão diminuída.

O diagnóstico do problema ocular foi realizado em $63,5 \%$ dos casos até o primeiro ano de vida; em 26,1\% entre 2 anos e 6 anos de vida e entre 7 e 13 anos de vida em 10,4\% (Tabela 30). Esses dados demonstram a freqüência maior de doenças oculares congênitas e a necessidade de detecção, tratamento e encaminhamento a serviços de intervenção precoce. O acometimento visual tardio, secundário a afecções, como a retinose pigmentar, se não detectados no ambiente familiar, deverão sê-lo na escola. 
Apesar do diagnóstico nos primeiros anos de vida, a maior parte das crianças com baixa visão foram encaminhadas a serviços de habilitação/reabilitação visual posteriormente: $53,9 \%$ dos aos 14 anos; $33,9 \%$ dos 2 aos 6 anos e 12,2\% no primeiro ano de vida (Tabela 31). Casos de deficiência visual moderada podem, de acordo com o contexto familiar, não apresentar incapacidade para realização de tarefas e concorrem para o atraso na detecção. Nesses, a condição da incapacidade visual somente foi evidenciada na escola, por dificuldade de leitura da lousa, dificuldade da escrita e de aprendizado. O ingresso na escola, portanto, tornou evidente a dificuldade previamente existente e que, de acordo com as atividades que deveriam ser desempenhadas, não se configurava como condição limitante no seu ambiente familiar. A dificuldade escolar criou, portanto, a necessidade do atendimento na área da habilitação visual para a inclusão do aluno.

Quando a criança em algum momento apresenta alguma defasagem em seu desenvolvimento, tornando-a um elemento diferente, a atuação convencional da família será influenciada. Ao se deparar com o novo contexto que abarca a questão da deficiência ou diferença, podem ser observadas repercussões que, em diferentes graus e de diferentes formas, refletem-se nas relações humanas. (Samea, 1994 apud Nobre, 2001)

O encaminhamento ao serviço de baixa visão foi realizado por oftalmologista em $60 \%$ dos casos, por professores em $11,3 \%$ e por conhecidos da família em 11,3\%(Tabela 32). O conceito de que não havia orientação por parte do oftalmologista quanto às perpectivas e possíveis atendimentos na área da baixa visão, mesmo após a sua avaliação (Nobre, 
2001), talvez tenha mudado nos últimos anos no nosso país. Várias ações podem ter contribuído para essa mudança: 1) O Conselho Brasileiro de Oftalmologia, por meio de sua Comissão de Ensino, definiu o Programa Mínimo para os Cursos de Especialização em Oftalmologia, artigo 100 de seu Regimento Interno, que aponta que todos os Cursos de Especialização em Oftalmologia devem desenvolver um curso teórico-prático para capacitação do oftalmologista; 2) o Curso de Capacitação de Recursos Humanos na Área de Baixa Visão para Atuação Junto ao Ensino Público. Esse projeto capacitou 54 oftalmologistas e foi o maior projeto de capacitação com abrangência nacional realizado no Brasil; 3) desenvolvimento de cursos na área de baixa visão nos principais congressos de Oftalmologia; 4) maior disponibilidade de publicações técnicas na área oftalmológica e 6) maior disponibilidade de auxílios ópticos de custo reduzido, que possibilita a prescrição .

Destaca-se também a participação do professor no encaminhamento aos serviços de baixa visão, da mesma forma que na detecção de problemas visuais e encaminhamento ao oftalmologista.

Somente $23,5 \%$ dos escolares foram atendidos previamente por outro serviço ou profissional de reabilitação visual (Tabela 33). Além dos serviços nos quais o presente estudo foi realizado e que constituem serviços terciários, na cidade de São Paulo dispõe-se da Fundação Dorina Nowill para Cegos, do Serviço de Visão Subnormal da Santa Casa de Misericórdia de São Paulo e do Serviço de Visão Subnormal da Universidade Federal de São Paulo, sendo que todos prestam atendimento gratuito à população. 
Apesar disso, $67 \%$ dos responsáveis não conheciam a existência de outros serviços especializados (Tabela 34). Esse fato sugere existir a falta de divulgação das instituições quanto aos serviços oferecidos na área.

$\mathrm{Na}$ população de escolares, $33 \%$ faziam uso de auxílios ópticos, sendo $71,1 \%$ para longe, $7,9 \%$ para perto e $21 \%$ para longe e perto. (Tabela 35) Porém, $48,6 \%$ desses escolares tinham dificuldade para usar o auxílio óptico para longe e o principal motivo referido pelo responsável foi a vergonha de usar o recurso (Tabelas 36 e 37). Uma das desvantagens dos sistemas telescópicos é sua falta de estética, expondo a condição visual do usuário, que pode rejeitar o recurso. Por outro lado, pode haver incompreensão por parte das pessoas da comunidade quanto à necessidade de seu uso. Carvalho et al (1998) relataram que entre escolares que tinham auxílios ópticos, 20,4\% não aceitaram seu uso, 9,3\% de seus colegas e $5,6 \%$ de seus professores também rejeitaram o uso do recurso por parte do aluno com baixa visão. É necessário, portanto, que o oftalmologista ,além da avaliação e prescrição, oriente a família e a escola quanto à necessidade do recurso óptico e às dificuldades no seu uso.

Alguns escolares achavam o auxílio óptico para longe desnecessário. A acuidade visual de 0,5 pode, muitas vezes, ser suficiente para a realização de tarefas. De acordo com a resolução visual presente, algumas modificações ambientais e de materiais (como, por exemplo, ficar mais próximo da lousa e o professor utilizar letras maiores) podem ser suficientes para o desempenho escolar. 
Observamos que $5,9 \%$ preferiam que o professor ditasse a lição e $5,9 \%$ preferiam copiar do caderno do colega, fatos que demonstram compreensão do problema e colaboração por parte do professor e do colega de classe. Nesses casos, possivelmente, o uso do sistema telescópico foi rejeitado por diminuir a velocidade de trabalho (pela necessidade de varredura do ambiente e da lousa secundária ao campo de visão menor do sistema telescópico).

Para os casos de dificuldade de manuseio de recurso, o oftalmologista deverá observar se a indicação, de acordo com as características funcionais e refracionais do escolar, está adequada. Caso esteja, deve-se verificar se não haveria outro motivo para rejeição do auxílio óptico e, se não, novas sessões de orientação para uso funcional do auxílio devem ser realizadas.

A necessidade de orientação constante à família quanto aos objetivos da prescrição do auxílio óptico ficou evidente em 1 caso, no qual a mãe não permitia que seu filho levasse o sistema telescópico para a escola por temer a possilidade de roubo ou avaria. (Tabela 36)

Quanto aos auxílios ópticos para perto, 45,4\% tinham dificuldade para usar e por motivos similares aos auxílios para longe: vergonha, não ajudava e achava desnecessário.(Tabela 37)

Quanto à aquisição dos auxílios ópticos prescritos, 80,5\% apresentaram dificuldade pelo custo ou por não terem encontrado em disponibilidade. Desses, 44,0\% receberam doação e 29,2\% conseguiram comprar; porém, 7,3\% não conseguiram o auxílio óptico. (Tabela 38) De forma similar, Carvalho et al (2002) apontaram que 41,7\% de escolares com 
a prescrição de auxílios ópticos não conseguiram adquiri-los por falta de recursos financeiros.

Os auxílios ópticos empregados na área de baixa visão são, na sua maior parte, produzidos em outros países. Até há cerca de 5 anos, o custo de recursos ópticos disponíveis no nosso país era considerado alto para a população. O encarecimento devia-se ao preço do produto e aos impostos de importação. Nessa época, Fernandes e Jacobovitz (2001) e Haddad et al.(2001) propuseram sistemas telescópicos de custo reduzido e de fácil montagem numa tentativa de colaborar com o acesso ao recurso. No ano de 2002, com o desenvolvimento do "Low Vision Resource Centre" da "HongKong Society for the Blind" com o apoio do projeto "Vision 2020: The Right to Sight", o custo dos auxílios ópticos diminuiu e permitiu maior acesso pela população economicamente desfavorecida. No Brasil, onde $78,4 \%$ das famílias têm rendimento médio mensal até 10 salários mínimos (IBGE, 2006), esses custos, apesar de comparativamente reduzidos, ainda não permitem o acesso integral por toda a população com baixa visão. Dessa maneira, pode ter havido maior acesso; porém, ainda não existe a garantia do acesso desse recurso importante para a inclusão escolar.

Quanto à escolaridade, 4,3\% cursavam a pré-escola na faixa etária de 7 a 10 anos, 1,7\% cursavam o Ciclo I na faixa de 11 a 14 anos e 5,2\% cursavam o Ciclo II na faixa de 15 a 16 anos(Tabela 1).. Esses dados apontam uma defasagem escolar em relação à idade e que podem ser indicativo das dificuldades escolares decorrentes da baixa visão. Segundo Arruda (2006), a deficiência visual implica em perdas que podem interferir 
em aspectos pessoais, prejudicando a concepção do indivíduo sobre si mesmo e repercutindo no desempenho de suas atividades.

Carvalho et al (1998) observaram defasagem escolar em alunos com baixa visão, na faixa etária de 11 a 14 anos $(30,7 \%)$ e na faixa etária de 15 a 18 anos (50\%). Montilha (2001) observou, entre as causas de repetência por escolares, o pouco preparo dos professores para o trabalho com alunos com deficiência visual e as dificuldades dos alunos em utilizarem o próprio resíduo visual. A repetência e o atraso na escolaridade podem relacionar-se com o desconhecimento dos professores, da família e do próprio escolar quanto ao seu potencial visual e os recursos existentes para seu benefício nas atividades escolares.

A principal dificuldade do escolar referida pelo responsável foi para realização de leitura na lousa e de livros (Tabela 39) Como discutido anteriormente, a dificuldade visual maior da criança é para distâncias longas já que, para perto, realiza a ampliação por aproximação do livro e foca a imagem por meio da acomodação. Dessa forma, o uso de auxílios ópticos para longe foi maior do que para perto. (Tabela 35)

A queixa de que o professor não compreendia o quadro visual do aluno e não colaborava na realização de tarefas (Tabela 39), indica a falta de preparo por parte do professor para atuar junto ao aluno com baixa visão.

Gasparetto et al (2001b) observaram que apesar de professores do ensino fundamental terem mostrado conhecimento de sinais e sintomas de dificuldades visuais, o conhecimento quanto à atuação junto ao aluno com baixa visão não existia. 
Hyvarinen (1998) afirmou que a baixa visão trouxe uma complexidade maior à educação especial; pois, enquanto a educação da pessoa cega é similar em todos os serviços, a educação do aluno com baixa visão é individualizada, de acordo com seu grau de deficiência e incapacidade visual, e requer a utilização de variados recursos nas suas atividades diárias. A escolha desses recursos requer a avaliação e o conhecimento de suas potencialidades.

Deve, portanto, haver maior integração do oftalmologista com o professor da classe comum para que informações precisas sobre a condição visual do aluno e sua funcionalidade sejam esclarecidas. O professor deve também ter conhecimentos básicos de como ajudar o aluno a utilizar melhor o auxílio óptico prescrito e como poderá modificar materiais e condições do ambiente para que o meio escolar seja propício para o desenvolvimento das potencialidades do aluno.

Gasparetto et al (2001b) apontaram a necessidade da capacitação de professores do sistema regular de ensino e dos diferentes profissionais que integram as áreas de saúde e educação visando ao preparo para a atuação junto ao aluno com baixa visão, que pode ser realizada por meio de parcerias entre universidades, serviços especializados e escolas.

Outras dificuldades escolares relatadas, como a falta de motivação, necessidade de tempo maior para realização de tarefas, dificuldade de alfabetização, excesso de claridade na lousa e preconceito por parte dos colegas poderão ser contornadas a partir da capacitação efetiva de professores para atuar com o aluno com baixa visão e também por medidas educativas da família e da comunidade sobre a deficiência visual. 
O recebimento de benefícios concedidos pelos órgãos governamentais ocorria em $61,7 \%$ da população (Tabela 40 ). Muitos dos benefícios auxiliam a família nos cuidados com a criança com baixa visão: isenção de tarifas para transportes coletivos, isenção de mpostos estaduais e federais e benefícios previdenciários.(Bolonhini Junior, 2004) Cabe ao profissional da área médica ou de reabilitação informar esses direitos à família. Importante ressaltar o papel do oftalmologista na confecção de laudos médicos que definirão o recebimento do benefício, de acordo com os preceitos legais, éticos e com base na legislação vigente no país. 


\section{CONCLUSÕES}




\subsection{Quanto aos aspectos clínicos referentes à população com baixa visão em idade escolar:}

- as principais causas da deficiência visual foram a retinocoroidite macular bilateral por toxoplasmose congênita, a catarata congênita, o albinismo oculocutâneo e o glaucoma congênito;

- a retina foi a principal localização da afecção ocular causadora da deficiência visual;

- as principais etiologias da deficiência visual foram hereditárias e pré-natais infecciosas;

- as classes de deficiência visual moderada e grave foram mais freqüentes;

- a sensibilidade ao contraste apresentou-se diminuída na maior parte dos casos;

- a amplitude do campo visual estava preservada na maioria dos escolares;

- a visão de cores era normal na maioria dos casos;

- as ametropias foram corrigidas na maior parte dos casos; 
- a correção óptica da ametropia foi prescrita para todos os casos de retinocoroidite macular bilateral, de amaurose congênita de Leber, de albinismo oculocutâneo, de retinose pigmentar, de Doença de Stargardt e de retinopatia da prematuridade;

- na maior parte dos casos de glaucoma congênito e nistagmo congêntio houve a prescrição da correção óptica de ametropias;

- todos os casos de afacia pós-cirúrgica de catarata congênita chegaram à avaliação com a correção óptica em uso;

- os auxílios ópticos para longe foram mais prescritos que os auxílios ópticos para perto;

- os auxílios ópticos para perto foram receitados principalmente nos casos de ausência da acomodação, como na afacia e pseudofacia após a cirurgia para catarata congênita;

- os sistema telescópicos de $6 \mathrm{X}$ de ampliação e de $4 \mathrm{X}$ de ampliação foram os mais prescritos;

- a barra de leitura de 2 X de ampliação foi o auxílio óptico para perto mais prescrito;

- os auxílios ópticos para longe e para perto foram mais indicados nas classes de deficiência visual moderada e grave;

- nas classes de deficiência visual com valores próximos à cegueira, não houve indicação de auxílios ópticos;

- encaminhamentos para avaliação educacional com profissionais especializados em deficiência visual foram realizados para todos os escolares; 
- encaminhamentos a programas de avaliação e atendimento na área de orientação e mobilidade foram realizados, principalmente, para os escolares com diminuição da amplitude do campo visual e/ou com valores de acuidade visual próximos à cegueira.

\section{2 Quanto à percepção de mães ou responsáveis:}

- a mãe foi a pessoa que percebeu primeiro e mais precocemente a dificuldade visual, na maioria dos casos;

- a escola foi importante na detecção de problemas visuais nos escolares com baixa visão, quando não houve a observação por parte da família;

- o pediatra, em vários casos, mostrou-se despreparado para a detecção de problemas visuais, tratamentos, orientação à família e encaminhamentos pertinentes;

- o oftalmologista, como primeiro profissional de saúde procurado, realizou o diagnóstico na maior parte das vezes;

- o sistema público de saúde respondeu por mais da metade das primeiras avaliações oftalmológicas;

- a queixa referida pelo atraso na avaliação oftalmológica no sistema público de saúde, logo após a identificação da dificuldade visual, foi a dificuldade para agendamento em alguns casos; 
- a maior parte dos casos foi avaliada pelo oftalmologista até 6 meses depois de observada a dificuldade visual;

- a maior parte considerou ser fácil conseguir consulta oftalmológica nos serviços públicos e privados conjuntamente;

- diagnosticou-se a baixa visão no primeiro ano de vida em mais da metade dos casos;

- o encaminhamento a serviços de reabilitação visual foi realizado tardiamente ao diagnóstico e ocorreu principalmente na idade escolar;

- o principal responsável pelo encaminhamento a serviços de reabilitação foi o oftalmologista;

- a menor parte dos escolares havia sido atendida por outro serviço de reabilitação visual previamente ao encaminhamento à Laramara ou ao SVSN HCFUMSP;

- apesar da existência de outros serviços terciários de reabilitação visual na cidade de São Paulo, a maior parte dos responsáveis não tinha conhecimento dos mesmos;

- a vergonha para usar os auxílios ópticos foi a principal justificativa para a rejeição dos mesmos por escolares que já tinham o recurso;

- a maior parte dos responsáveis teve dificuldade em adquirir o auxílio óptico prescrito pelo seu custo alto ou por não encontrarem os produtos disponíveis para a compra;

- quanto às dificuldades escolares, enxergar na lousa foi referida como a principal limitação do escolar com baixa visão; 
- todos as crianças em idade escolar estavam inseridas no sistema regular de ensino;

- algumas crianças e adolescentes apresentavam defasagem na escolaridade;

- a maior parte dos escolares recebiam algum benefício doado por entidade governamental por causa de deficiência visual.

\subsection{Quanto aos subsídios para desenvolvimento de ações para habilitação/reabilitação visual, apontou-se a necessidade de:}

- programas para detecção precoce de problemas visuais na infância, por meio de capacitação de pediatras quanto aos principais aspectos de saúde ocular para o encaminhamento a serviços de oftalmologia;

- programas para detecção de problemas oculares na idade escolar,com parceria entre as áreas da saúde e da educação, como a "Campanha Olho no Olho";

- capacitação de professores do sistema regular de ensino, quanto aos aspectos da saúde ocular e da baixa visão no escolar;

- maior acesso a auxílios ópticos prescritos à pessoa com baixa visão, por meio de políticas públicas para diminuição de encargos 
tributários sobre produtos importados e de desenvolvimento de recursos de custo reduzido;

- educação continuada de oftalmologistas para atuação na área da baixa visão, principalmente, nos cursos de especialização em oftalmologia credenciados pelo Conselho Brasileiro de Oftalmologia e Associação Médica Brasileira;

- desenvolvimento de recursos e de materiais para avaliação oftalmológica do escolar com baixa visão, de menor custo e maior acesso;

- desenvolvimento de parcerias entre o oftalmologista, a família e a escola para melhor atendimento às necessidades do escolar com baixa visão, criando compromisso para sua inclusão educacional e social;

- maior divulgação das implicações da baixa visão na infância e dos serviços disponíveis na comunidade. 


\section{ANEXOS}


ANEXO A - QUESTIONÁRIO

Habilitação e reabilitação visual de escolares com baixa

visão: aspectos médico-sociais

Questionário

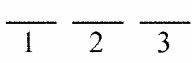

Pesquisador: MARIA APARECIDA ONUKI HADDAD

1. O que o (a) Sr. (a) é da criança?

Mãe (1)

Pai (2)

Avó (

(4) O que?

Outro (4) que?

2. O Sr. (pai da criança) trabalha e ganha pelo que faz?

Sim __ (1) ECA: O que faz?

Não _(2)

3. A Sra. (mãe da criança) trabalha e ganha pelo que faz?

Sim (1) ECA: O que faz?

Não

4. Até que ano a Sra (ou a mãe da criança) estudou ou estuda na escola,sim ou não? ECA: Até que série estudou ou estuda em que série?

Não

Sim

ensino fundamental

série

ensino médio

série

ensino superior

completo

incompleto

não estudou

5. Até que ano a Sra (ou a mãe da criança) estudou ou estuda na escola,sim ou não? ECA: Até que série estudou ou estuda em que série?

Não

Sim 
ensino fundamental

série

ensino médio

série

ensino superior

completo

incompleto

não estudou

6. Os pais da criança moram juntos, sim ou não? ECA: A criança vive com eles?

Moram juntos: pai, mãe e filho(s)

A criança mora apenas com a mãe e outros familiares

A criança mora apenas com o pai e outros familiares

A criança não mora com a mãe ou com o pai

7. De quem é a responsabilidade principal do sustento da casa?

apenas do pai?

apenas da mãe?

do pai e da mãe em conjunto

de outros familiares?

do pai, da mãe e de outros familiares?

do pai e de outros familiares?

da mãe e de outros familiares?

8. Quem percebeu primeiro que a criança parecia ter problema para enxergar?
Mãe
Pai
Avó
Professora
Outros familiares
Outra pessoa
(6)Quem?

9. Que idade tinha a criança tinha quando foi suspeitado que ela não enxergava bem?

Meses: 
10. Ela foi levada ao médico por causa desse problema de vista depois que foi suspeitado?

Sim (1)

Não

11. Para que médico ela foi levada: pediatra, oculista, para os dois? Ou foi para outro médico?

\section{Pediatra}

$\operatorname{Sim}(1) \quad N a ̃ o(2)$

Oculista

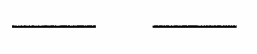

Outro médico
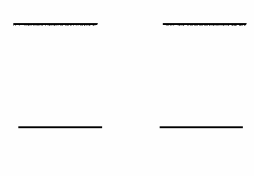

12. O que o médico disse sobre o problema de vista?

- idade do diagnóstico:

13. Onde a criança foi atendida por oculista pela primeira vez: no Posto de Saúde, em hospital público por convênio ou em consultório particular?

posto de saúde
hospital público
convênio
consultório particular
não lembra

14. Depois de suspeitado o problema da vista, quanto tempo levou para a criança ser atendida pela primeira vez por oculista: logo depois, 6 meses depois ou mais do que 6 meses depois?

Logo depois (1)

6 meses depois

mais do que 6 meses depois

Por quê levou mais de 6 meses? 
15. Para a criança ser atendida foi muito fácil, mais ou menos fácil, pouco fácil ou nada fácil? Ou o Sr(a) não lembra?

muito fácil

mais ou menos fácil

pouco fácil

nada fácil

não lembra

16. Há quanto tempo a criança é atendida por este serviço?

(tempo)

17. Quem encaminhou para o atendimento neste serviço?

18. Foi atendida antes em outro serviço para deficiência visual?

Sim (1) ECA: Qual?

Não (2) (serviço)

19. $\mathrm{O}(\mathrm{a}) \mathrm{Sr}(\mathrm{a})$ sabe se existem outros serviços para atender criança com deficiência visual, além deste serviço, sim ou não?

$\operatorname{Sim}(1)$

Não

20. A criança está estudando? ECA: em que série ela está?ECN: Porque não está estudando?
Sim (1) Série:

Não (2) Porque?

21. Se ela está estudando, têm dificuldade na escola? ECA: Qual?

Sim (1)

Não (2)

Qual(is)?

22. A criança tem lupas especiais para ver de longe, sim ou não? ECA: ela usa bem, ela tem dificuldade para usar, ela não gosta de usar porque acha feio, ela não gosta de usar porque acha que não ajuda muito?

Sim (1)

Não $\quad(2)$ 
Ela usa bem?

Ela tem dificuldade para usar?

Não gosta de usar porque acha feio?

Não gosta de usar porque não ajuda?

Não usa por outro motivo?

$$
\operatorname{Sim}(1) \text { não(2) }
$$

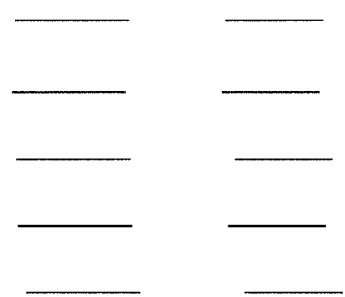




\section{$\operatorname{Sim}(1) \quad$ Não(2)}

Era muito caro, sim ou não?

Não sabia onde comprar, sim ou não?

Não encontrou para comprar, sim ou não?

A lupa foi doada, sim ou não?

25. A criança recebe algum tipo de benefício do governo? ECA:Qual(is)? Carteira de passageiro especial, sim ou não? Passe livre, sim ou não? Benefício pela deficiência, sim ou não? ECN: não sabia dos benefícios? Pediu mas a criança não tem direito?Ainda não foram solicitados? Não precisa dos benefícios?

$\operatorname{Sim}$

Não

(2)

Carteira de passageiro especial, sim ou não?

$$
\operatorname{Sim}(1) \quad \text { não(2) }
$$

passe livre, sim ou não?

benefício mensal pela deficiência, sim ou não?

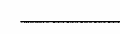

\begin{tabular}{c}
\hline 47 \\
\hline 48 \\
\hline 49 \\
\hline 50
\end{tabular}

Outro, sim ou não? 
ANEXO B

Avaliação $\frac{1}{2} \frac{}{3}$

HABILITAÇÃO E REABILITAÇÃO VISUAL DE ESCOLARES COM BAIXA VISÃO: ASPECTOS MÉDICO-SOCIAIS

DADOS OFTALMOLÓGICOS

\section{DIAGNÓSTICO (ANATÔMICO E ETIOLÓGICO)}

$\underline{O D}$

OE

2. ETIOLOGIA DA DEFICIÊNCIA VISUAL:

Olho direito Olho esquerdo

Confirmado suspeita confirmado suspeita

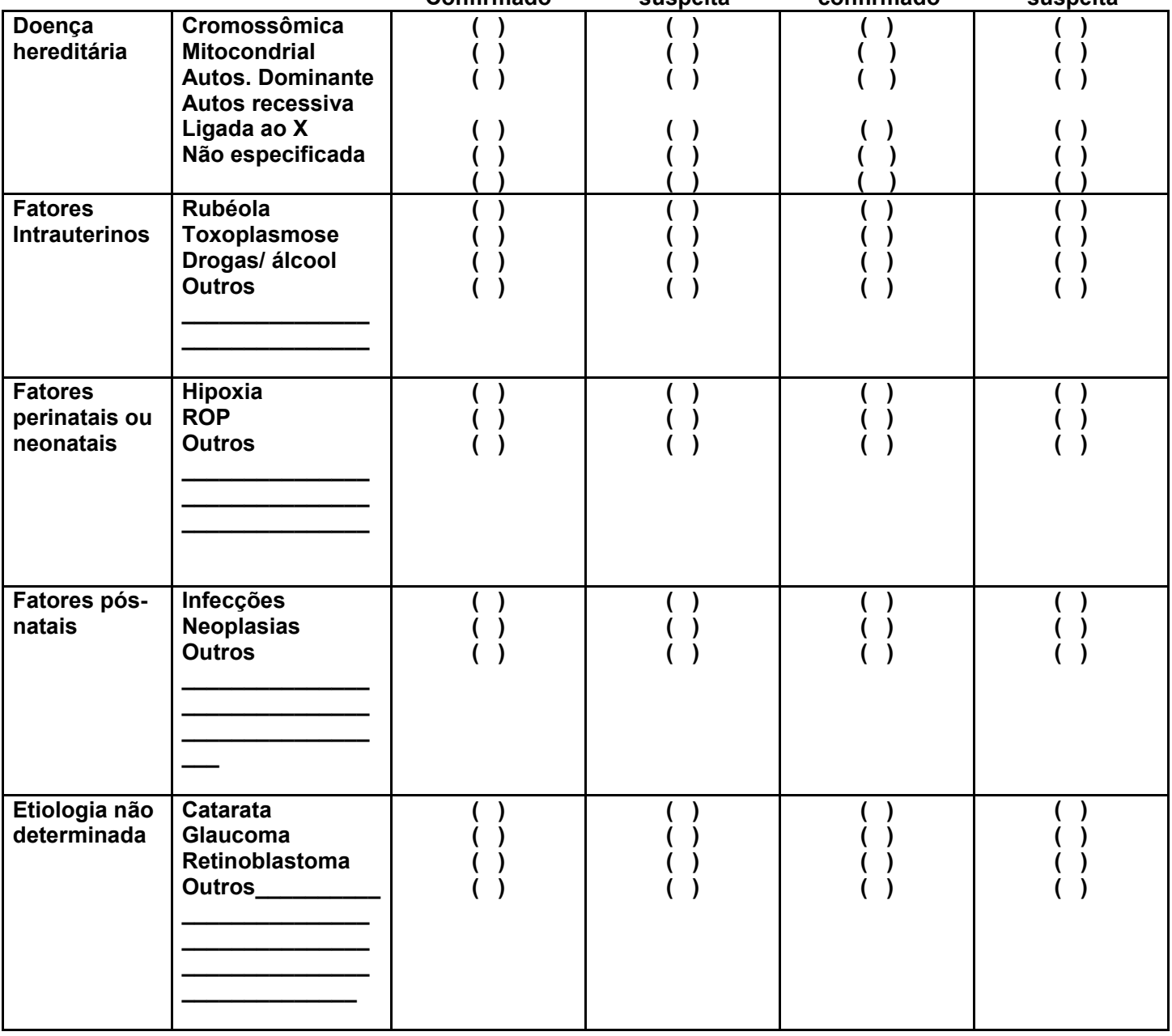

Principal etiologia da deficiência visual: 
3. LOCAL DA ANORMALIDADE QUE LEVOU À DIFICULDADE VISUAL

Olho direito

Olho esquerdo

\begin{tabular}{|c|c|c|c|c|}
\hline & Principal & secundário & principal & secundáric \\
\hline $\begin{array}{l}\text { Globo ocular } \\
\text { Phthisis } \\
\text { Anoftalmia } \\
\text { Microftalmia } \\
\text { Buftalmia } \\
\text { Glaucoma } \\
\text { Eviscerado } \\
\text { Desorganizado } \\
\text { Outro } \\
\end{array}$ & 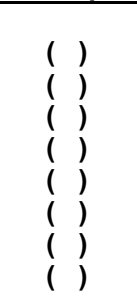 & 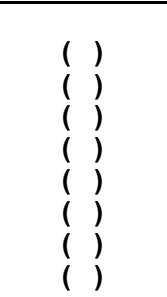 & 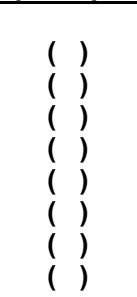 & 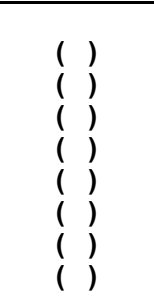 \\
\hline $\begin{array}{l}\text { Córnea } \\
\text { Estafiloma } \\
\text { Ulcera } \\
\text { Ceratocone } \\
\text { Distrofia } \\
\text { Outra } \\
\text { opacidade }\end{array}$ & 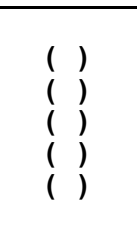 & 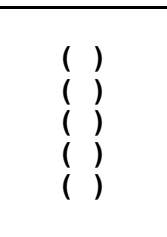 & 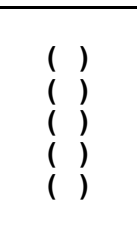 & 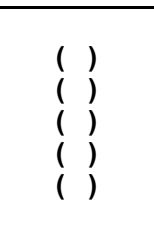 \\
\hline $\begin{array}{l}\text { Cristalino } \\
\text { Catarata } \\
\text { Afacia } \\
\text { Ectopia } \\
\text { Outros }\end{array}$ & $\begin{array}{l}() \\
() \\
()\end{array}$ & 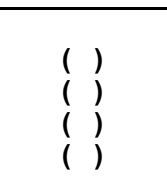 & $\begin{array}{l}\text { () } \\
() \\
()^{\prime}\end{array}$ & 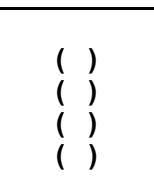 \\
\hline $\begin{array}{l}\text { Úvea } \\
\text { Aniridia } \\
\text { Coloboma } \\
\text { Uveíte } \\
\text { Outro }\end{array}$ & 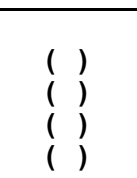 & 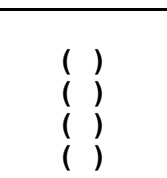 & $\begin{array}{l}() \\
() \\
()\end{array}$ & $\begin{array}{l}\left(\begin{array}{l}1 \\
() \\
()\end{array}\right. \\
()\end{array}$ \\
\hline $\begin{array}{l}\text { Retina } \\
\text { Distrofia } \\
\text { Albinismo } \\
\text { ROP } \\
\text { Retinoblastoma } \\
\text { Outro } \\
\end{array}$ & $\begin{array}{l}(1) \\
() \\
()\end{array}$ & $\begin{array}{l}() \\
() \\
()\end{array}$ & $\begin{array}{l}() \\
() \\
()\end{array}$ & $\begin{array}{l}() \\
() \\
()\end{array}$ \\
\hline $\begin{array}{l}\text { Nervo óptico } \\
\text { Atrofia } \\
\text { Hipoplasia } \\
\text { Outro }\end{array}$ & $\begin{array}{l}\text { () } \\
(\text { ) }\end{array}$ & $\begin{array}{l}\text { () } \\
(\text { ) }\end{array}$ & $\begin{array}{l}() \\
(\text { ) }\end{array}$ & $\begin{array}{l}\text { () } \\
(\text { ) }\end{array}$ \\
\hline Outros & ( ) & ( ) & ( ) & ( ) \\
\hline $\begin{array}{l}\text { Globo sem } \\
\text { alterações } \\
\text { Erro de refração } \\
\text { Ambliopia } \\
\text { DVC } \\
\text { Nistagmo } \\
\text { idiopático } \\
\text { Visão normal } \\
\end{array}$ & 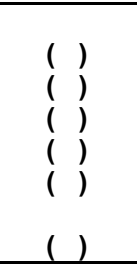 & 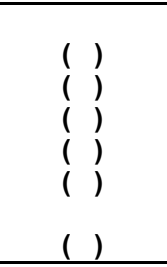 & 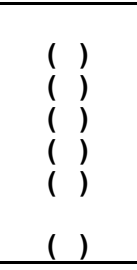 & 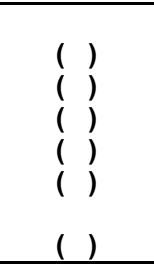 \\
\hline
\end{tabular}




\section{FUNČ̃̃ VISUAL}

\section{- $\quad$ Acuidade visual}

\begin{tabular}{|c|c|c|c|c|c|c|c|}
\hline Classes de resposta visual & Valores de acuidade visual & $\begin{array}{l}O D \\
S C\end{array}$ & $\begin{array}{l}O E \\
S C\end{array}$ & $\begin{array}{l}A O \\
S C\end{array}$ & $\begin{array}{l}O D \\
C C\end{array}$ & $\begin{array}{l}O E \\
C C\end{array}$ & $\begin{array}{l}A O \\
C C\end{array}$ \\
\hline Visão próxima ao normal & $20 / 32,20 / 40,20 / 50,20 / 63$ & & & & & & \\
\hline Deficiência visual moderada & $20 / 80,20 / 100,21 / 125,20 / 160$ & & & & & & \\
\hline Deficiência visual grave & $20 / 200,20 / 250,20 / 320,20 / 400$ & & & & & & \\
\hline Deficiência visual profunda & $20 / 500,20 / 630,20 / 800,20 / 1000$ & & & & & & \\
\hline Próxima à cegueira & $\begin{array}{l}\text { 20/1250, 20/1600, 20/2000, 20/2500 } \\
\text { Percepção de luz }\end{array}$ & & & & & & \\
\hline \multicolumn{8}{|l|}{ Cegueira } \\
\hline & & & & & & & \\
\hline
\end{tabular}

\section{- $\quad$ Acuidade visual para perto}

$\begin{array}{ll}\text { ODsc } & c c \\ \text { OEsc } & c c \\ \text { AOsc } & c c\end{array}$

\section{- Sensibilidade ao contraste:}

\section{- $\quad$ Visão de cores}

\section{- $\quad$ Campo visual}

\section{CORREÇÃO ÓPTICA}

\section{- Refração}

OD

OE

- Correção óptica em uso

OD

$\mathrm{OE}$ EE AV

EE AV 


\section{AUXÍLIOS ÓPTICOS}

- $\quad$ Em uso

Para longe:

OD

OE

AV

Para perto:

OD

$\mathrm{OE}$

AV

AV

AV

- Indicados

Para longe:

OD

AV

$\mathrm{OE}$

AV

Para perto:

$\mathrm{OD}$

$\mathrm{OE}$ AV

AV

\section{NECESSIDADES ATUAIS:}

\section{- Ópticas:}

( ) Correção óptica Auxílios ópticos

( ) indicado, nunca usou

( ) atualização ( ) não indicada ( ) mantida Outros ( ) indicado, nunca usou

- Áreas de reabilitação multidisciplinar:

( ) atendimento e orientações em programas educacionais

( )Outro Especificar

\section{- Outras:}

( ) Especificar: 


\section{ANEXO C}

\section{TERMO DE CONSENTIMENTO LIVRE E ESCLARECIDO}

Estamos realizando uma pesquisa sobre a deficiência visual na idade escolar. Para isso, gostaríamos de contar com o seu consentimento para realizar a avaliação oftalmológica de seu filho(a) e de sua colaboração para responder a um questionário sobre problemas da deficiência visual na infância.

Gostaríamos de deixar claro que esta pesquisa é independente do atendimento de seu filho(a) neste serviço e ele(a) não será prejudicado(a) caso o(a) senhor(a) não concorde em participar.

Asseguramos que todas as informações prestadas pelo(a) senhor(a) e os dados do exame oftalmológico são sigilosas e serão utilizadas somente para esta pesquisa. Garantimos o anonimato das informações.

$\mathrm{O}(\mathrm{a})$ senhor(a) é livre para cancelar sua participação neste estudo, a qualquer momento, sem qualquer prejuízo para o(a) senhor(a) ou para a sua criança.

Data

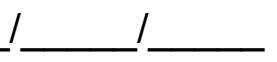

Nome do escolar avaliado:

Nome do responsável entrevistado:

Assinatura do responsável:

Nome do pesquisador:

Assinatura do pesquisador: 


\section{ANEXO D}

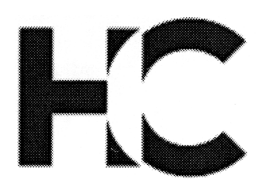

\section{APROVAÇÃO}

A Comissão de Ética para Análise de Projetos de Pesquisa - CAPPesq da Diretoria Clínica do Hospital das Clínicas e da Faculdade de Medicina da Universidade de São Paulo, em sessão de 14.09.05, APROVOU o Protocolo de Pesquisa $n^{\circ}$ 789/05, intitulado: "Habilitação e reabilitação visual de grupo populacional de idade escolar: aspectos médico-sociais" apresentado pelo Departamento de OFTALMOLOGIA E OTORRINOLARINGOLOGIA, inclusive o Termo de Consentimento Livre e Esclarecido.

Cabe ao pesquisador elaborar e apresentar à CAPPesq, os relatórios parciais e final sobre a pesquisa (Resolução do Conselho Nacional de Saúde $n^{\circ} 196$, de 10.10.1996, inciso IX. 2, letra "c")

Pesquisador(a) Responsável: Prof. Dr. Newton Kara José

Pesquisador (a) Executante: Dra. Maria Aparecida Onuki Haddad

CAPPesq, 14 de Setembro de 2005.

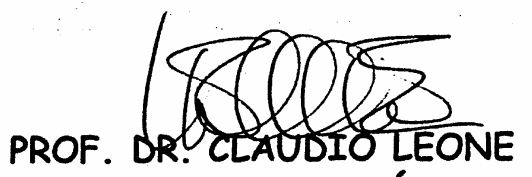

Vice-Presidente da Comissão de Ética para Análise de Projetos de Pesquisa

\footnotetext{
Comissāo de Ética para Análise de Projetos de Pesquisa do HCFMUSP e da FMUSP Diretoria Clínica do Hospital das Clínicas da Faculdade de Medicina da Universidade de São Paulo Rua Ovídio Pires de Campos. 225, $5^{\circ}$ andar - CEP 05430010 - São Paulo - SP Fone: 011 - 30696442 fax: 011 - 30696492 - e-mail : cappesq@hcnet.usp.br / secretariacappesq2@hcnet.usp.br 
Abreu MT, Belfort Jr. R, Oréfice F. Toxoplasmose. In: Oréfice F, Belfort Jr R. Uveítes. São Paulo: Roca; 1987. p 213-30.

Amiralian MLTM. Compreendendo o cego: uma visão psicanalítica da cegueira por meio de desenhos-estórias. São Paulo: Casa do Psicólogo, 1997.

Arieta CEL, Kara-José N. Catarata congênita: dificuldades no tratamento. Arq Bras Oftalmol. 1987;50(3):116

Armond JE, Temporini ER. Crenças sobre saúde ocular entre professores do sistema público de ensino no Município de São Paulo. Rev Saúde Pública. 2000;34:9-14.

Arruda SMCP. Percepções de auto-eficácia nas atividades de vida diária e qualidade de vida de estudantes com baixa visão e cegueira [tese]. Campinas: Universidade Estadual de Campinas; 2006.

Barraga NC. Rehabiltation of low vision. In: $V$ International Conference on Low Vision Proceedings. Madrid, 1996;2: 93-9.

Betinjane AJ. Glaucoma infantil.In: Susanna Jr R. Glaucoma. 1a ed. Rio de Janeiro: Cultura Médica; São Paulo:Ciba Vision:CBO; 1999. p 145-79.

Bishop VE. Identifyng the components of success in mainstreaming. JVisual Impairm \& Blindness 1986;80:253-60.

Boer MR, Moll AC, Vet HCW, Terwee CB, Völker - Dieben HJM, Van Rans GHMB. Psychometric properties of vision - related quality of life questionnaires: a systematic review. Ophthal Physiol Opt. 2004; 24:257-273.

Bolonhini Junior R. Portadores de necessidades especiais. 1a ed. São Paulo: Arx, 2004.

Brohier W- Low vision: Four perspectives. A professional viewpoint. The Educator, 1990.

Bruno MMG. Deficiência visual: reflexão sobre a prática pedagógica. São Paulo: Laramara; 1997.

Bruno MMG. O significado da deficiência visual na vida cotidiana: análise das representações dos pais-alunos-professores[dissertação]. Campo Grande: Universidade Católica Dom Bosco; 1999. 
Carani JCE, Betinjane AJ, Carvalho CA. Método (Fórmula) para o cálculo da refração ocular no glaucoma congênito. Arq. Bras. Oftalmol. 1994;25:137-40.

Carvalho KM, Minguini N, Moreira Filho D, Kara-José N. Characteristics of a pediatric low-vision population. J.Pediatr. Ophthalmol.Strabismus 1996; 35: 162-5.

Carvalho KMM, Venturini NHB, Melo HFR, Venturini TBP, Shiroma LO, Buono CL. Eficácia das condutas de um serviço de visão subnormal. Arq. Bras.Oftal. 1998;61:684-9.

Carvalho KMM, Freitas CC, Kimolto EM, Gasparetto MERF. Avaliação e conduta em escolares portadores de visão subnormal atendidos em sala de recursos. Arq Bras Oftalmol 2002;65:445-9

Castro DDM. Visão Subnormal. Rio de Janeiro: Cultura Médica; 1994.

Catalano RA, Nelson LB - Pediatric Ophthalmology. Norwalk, Appleton\&Lange, 1994.

Cohen J A. An overview of enhancement techniques for peripheral field loss. J. Am. Optom. Assoc. 1993; 64(1):60-70.

Cole RG , Rosenthal BP. Remediation and Management of Low Vision. New York: Mosby, 1996.

Colenbrander A, Fletcher D C. Low vision rehabilitation. A study guide and outline for ophthalmologists, residents and allied health personnel., Anaheim: JCAHPO, 2003.

Conceição JAN. Saúde escolar: a criança, a vida e a escola. São Paulo: Sarvier, 1994.

Corde. Declaração de Salamanca e linha de ação sobre necessidades educativas especiais. Brasília: Corde, 1994.

Costa Filho HA, Berezovsky A. Análise crítica do desempenho evolutivo da visão subnormal no Instituto Benjamin Constant. Arq Bras Oftalmol. 2005;68(6):815-20

Culham LE, Ryan B, Jackson AJ, Jones B, Miles C, Young JÁ, Bunce C Bird AC. Low vision services for vision rehabilitation in the United Kingdom. $\mathrm{Br} J$ Ophthalmol. 2002; 86:743-747.

Daw N. Visual Development. New York: Plenm Press. 1995

Du JW, Schimid K, Bevan JD, Frater KM, Ollet R, Hein B. Retropective analysis of refractive errors in children with vision impairment. Optom Vis Sci 2005;82:807-16.

Eckstein MB, Foster A, Gilbert CE. Causes of childhood blindness in Sri Lanka: results from children attending six schools for the blind. Br J Ophthalmol 1995; 79: 633-636. 
Ellwein LB, Fletcher A, Negrel AD et al. Quality of life assessment in blindness prevention interventions. Int Ophthalmol 1995; 18:263-268.

Faye EE - El enfermo com deficit visual. Barcelona: Editorial Cientifico-Médica, 1972.

Faye EE - Clinical Low Vision. $2^{\text {nd }}$ ed. New York, Little, Brown and Company, 1984.

Faye EF, Albert DL, Freed B, Seidman K, Fischer M. A new look at low vision care. New York: Lighthouse International, 2000.

Fernandes LC, Jacobovitz S. Sistema telescópico de custo reduzido I. Telescópio de baixo custo: uma adequação à realidade brasileira. In: Sampaio MW, Haddad MAO, Kara-José N. Auxílios para baixa visão. São Paulo: Laramara; 2001. p 45-8

Ferris LF, Kassoff A, Bresnick GH, Bailey I - New visual acuity charts for clinical research. Am. J. Ophthalmol. 94: 91-6, 1982.

Fonda G. Most useful visual aids for the partially sight. In: Woo G. Low vision principles and applications. Waterloo: Springer-Verlag; 1986. p 232-42.

Fonda G. Management of the patient with subnormal vision. Saint Louis: The C.V. Mosby Company, 1965.

Foster A, Gilbert C, Rahi J. Epidemiology of cataract in childhood: a global perspective. J. Cataract Refract. Surg. 1997;23:601-4.

Foster A, Gilbert C. - Epidemiology of childhood blindness. Eye 1992; 6:173-6.

Freeman PB, Jose RT. The art and practice of low vision . $2^{\text {nd }}$ ed. Newton: Butterworth - Heineman, 1997.

Fuller D G, Birch D G. Assessment of visual function for the clinician. Ophthalmol Clin North Am, 1989; 2(3).

Garcia N. Programas de Orientação e Mobilidade no processo de educação da criança portadora de cegueira [tese]. São Paulo: Faculdade de Educação, Universidade de São Paulo; 2001.

Gasparetto MERF. Visão subnormal em escolas públicas: Conhecimento, opinião e conduta de professores e diretores do ensino fundamental [tese]. Campinas: Faculdade de Ciências Médicas da Universidade Estadual de Campinas; 2001a.

Gasparetto MERF, Temporini ER, Carvalho KMM et al. O aluno portador de visão subnormal na escola regular: desafio para o professor? Arq. Bras. Oftamol. 2001b; 64:45-51.

Gasparetto MERF, Temporini ER, Carvalho KMM, Kara-José N. Dificuldade visual em escolares: conhecimentos e ações de professores do ensino fundamental que atuam com alunos que apresentam visão subnormal. Arq. Bras. Oftalmol., 2004; 67:65-71. 
Gieser JP. When Treatment fails. Caring for patients with visual disability. Arch. Ophthalmol. 2004; 122: 1208-1209.

Gilbert C, Awan H - Blindness in children. BMJ. 2003;327:760-1

Gilbert C, Canovas R, Canovas RK et al. Causes of blindness and severe visual impairment in children in Chile. Dev Med Child Neurol 1994 36:326-33.

Gilbert C, Foster A, Negrel AD et al. Childhood blindness: a new form for recording causes of visual loss in children. Bull. World Health Organ. 1993; 71:485-9

Gilbert CE, Foster A. Childhood blindness in the context of VISION 2020 - The right to sight. Bull. World Health Organ. 2001a; 79:227-32.

Gilbert C, Foster A. Blindness in children: Control priorities and research opportunities. Br. J. Ophthalmol. 2001b; 85:1025-27.

Goodman R. The strengths and difficulties questionnaire: a research note. $J$ Child Psychol Psychiat 1997; 38:581-6.

Green J, Siddall H, Murdoch I. Learning to live with glaucoma: a qualitative study of diagnosis and the impact of sight loss. Soc. Sci. Med. 2002; 55: 257-267.

Gwiazda J, Thorn F, Bauer J, Held R. Invest. Ophthalmol. Vis. Sci. 1993;34:690-4.

Haddad MAO, Sei Mayumi, Sampaio MW, Kara-José N. Causes of visual impairment in children: Study of 3210 cases. J. Pediatr. Ophthalmol. Strabismus. In press 2006 a

Haddad MAO, Lobato FJC, Sampaio MWS, Kara-José N. População infantil e adolescente com deficiência visual: estudo de 385 casos. Clinics. In press $2006 \mathrm{~b}$

Haddad MAO, Sampaio MW, Kara-José N. Baixa visão na infância. Manual Básico para oftalmologistas. São Paulo: Laramara; 2001.

Haddad MAO, Sampaio MW, Oltrogge E, Betinjane AJ, Kara-José N. População infantil com baixa visão secundária ao glaucoma congênito: resposta visual, correção óptica e auxílios ópticos. Arq. Bras. Oftalmol.2000; 63- supl: 42 (Apresentado no $14^{\circ}$ Congresso Brasileiro de Prevenção da Cegueira e Reabilitação Visual; 6 a 10 de setembro de 2000; Natal, Rio Grande do Norte . Resumos)

Haddad MAO, Sei M, Sampaio MWS, Kara-José N. Retinopatia da prematuridade Estudo de 210 casos com deficiência visual. Arq. Bras. Oftalmol. 2003; 66(4 supl.): 74. (Apresentado no $32^{\circ}$ Congresso Brasileiro de Oftalmologia. 10 a 13 de setembro de 2003. Salvador. BA. Resumo)

Haddad MAO, Braga AP, Sei M, Sampaio MW, Kara-José N. Sistema telescópico de custo reduzido II. In: Sampaio MW, Haddad MAO, Kara-José N. Auxílios para baixa visão. São Paulo: Laramara; 2001. p 49-52 
Haddad MAO, Sei M, Braga AP, Sampaio MW, Kara-José N. Causes of visual impairment in childhood and adolescence: a retrospective study of 1917 cases. In: Stuen C, Arditi A, Horowitz A., Lang MA et al. Vision Rehabilitation - Assessment, Intervention and Outcomes, New York: Swets \& Zeitlinger, 2000a: 371-5.

Haddad MAO, Sei M, Braga AP, Sampaio MW, Kara-José N. Low cost telescopic system: its effectiveness in cases of macular retinochoroiditis due to congenital toxoplasmosis. In: Stuen C, Arditi A, Horowitz A., Lang MA et al. Vision Rehabilitation - Assessment, Intervention and Outcomes. New York: Swets \& Zeitlinger, 2000b: 195-9.

Hassell JB, Keeffe JE - A measure of handicap for low vision rehabilitation: the impact of vision impairment profile. Clin. Experiment. Ophthalmol. 2000; 28: 156-61.

Haynes AS, Johnston AW, Heyes AD. Relationship between vision impairment and ability to perform activities of daily living. Ophthal. Physiol. Opt. 2002; 22: 79-91.

Herring J. Adjusting to your child's visual impairment. In:Holbrook MC.Children with visual impairments: a parent's guide. New York:Woodbine House, 1996.

Hinds A, Sinclair A, Park J, Suttie A, Palerson H, Macdonald M. Impact of na interdisciplinary low vision service on the quality of life of low vision patients. $\mathrm{Br}$. J. Ophthalmol .2003; 87: 1391-1396.

Hyvärinen L. $\quad O$ desenvolvimento normal e anormal da visão. São Paulo:Laboratórios Aché, 1988.

Hyvärinen L. The LH symbol tests. A system for vision testing in children. New York: Lighthouse Low Vision Products;1992.

Hyvärinen L. Quantitative color vision test. PV-16 manual. Villa Park:Precision Vision; 1993.

Hyvärinen L. - Assessment of low vision for educational purposes. Part 1. La Salle: Precision Vision, 1998.

IBGE. Instituto Brasileiro de Geografia e Estatística. Indicadores sociais mínimos [citado 10 jun 2006]. Disponível em: http://www.ibge.gov.br

International Council of Ophthalmology. Visual Standards - Aspects and ranges of vision loss. ICO Report. Sydney, 2002.

International Council of Ophthalmology. Low vision rehabilitation. Guidelines and Standards for Education of an Ophthalmologist: [cited 2006 jun 5] Available from: www.icoph.org/ed/res15lowvision.html

International Society for Low-vision Research and Rehabilitation. Toward a reduction in the global impact of low vision. Oslo: ISLVRR, 2005 .

Jose RT. Vision Subnormal. Madrid: Organizacion Nacional de Ciegos Españoles; 1995. 
Kara-José N, Alves MR. Problemas oftalmológicos mais freqüentes em escolares. In: Conceição JAN.coordenadora. Saúde ocular: a criança, a vida e a escola. São Paulo: Sarvier; 1994.p195-203.

Kara-José N, Carvalho KMM, Pereira VL, et al. Estudo retrospectivo dos primeiros 140 casos atendidos na Clínica de Visão Subnormal do Hospital de Clínicas da Unicamp. Arq.Bras. Oftalmol. 1988, 51: 6.

Kara-Jose N, Gonçalves ER, Carvalho RS. Olho no Olho.Campanha Nacional de Prevenção à Cegueira e Reabilitação Visual do Escolar. Rio de Janeiro:Cultura Médica, São Paulo:CBO, 2006.

Keeffe JE, Cheung A, Dinh T, Mccarty CA. Impact of vision impairment on funcioning. Aust. N. Z. J. Ophthalmol. 1998; 26: 16-8.

Keeffe J. Childhood vision impairment. Br. J. Ophthalmol. 2004; 88(6):728-29.

Kitadai SPS, Bonomo PP. Catarata congênita: freqüência etiológica. Arq. Bras. Oftalmol. 1994;57(6):404-6.

Leal DB, Tavares SS, Ventura LO, Florencio T. Atendimento a portadores de visão subnormal: estudo retrospectivo de 317 casos..Arq.Bras. Oftalmol 1995; 58:439-47.

Lee MS, Balcer LJ, Volpe NJ, Liu G, Ying GS, Galetta SL. Laser pointer visual screening. J Neuro-Ophthalmol 2003;23:260-3

Leonard R. Statistics on vision impairment. A resource manual. New York, NY: Arlene R Gordon Research Institute of Lighthouse International. The Lighthouse Inc. 2002:14-29.

Lindsted E. Acommodation in the visually impaired child. In: WOO G. Low vision principles and applications. Waterloo: Springer-Verlag; 1986. p 425-35.

Lobato FJC, Haddad MAO, Sampaio MW. Visão subnormal e retinocoroidite macular bilateral: estudo de 60 casos. Arq. Bras. Oftalmol.2003;66 (4supl):180. (Apresentado no $32^{\circ}$ Congresso Brasileiro de Oftalmologia. 10 a 13 de setembro de 2003. Salvador, Bahia. Resumo)

Lopez J.M.V. - Apuntes Sobre Rehabilitacion Visual . Madrid: Organizacion Nacional de Ciegos Españoles, 1994.

Lora TDP. O professor especializado no ensino de deficientes visuais- Um estudo centrado em seus papéis e competências[tese]. São Paulo:Faculdade de Educação, Universidade de São Paulo; 2000.

Lovie-Kitchin JE. Low vision services in Australia. J. Vis. Impair. Blin. 1990; 84:298-304.

Lowenfeld B. The visually handicapped child in school. New York. The John Day Company, 1973. 
Maestrini HA, Fernandes LC, Oliveira ACM. Distrofias retinianas na infância: análise retrospectiva. Arq. Bras. Oftalmol. 2004;67(6):867-76.

Manica M B, Correa Z M S, Marcon I M, Telichevesky N, Loch L F. O que os pediatras conhecem sobre afecções oculares na criança? Arq. Bras. Oftalmol. 2003;66(4):

Massof RW, Fletcher DC. Evaluation of the NEI visual functioning questionnaire as na interval measure of visual ability in low vision. Vision Res. 2001; 41:397-413.

Massof RW. Thw measurement of cision disability. Optom. Vis. Sci. 2002; 78:516-552.

Mérula RV, Fernandes LC. Catarata Infantil: importância do diagnóstico e tratamento precoces. Arq. Brás.Oftalmol. 2005;68:299-305.

Mets MB. Hereditary retinal diseases in children. Ophthalmol. Clin. North. Am. 1990;3:149-162.

Min HY, Sampaio MW, Haddad MAO. Baixa Visão: conhecendo mais para ajudar melhor. 1a ed. São Paulo:Laramara; 2001. 32 p

Montilha RCl. Escolarização e Reabilitação de portadores de deficiência visual: Percepeção de escolares e ações de reabilitação[Tese]. Campinas: Faculdade de Ciências Médicas, Universidade Estadual de Campinas. Campinas, 2001.

Moreira ATR, Moreira JR CA, Arana J. - Causas de Cegueira no Instituto de Cegos do Paraná. Arq.Bras.. Oftalmol. 1991, 54:275.

Moribe L, Veitzman S. Prevalência de miopia em portadores de cicatrizes de retinocoroidite toxoplásmica congênita bilateral. Arq.Bras.Oftalmol. 1994; 57:299-302.

Muñoz B, West SK. Blindness and visual impairment in the Americas and the Caribbean. Br. J. Ophthalmol. 2002;86: 498-504.

Nallin A. Reabilitação em instituição: suas razões e procedimentos: análise de representação de discurso. Brasília. Corde, 1994.

Nizetic B. Perspectives in ophthalmology - public health point of view. Can. $L$ Ophthalmol. 1973;8(3):311-6

Nobre MIRS. Atendimento de estimulação em serviço de visão subnormal: características de usuários, opinião e conduta de mães[dissertação]. Campinas: Faculdade de Ciências Médicas, Universidade Estadual de Campinas, 1997.

Nobre MIRS . Identificação de crianças portadores de deficiência visual: percepção e conduta de mães [tese]. Campinas: Faculdade de Ciências Médicas,Universidade Estadual de Campinas, 2001.

Nowill DG. E eu venci assim mesmo. 1a ed. São Paulo:Totalidade, 1996. 
Organização Mundial da Saúde - Classificação Internacional de Doenças e Problemas Relacionadas à Saúde - Décima Revisão. São Paulo: Edusp, 1993.

Organização Mundial da Saúde. Classificação Internacional de funcionalidade, incapacidade e saúde. São Paulo: Editora da Universidade de São Paulo, 2003.

Parrish RK. Visual impairment, visual functioning and quality of life assessments in patients with glaucoma. Trans. Am. Ophthalmol. Soc. 1996; 19: 919-1028.

Pizzarello L, Abiose A, Ffyche T, Duerksen R, Thulasiraj R, Taylor H, Faal H, Rao G, Kocur I, Resnikoff S. Vision 2020: The right to sight. A global initiative to eliminate avildable blindness. Arch. Ophthalmol. 2004;122: 615-20

Procianoy RS. Retinopatia da prematuridade: uma doença solicitando a atenção do neonatologista. J. Pediatr. (Rio J).1997;73:361-2.

Pollard TLP, Simpson JÁ, Lamoureux EL, Keeffe JE. Barriers to acessing low vision services. Ophthal Physiol Opt 2003; 23: 321-327.

Rahi JS, Dezteux C. Epidemiology of visual impairment in Britain. Arch. Dis. Child. 1998; 78:381-386

Rahi JS, Williams C, Bedford H, Elliman D. Screening and surveillance for ophthalmic disorders and visual deficits in children in the United Kingdom. $\mathrm{Br}$. J.Ophthalmol.2001;85:257-60.

Rahi JS. Measuring the burden of childhood blindness. Br.J. Ophthalmol. 1999; 83:387-388.

Regesnteiner DBW, Kara-José N. Condição de diagnóstico e idade em que foram operadas crianças com catarata congênita em São Paulo. Arq.Bras. Oftalmol. $1987 ; 50: 130-4$

Resnikoff S, Pascolini D, Etyaále D, Kocur I, Parajasegarm R, Pokharel GP, Mariotti SP. Global data on visual impairment in the year 2002. Bull. World Health Organ. 2004;82(11):844-51.

Resnikoff S. National prevention of blindness programmes and Vision 2020. J .Com. Eye .Health. 2000;13(1):49-50

Ricci B. Refractive errors and ocular motility disorders in preterm babies with and without retinopathy of prematurity. Ophthalmologica 1999;213:295-9

Rosenbaum P, Sailgal S, Szatmari P et al. Vineland adaptative scale as a summary of functional outcome o extremely low birth weight children. Dev. Med. Child. Neurol. 1995; 37:577-86.

Rosenthal B.; Cole RG. Functional Assessment of low vision. St. Louis: Mosby, 1996.

Sampaio MW, Haddad MAO, Kara-José N. Auxílios para baixa visão. São Paulo: Laramara; 2001. 
Sampaio MW, Cibils CA. Visão Subnormal. In: Oliveira RCS, Kara-José N. Auxiliar de Oftalmologia. 1a ed. São Paulo: Roca, 2000. p323-33.

Scholl GT.- Growth and development. In: Foundations of education fot blind and visually handicapped children and youth. New York, American Foundation for the Blind, 1986. P.65 - 81.

Schimiti RB, Costa VP, Gregui MJ, Kara-José N, Temporini ER. Prevalence of refractive erros a ocular disorders in preschool and choochildren if Ibiporã-PR, Brazil (1989 to 1996). Arq. Bras. Oftalmol. 2001;64:379-84

Sei $M$, Haddad MAO, Braga AP. Recursos ópticos para a visão à distância adaptados em 28 crianças e adolescentes com retinocoroidite macular bilateral congênita causada por toxoplasmose. Arq. Bras. Otalmol. 1998; 61: 451. (Apresentado no $13^{\circ}$ Congresso Brasileiro de Prevenção da Cegueira e Reabilitação Visual. 7 a 10 de setembro de 1998. Rio de Janeiro. RJ. Ressumo)

Siaulys MOC. Inclusão social e escolar de pessoas com deficiência visual: estudo sobre a importância do brinquedo e do brincar [dissertação]. São Paulo: Universidade Presbiteriana Mackenzie; 2006.

Sicorde. Decreto $\mathrm{n}^{\circ} 5.296$ de 2 de dezembro de 2004. [citado 12 maio de 2006].Disponívelem:http://www.mj.gov.br/sedh/ct/CORDE/dpdh/sicorde/dec5296.asp

Soori $\mathrm{H}$. Measuring health-related quality of life among primary school children in Ahwaz, Iran. J. Prim. Prev. 2004; 25:125-32

Stanford MR, Tomlin EA, Comyn O, Holland K, Pavesio C. The visual field in toxoplasmic retinochoroiditis. Br. J. Ophthalmol.2005:89:812-4.

Stemack J. Quality of life of low vision patients and outcomes of low vision rehabilitation. Optom. Vis. Sci.2001; 78:335-342.

Studebaker J, Pankow L - History and evolution of vision rehabilitation. Topics in Geriatric Rehabilitation. 2004; 20:142-53.

Tartarella MB, Nakano K, Castro CTM, Martins AP. Visão subnormal em crianças. Arq. Bras. Oftalmol. 1991;54(5):221-4

Teller D. - Teller Acuity Card Handbook. Dayton: Vistech Consultants, Inc., 1989.

Temporini E, Kara-José N - A perda da visão - Estratégias de prevenção. Arq. Bras. Oftalmol., 2004;67(4):597-601.

Temporini ER. Percepção de professores do sistema de ensino do estado de São Paulo sobre seu preparo em saúde do escolar. Rev. Saúde Publ. 1988; 22(5):411-21.

Temporini ER. Prevenção de problemas visuais de escolares: conduta de professores do sistema de ensino do Estado de São Paulo, Brasil. Rev. Brás. Saúde Esc. 1990; 1:68-75. 
Temporini E R. Ação preventiva em problemas visuais de escolares. Rev Saúde Publ., 1984;18:259-62

Teplin SU. - Visual impairment in infants and young children. Inf. Young children 1995, 8:18-51.

Thylefors B, Negrel AD, Pararajasegaram R, Dadzie KY. Global data on blindness. Bull. World Health Organ. 1995; 73:115-121.

Thylefors B A simplified methodology for the assessment of blindness and its main causes. World Health Stat Q. 1987;40:129-41

Unonius N, Farah ME, Sallum JMF. Classificação diagnóstica dos portadores de doenças degenerativas de retina integrantes dos grupos Retina São Paulo e Retina Vale do Paraíbe. Arq. Bras. Oftalmol. 2003;66:443-8.

Weiss A. Ocular malformation. Ophthalmol. Clin. North Am. 1990;3:131-148.

West S, Sommer A - Prevention of blindness and priorities for the future. Bull. World Health Organ.2001;79(3):244-8

Wolffsohn JS, Cochrane AL, Watt NA. Implementation methods for vision related quality of life questionnaires. Br. J. Ophthalmol. 2000; 84:1035-1040.

Woodhouse JM, Meades JS, Leat SJ, Saunders K. Reduced accommodation in children with Down Syndrome. Invest. Ophthalmol .Vis. Sci1993;34:2382-7.

World Health Organization - Magnitude and causes of visual impairment. Geneve,:WHO fact sheet n.282, 2004

World Health Organization - Programme for the Prevention of Blindness Management of low vision in children - Report of a WHO Consultation. Bangkok : WHO/PBL/93.27; 1992.

World Health Organization .A five-year project for the prevention of blindness-Report of WHO consultation. Geneva: WHO/PBL/02.88; 2002.

World Health Organization. Preventing blindness in children. Report of a WHO/IAPB scientific meeting. Hyderabad,:WHO/PBL/00.771999.

World Health Organization. Consultation on development os standars for characterization vo visual loss and visual functioning. Geneva: WHO/PBL/03.91;2003. 